\title{
Characterization of Airborne Uranium From Test Firings of XM774 Ammunition
}

J. A. Glissmeyer

J. Mishima

November 1979

Prepared for the U.S. Army under U.S. Department of Energy

Contract EY-76-C-06-1830

Pacific Northwest Laboratory

Operated for the U.S. Department of Energy

by Battelle Memorial Institute 


\title{
NOTICE
}

This report was prepared as an account of work sponsored by the United States Government. Neither the United States nor the Department of Energy, nor any of their employees, nor any of their contractors, subcontractors, or their employees, makes any warranty, express or implied, or assumes any legal liability or responsibility for the accuracy, completeness or usefulness of any information, apparatus, product or process disclosed, or represents that its use would not infringe privately owned rights.

The views, opinions and conclusions contained in this report are those of the contractor and do not necessarily represent those of the United States Government or the United States Department of Energy.

\author{
PACIFIC NORTHWEST LABORATORY \\ operated by \\ BATTELLE \\ for the \\ UNITED STATES DEPARTMENT OF ENERGY \\ Under Contract EY-76-C-06-1830
}

Printed in the United States of America Available from

National Technical Information Senice

United States Department of Commerce 5285 Port Royal Road

Springlield, Virginia 22151

Price: Printed Copy s

$\therefore$ Microfiche $\$ 3.00$

$\begin{array}{cc}\text {-Pages } & \text { Selling Price } \\ 001-025 & \$ 4.00 \\ 026-050 & \$ 4.50 \\ 051-075 & \$ 5.25 \\ 076-100 & \$ 6.00 \\ 101-125 & \$ 6.50 \\ 126-150 & \$ 7.25 \\ 151-175 & \$ 8.00 \\ 176-200 & \$ 9.00 \\ 201-225 & \$ 9.25 \\ 226-250 & \$ 9.50 \\ 251-275 & \$ 10.75 \\ 276-300 & \$ 11.00\end{array}$




\title{
33679000533200
}

PNL -2944

UC -35

CHARACTERIZATION OF AIRBORNE URANIUM

FROM TEST FIRINGS OF XM774 AMMUNITION

\author{
J. A. Glissmeyer \\ J. Mishima
}

R. L. Gilchrist, Project Manager

November 1979

Prepared for the U.S. Army under U.S. Department of Energy Contract EY-76-C-06-1830

Pacific Northwest Laboratory

Richland, Washington 99352 


\section{NOT ICE}

The views, opinions, and/or findings contained in this report are those of the author(s) and should not be construed as an official Department of Army position, policy, or decision, unless so designated by other documentation. 



\section{PROLOGUE}

As stated in the foreward, this study was conducted at the recommendation of the Joint Technical Coordinating Group for Munitions Effectiveness (JTCG/ME) Working Group on Depleted Uranium Munitions. This was the first time that an attempt was made to sample the particulate generated during the impact of a $105-\mathrm{mm}$ depleted uranium kinetic energy penetrator into a NATO heavy triple target.

Much useful data were gathered but unexpected conditions have led to some questionable results beyond the control of the experimenters. These conditions included: (1) particulate samplers became clogged and flow rates went to zero necessitating an estimate of when the filters clogged. The time used influenced the concentrations in Table 6 and the mass of penetrators airborne; (2) cloud films were of poor quality and also were not taken 90 degrees apart which made it difficult to evaluate the cloud volumes, and (3) fallout sampling, Figure 25, was much too sparse close to the target to adequately determine the amount of depleted uranium deposited on the ground.

The mass of penetrator airborne varied from 36 to $104 \%$ of the original mass attesting to the problems in 1 and 2 above. Some of the problems were alleviated during the subsequent experiments on the XM735A1. However, it is believed that obtaining a better mass balance during an impact would aid significantly in understanding the hazards of firing DU during testing and wartime. Therefore, it is proposed that additional tests be conducted using an improved experimental design to overcome the problems listed above.

ERNEST W. BLOORE Chairman JTCG/ME Working Group on Du Munitions 


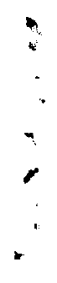




\section{FOREWORD}

This study was conducted at the recommendation of the Joint Technical Coordinating Group for Munitions Effectiveness (JTCG/ME) Working Group on Depleted Uranium Munitions and was supported by the Office of Assistant Project Manager for Tank Main Armament Development, XM1 Tank System, under Army Project Number IL663608D060. The technical monitors were the Working Group Chairman, Ernest W. Bloore, and Edward F. Wilsey, both of the U.S. Army Armament Research and Development Command, Dover, New Jersey.

This study is one of three studies recommended by the JTCG/ME Working Group. The first two studies, Radiological and Toxicological Assessment of an External Heat (Burn) Test of the $105 \mathrm{~mm}$ Cartridge, APFSDS-T, XM774, ${ }^{(1)}$ and Radiation Dose Rate Measurements Associated with the Use and Storage of XM774 Ammunition, ${ }^{(2)}$ have been distributed. R. L. Gilchrist served as overall Project Manager for Pacific Northwest Laboratory.

The authors wish to acknowledge the Army Environmental Hygiene Agency for providing meteorological support and the Material Testing Directorate of the Testing and Evaluation Command, especially Mr. K. Ruff for support in conducting the part of the study at Aberdeen Proving Grounds, Maryland. 


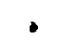

,

$-1$

$-$

$-$

,

$?$

: 


\section{SUMMARY}

Pac ific Northwest Laboratory $(\mathrm{PNL})^{(\mathrm{a})}$ conducted experiments at Aberdeen Proving Grounds, Maryland, to characterize the airborne depleted uranium (DU) resulting from the test firings of $105-\mathrm{mm}$, APFSDS-T XM774 ammunition. The study was conducted at the recommendation of the ad hoc Working Group on Depleted Uranium Munitions of the Joint Technical Coordinating Group for Munitions Effectiveness (JTCG/ME). The goal was to obtain data pertinent to evaluations of human inhalation exposure to the airborne DU. Data was desired concerning the following:

1. Size distribution of airborne DU

2. Quantity of airborne DU

3. Dispersion of airborne DU from the target vicinity

4. Amount of DU deposited on the ground

5. Solubility of airborne DU compounds in lung fluid

6. Oxide forms of airborne and fallout DU.

The experiments involved extensive air sampling for total airborne DU particulates and respirable DU particles both above the targets and at distances downwind. Fallout and fragments were collected around the target area. High-speed movies of the smoke generated from the impact of the penetrators were taken to estimate the cloud volumes.

From the results, it is estimated that roughly $2.4 \mathrm{~kg}$ of airborne DU is generated by each test firing. About $75 \%$ of the airborne DU was $\mathrm{U}_{3} \mathrm{O}_{8}$ and $25 \%$ was $\mathrm{UO}_{2}$. Immediately above the targets about half of the airborne DU was respirable, and of that amount $43 \%$ was soluble in simulated lung fluid within 7 days. After 7 days the remaining material was essentially insoluble. The particles in the respirable range were predominantly $\mathrm{U}_{3} \mathrm{O}_{8}$. Iron and traces of tungsten, aluminum and silicon compounds were found in the airborne particles.

(a) PNL is operated for the Department of Energy (DOE) by Battelle Memorial Institute. 
Measurements of airborne DU in the target vicinity (within $20 \mathrm{ft}$ ) after a test firing showed that personnel involved in routinely changing targets can be exposed to concentrations exceeding recommended maximums. This may have resulted in part from mechanical resuspension of DU from the soil or other surfaces. A study was recommended that includes further air sampling related to occupational exposure, soil sampling and solubility measurements. 


\section{CONTENTS}

NOTICE

PROLOGUE

FOREWORD

SUMMARY

FIGURES

TABLES

1.0 INTRODUCTION.

2.0 CONCLUSIONS AND RECOMMENDATIONS

3.0 DESCRIPTION OF EXPERIMENTS

3.1 SOURCE TERM CHARACTERIZATION EXPERIMENTS

3.1.1 Target-Area Air Sampling

3.1.2 Upwind/Downwind Air Sampling. .

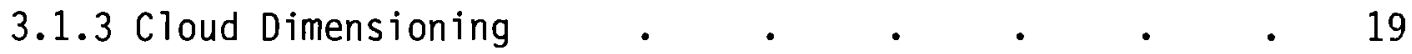

3.1.4 Meteorological Data Collection $\quad$. $\quad . \quad . \quad . \quad 19$

3.1.5 Target-Area Airborne-Uranium Dispersion Rate $\quad$. 20

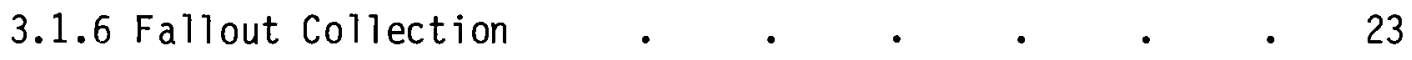

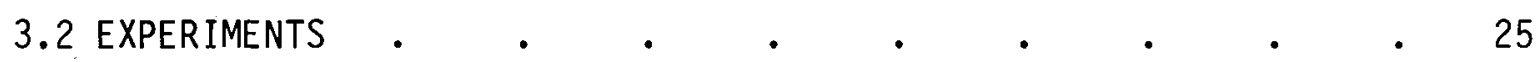

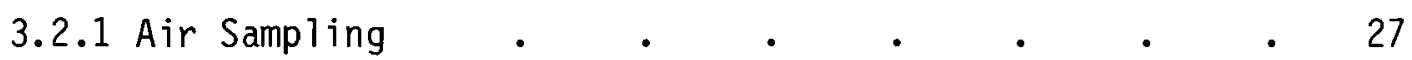

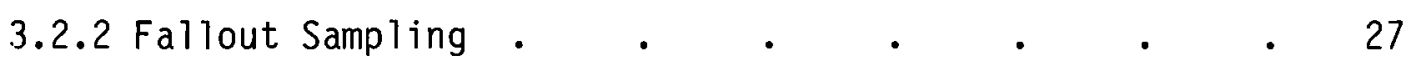

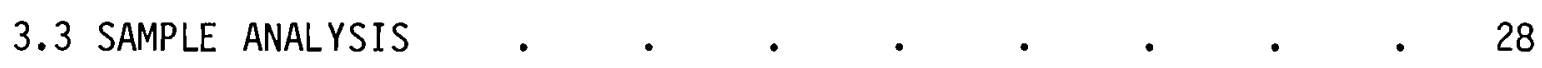

3.3.1 Field Handling of Air Samples • • • • • . $\quad 30$

3.3.2 Uranium Analysis Procedures . $\quad . \quad$. $\quad . \quad 30$

3.3.3 Lundgren Impactor Substrates . $\quad$ • . . $\quad$. 31

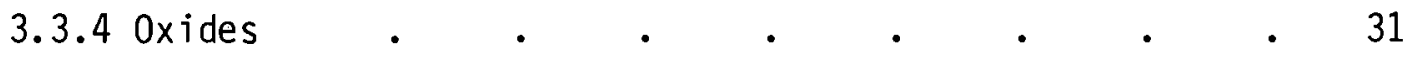

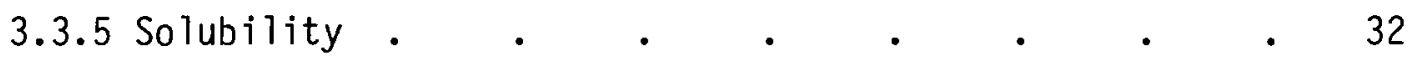




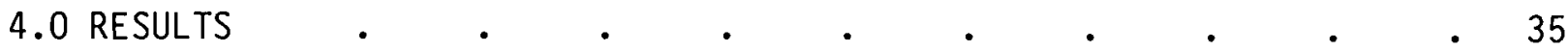

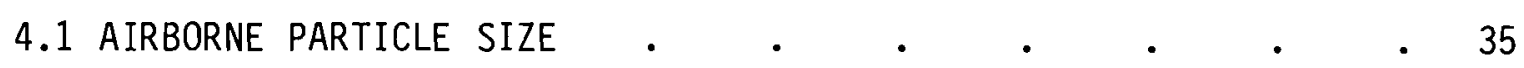

4.1.1 High-Volume Cascade Impactors . . . . . 35

4.1.2 Lundgren Cascade Impactors . . . . . 37

4.2 AIRBORNE URANIUM CONCENTRATION VERSUS TIME . . . . 40

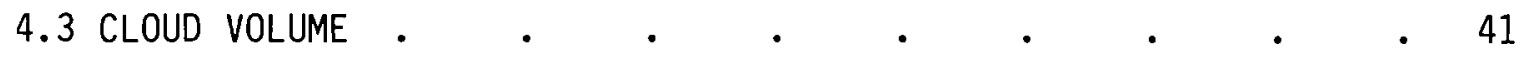

4.4 TOTAL AIRBORNE URANIUM PARTICULATES $\quad$ • . . . . . 43

4.4.1 Target-Area Total Airborne Uranium . . . . 43

4.4.2 Environmental Airborne Uranium . . . . . 44

4.5 FALLOUT . . . . . . . . . . . . . 47

4.5.1 Wet Fallout . . . . . . . . . . 47

4.5 .2 Dry Fallout . . . . . . . . . . 48

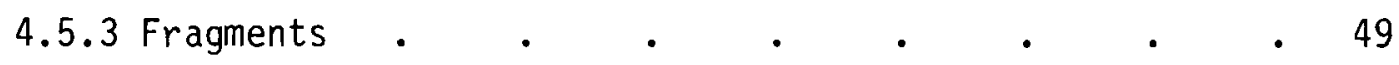

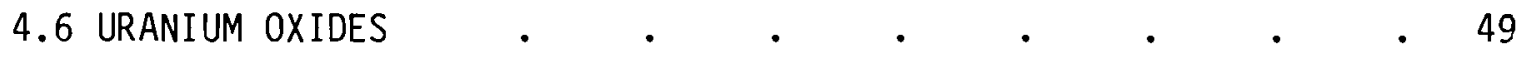

4.6.1 Total Particulate Samples . . . . . . 50

4.6.2 High-Volume Cascade Impactor Samples . . . 51

4.6.3 Dry Fallout Samples . $\quad . \quad$. $\quad . \quad$. 51

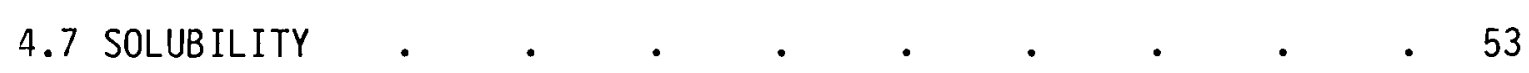

4.8 DOWNWIND DOSE $\quad . \quad$. $\quad . \quad$. $\quad . \quad$. $\quad . \quad .60$

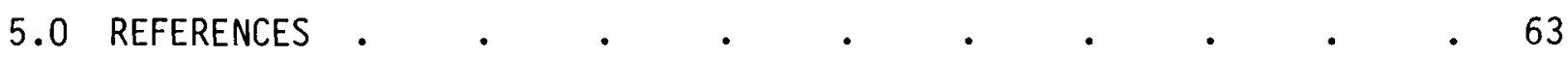

APPENDIX A.1 - PLACEMENT AND OPERATION OF SAMPLERS •

APPENDIX A.2 - METEOROLOGICAL DATA EXTRACTED FROM
REPORT FURNISHED BY AEHA . . . . . . . A.9

APPENDIX B.1 - PREPARATION OF SAMPLES FOR URANIUM ANALYSIS . . . B. 1 
APPENDIX B.2 - PREPARATION OF LUNDGREN IMPACTOR SUBSTRATES

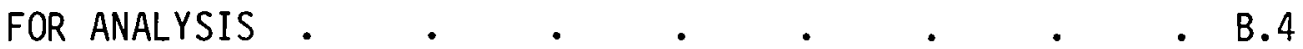

APPENDIX B.3 - SAMPLE DATA REDUCTION FOR A LUNDGREN

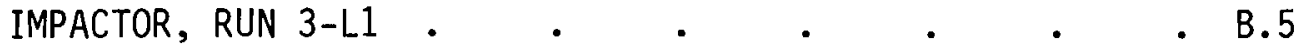

APPENDIX B.4 - PREPARATION OF SAMPLES FOR OXIDE ANALYSES • • • • B. 6

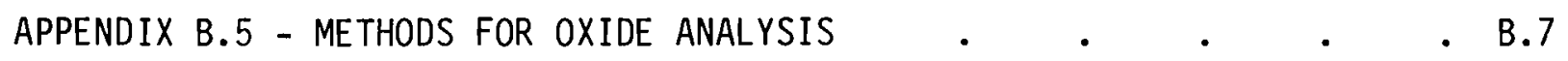

APPENDIX B.6 - SAMPLE PREPARATION FOR SOLUBILITY MEASUREMENTS • • • B.8

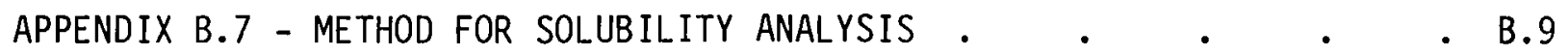

APPENDIX C - SAMPLE SIZE DISTRIBUTION DATA REDUCTIONS $\quad$ • • C.1

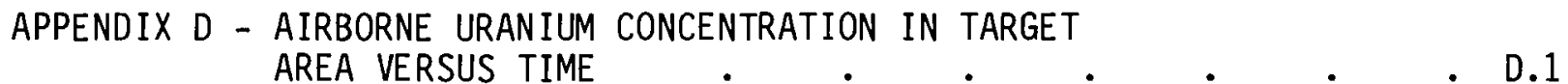

APPENDIX E - CALCULATION OF TOTAL EXPOSURE IN TARGET AREA • • • • E.1 


\section{FIGURES}

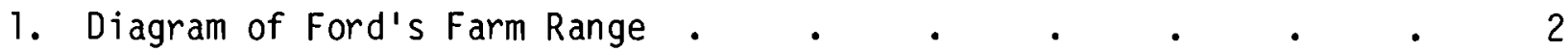

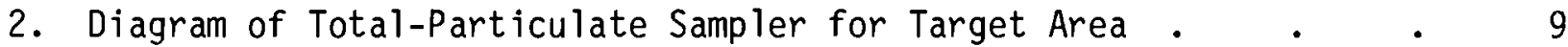

3. Assembled Total-Particulate Sampler for Target Area . 9

4. Assembled High-Volume Cascade Impactor for Target Area $\quad$ - $\quad 10$

5. Exploded View of Anderson Model 65-800 Four-Stage High-Volume

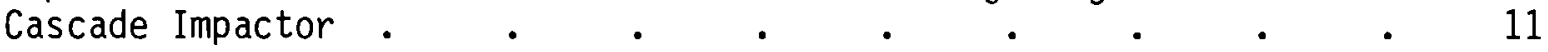

6. Plan of Sampler Array in the Target Area of the

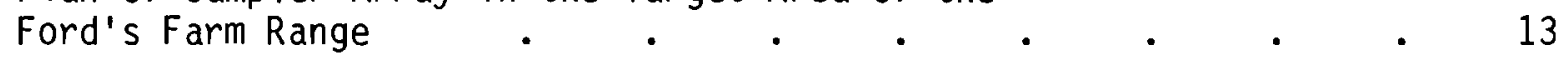

7. Target Showing Probes of Samplers T1-T6 and I1, I2 . . . 14

8. Rear of Film Frame Showing Samplers I1, I2, T5, T6, and L2 . $\quad 15$

9. Rear View of Samplers Mounted on Bombproof $\quad . \quad \ldots \quad$ e $\quad . \quad 16$

10. Position of Auxiliary Samplers Relative to Ford's Farm

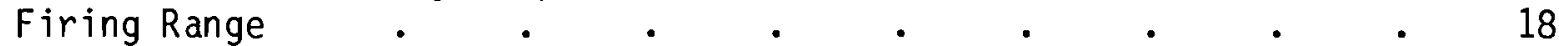

11. Upwind Samplers Located About $80 \mathrm{ft}$ from Target . $\quad$. $\quad$. 20

12. Downwind Samplers Located About $145 \mathrm{ft}$ from Target . . . 21

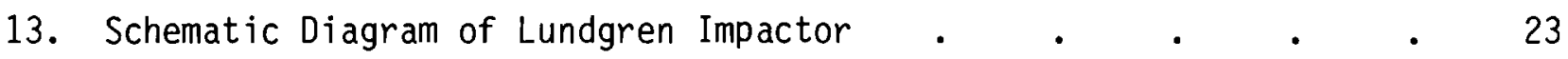

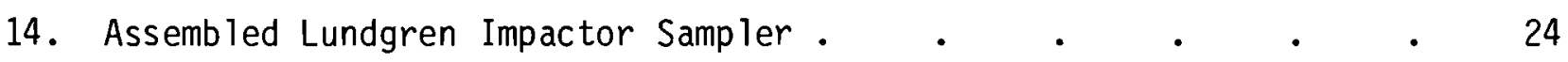

15. Approximate Locations of Dry Fallout Trays $\quad$ • $\quad$ • $\quad$ • $\quad 25$

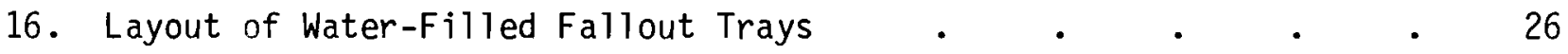

17. Simplified Flow Chart for Uranium Analysis $\quad . \quad$ e $\quad$ • $\quad$ • 32

18. Typical Mylar Substrates from Lundgren Impactor . • . . 33

19. Size Distribution Plots for High-Volume Cascade Impactor . • 36

20. Combined High-Volume Impactor Airborne Uranium

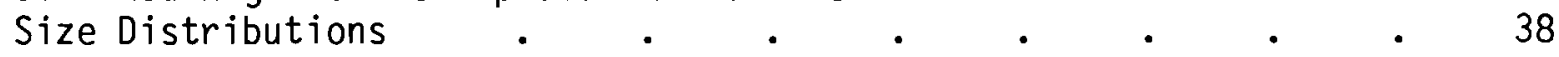

21. Size Distributions for all Lundgren Impactors Sampling

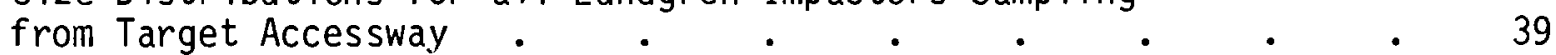


22. Size Distributions for all Lundgren Impactors Behind

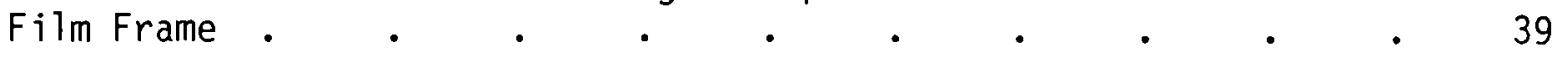

23. Airborne Uranium Size Distributions . . . . . . . . 40

24. Airborne Depleted Uranium Concentration Versus Time . . . 42

25. Est imated Amount of Uranium Fallout in Sectors Within
$50 \mathrm{ft}$ of Target Center. . . . . 48

26. Scanning Electron Micrographs of Particles Collected
on Filter Paper . . . . . . . . . 52

27. Scanning Electron Microscope SEM Photomicrographs of Materials Collected in a Target Area High-Volume Cascade Impactor During Run 3 •

28. Scanning Electron Micrographs of Sample Fallout $\quad$. $\quad$. 59

29. Percent Uranium (as $\mathrm{U}_{3} \mathrm{O}_{8}$ ) Soluble in Seven Days Versus

A.1.1 Sampler Placement Run 1, October 4, 1977 . . . . . A.1

A.1.2 Sampler Placement Run 2, October 6, 1977 . . . . . A.3

A.1.3 Sampler Placement Run 3, October 6, 1977 . . . . A.4

A.1.4 Sampler Placement Run 4, October 7, 1977 . . . . A.6

A.1.5 Sampler Placement Run 5, October 8, 1977 . . . . A.7

B.1 Partitioning of 8-in. x 10-in. Filter . . . . . . B.1

B.2 Division of High-Volume Impactor 12-in. Substrates • • • B.2

B.3 Division of Staplex Filter Samples . . . . . . . B.3 


\section{TABLES}

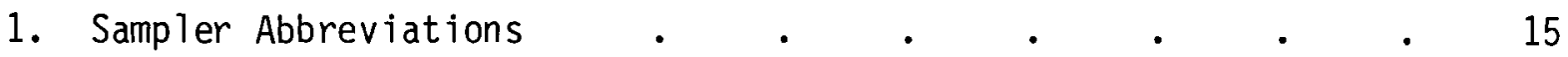

2. Firing Times During Which Fallout Was Collected . . . 28

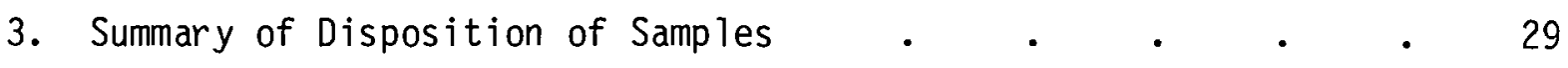

4. Size Distribution Summary . . . . . . . . . . 40

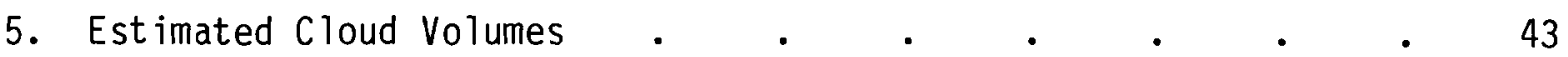

6. Total Airborne Uranium Assuming $7.5 \mathrm{sec}$ Sampling Interval
at $50 \mathrm{cfm}$
.

7. Environmental Airborne Uranium Concentrations . . . $\quad$. 46

8. Relative Abundance of Uranium Oxides in Target

9. Characteristics of Material Collected in a Target Area

\begin{tabular}{l} 
10. Measured Solubilities of Airborne Depleted Uranium in \\
Simulated Lung Fluid \\
\hline
\end{tabular}

A.1.1 Sampler Operation, Run 1, October 4, $1977 \quad$. $\quad$. $\quad$. $\quad$ A.2

A.1.2 Sampler Operation, Run 2, October 6, $1977 \quad$ • $\quad$. . . A.3

A.1.3 Sampler Operation, Run 3, October 6, $1977 \quad$ • $\quad$ • $\quad$ • $\quad$ A $\quad$ A.5

A.1.4 Sampler Operation, Run 4, October 7, 1977 . . . . . A.6́

A.1.5 Sampler Operation, Run 5, October 8, 1977 . $\quad$. . . . A.8

A.2.1 AEHA Meteorological Data for October 4, 1977
to October 9, 1977 . $\quad . \quad . \quad$.

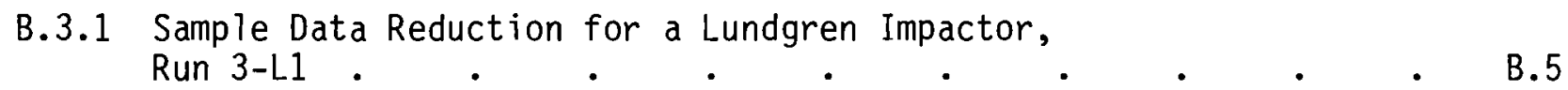

\begin{tabular}{l} 
C.1 High-Volume Cascade Impactor Example Size Distribution \\
Run 1-I1 \\
\hline
\end{tabular}

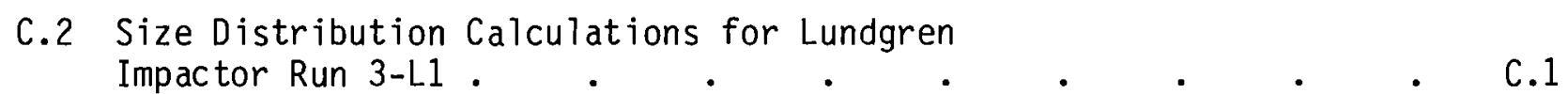

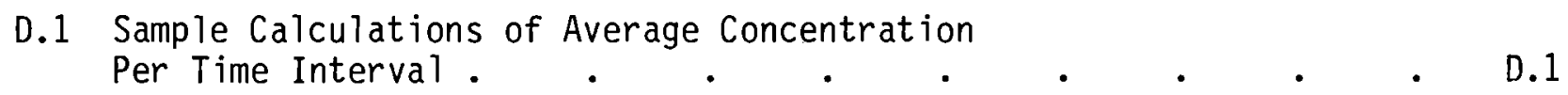




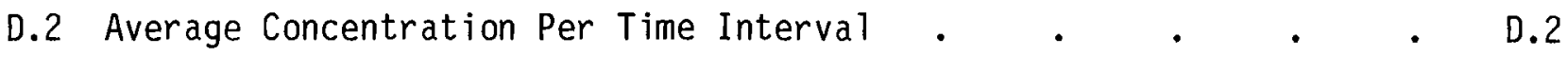

E.1 Calculation of Total Exposure in Target Area . . . . . . E.1 


\subsection{INTRODUCTION}

Knowing the characteristics of an airborne material is essential to understand its environmental impact on humans. The objective of this study was to provide data pertinent to the evaluation of human exposures to airborne depleted uranium (DU) generated during the test firings of the XM774 ammunition. The data sought included:

- Size distribution of airborne (DU) particulates

- Quantity of airborne DU

- Dispersion of airborne DU from the target vicinity

- Amount of DU deposited on the ground

- Solubility of airborne DU compounds in lung fluid

- Oxide forms of airborne and fallout DU.

The program of field experiments included the collection of fallout, fragments and total-particulate and particle size-fractionated air samples. This report presents the findings of those experiments relative to the areas listed above.

This study was performed at the Ford's Farm Range at Aberdeen Proving Ground. A diagram of the firing range is shown in Figure 1. The XM774 ammunition was fired from a $105-\mathrm{mm}$ gun at a NATO Heavy Triple Target, a series of three plates, from a distance of $200 \mathrm{~m}$. The plates were inclined at an angle towards the gun so that fragments were deflected towards the ground as the penetrator impacted the plates in sequence. Structures adjacent to the targets housed flash $X$-ray equipment for recording the penetration through the targets.

The XM774 ammunition consists of a $3.4 \mathrm{~kg}$ penetrator body of depleted uranium alloyed with 0.75 percent titanium by weight. A steel-tipped, aluminum windshield, an aluminum tail fin and an aluminum sabot are attached to the body.

A study by Hanson et al. (3) obtained particle size data for the test firings of a smaller caliber DU ammunition. The study also estimated the amount and respirable fraction of airborne DU. Because air sampling in 


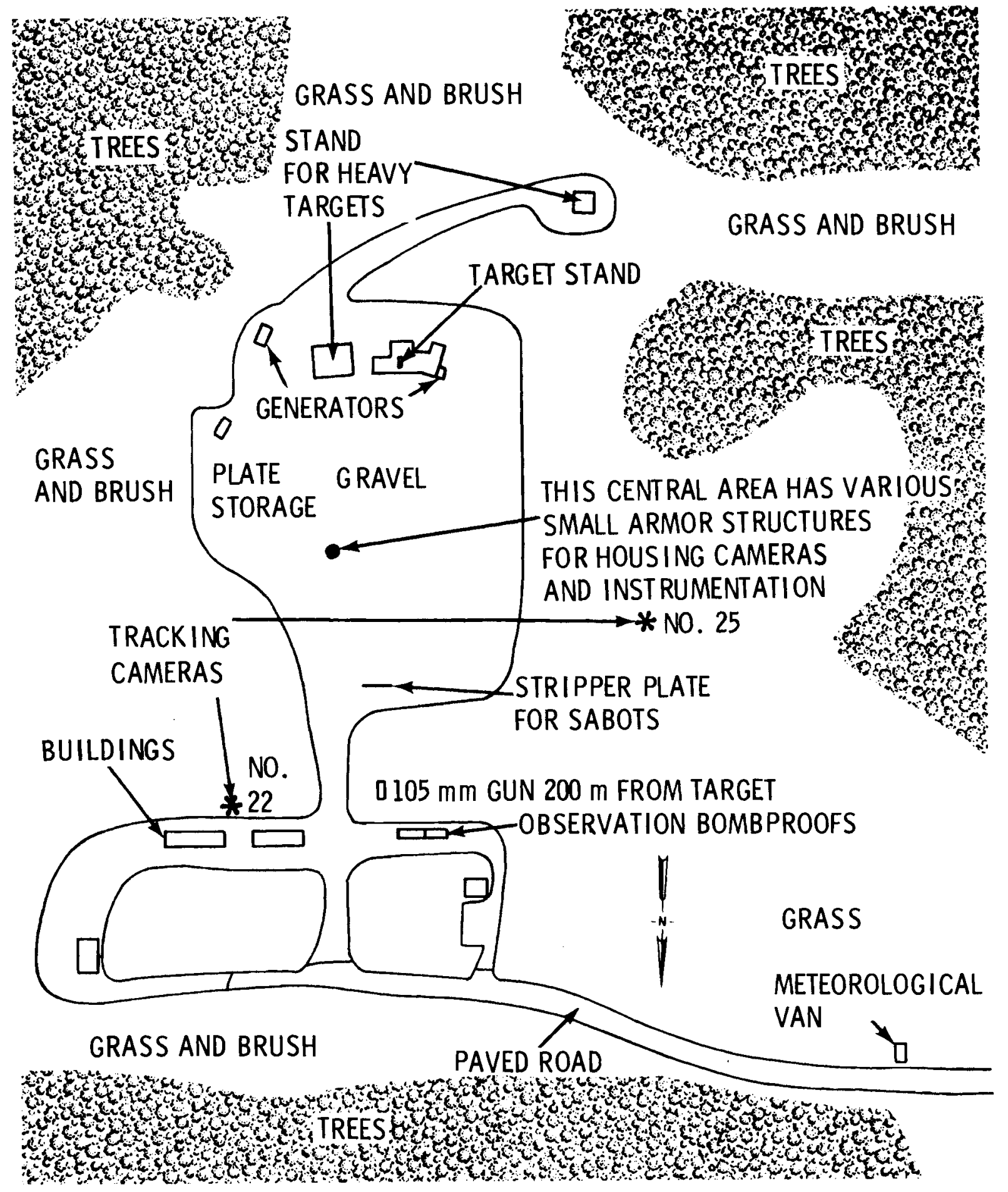

FIGURE 1. Diagram of Ford's Farm Range 
Hanson's study was performed using a chamber to enclose the target and the target was different, the results could not be scaled-up to the larger ammunition examined in this study. 


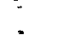

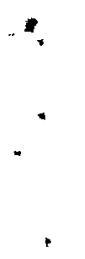




\subsection{CONCLUSIONS AND RECOMMENDATIONS}

From the experiments the following conclusions can be drawn:

1) On the average, approximately $2.4 \mathrm{~kg}$ of airborne uranium was generated per test firing of the XM774 ammunition, an estimate that suffers from several uncertainties as discussed in the report. It cannot be concluded how much of the airborne material actually came from the fired penetrator or from resuspended contaminated soil.

2) Roughly one-half of the airborne uranium can be considered respirable.

3) The geometric mean size of the airborne uranium was about 2.5 to $3 \mu \mathrm{m}$ aerodynamic equivalent diameter.

4) About three-fourths of the airborne uranium was $U_{3} \mathrm{O}_{8}$, the other fourth was $\mathrm{UO}_{2}$.

5) Nearly $43 \%$ of the respirable airborne uranium was soluble in 7 days in simulated lung fluid. This result indicates a possible chemical toxicity hazard apart from a radiation hazard.

6) In the personnel accessway adjacent to the target mounts, the concentration of airborne uranium was near or above the occupational Maximum Permissible Concentration $\left(\mathrm{MPC}_{\mathrm{a}}\right.$ ) during routine target changing after a test firing. Resuspension of contaminated soil may be a contributor to this concentration.

7) In the same personnel accessway, the airborne concentration was about a factor of two below MPC $a$ when routine target changing was suspended after one of the test firings.

8) Behind the $X$-ray film frame adjacent to the target, the measured concentration of airborne uranium was near, or below, that of the accessway and the $M P C_{a}$ during normal target-changing activity. The concentration in the same location was an order of magnitude lower when target changing was not conducted after one of the test firings.

9) During several test firings the quantity of uranium fallout deposited per firing was about $360 \mathrm{~g}$ within $50 \mathrm{ft}$ of the targets. This estimate was 
based on the assumption of uniform deposition around each sample; however, there were indications that this assumption may not be true in the area within $10 \mathrm{ft}$ of the target. Additionally, large fragments also contributed to the uranium deposited on the ground, the largest of which weighed about $150 \mathrm{~g}$; however, the large fragments were often scavenged and set aside.

The following are recommended as a result of this study:

1) Investigate the magnitude of the chemical toxicity hazard of the airborne compounds associated with the test firings.

2) More accurately assess the occupational hazard from the test firings. The contribution of resuspended material from contaminated soil to the respirable concentration of uranium should be determined.

3) Consider ways to control the resuspension of deposited airborne material in the target area to minimize personnel hazards. 


\subsection{DESCRIPTION OF EXPERIMENTS}

The experiments conducted to characterize the airborne depleted uranium generated by the five XM774 test firings are described. The experimental methods are described first, then the deployment of sampling equipment during the tests and finally, the analytical methods are outlined.

\subsection{SOURCE TERM CHARACTERIZATION EXPERIMENTS}

Experiments to characterize the airborne depleted uranium resulting from the test firings were divided into the following tasks:

1. Target-area air sampling

2. Upwind/downwind air sampling

3. Cloud dimensioning

4. Meteorological data collection

5. Target-area airborne-uranium dispersion rate

6. Fallout collection

Time and funds did not permit a detailed dispersion study employing towermounted, multilevel air samplers arranged in arcs embracing the cloud. Instead, air samples were obtained from just above the target plates and from a limited number of locations near ground level. Fallout collection was limited to an area within a 50-ft radius of the mounted targets and was collected to allow identification of uranium oxides. The dispersion rate of airborne uranium was to be measured in the immediate target area in order to estimate when personnel could re-enter the area. Methods used in the six tasks are described in detail in the following subsections.

\subsubsection{Target-Area Air Sampling}

Total particulate samplers were used to estimate the mass of airborne material, and cascade impactors were used to estimate the size distribution of airborne particulates. Six total-particulate samplers and two high-volume cascade impactors were used to collect airborne particulate material in the target area. Each total-particulate sampler consisted of a 2-in., stainless-steel-pipe probe, an in-line $8-\times 10-i n$. filter holder, $(a)$ an

(a) Model IF-2150, General Metal Works Inc., 8368 Bridgetown Road, Village of Cleves, Ohio 45002. 
8- $x$ 10-in. rectangle of Whatman 41 filter paper, (a) and a blower. (b) The samplers were set to operate at 50 cubic feet per minute (cfm). A diagram of the total-particulate sampler is shown in Figure 2; an assembled sampler is shown in Figure 3.

Each cascade impactor sampler consisted of a 2-in. stainless-steel-pipe probe, a conical adapter, a high-volume cascade impactor (c) loaded with Whatman 41 substrates and backup filter, a filter holder, and a blower of the type used on the total-particulate samplers. These impactors were operated at $20 \mathrm{cfm}$. An assembled impactor sampler is shown in Figure 4.

The cascade impactor fractionates the airborne particulates by using aerodynamic properties. The impactor, shown in an exploded view in Figure 5 , fractionates particles in four stages, each using a jet plate and a whatman 41 collection substrate. The four fractionating stages are followed by a backup Whatman 41 filter. The sampled air passes through a jet plate at a velocity determined by the sampling rate and the jet dimensions. Particles with sufficient inertia are impacted on the substrate and the smaller particles pass on to the next jet plate. The stages are ordered so that progressively smaller particles are impacted in the later stages. The backup filter captures the remaining fine particles not impacted on the stages.

Since size fractionation depends more on the aerodynamic behavior of a particle than on its physical size, each stage has a calibrated aerodynamic equivalent cutoff diameter, and the material collected on the impaction substrate has that same mean aerodynamic equivalent diameter (AED). (d) Analysis of the materials collected on each impactor surface and on the backup filter can help reconstruct the size distribution of the aerosol particles in terms of AED.

(a) Whatman Inc., 9 Bridewell Place, Clifton, New Jersey 07014.

(b) Model GMWL-2000, General Metal Works Inc.

(c) Andersen High-Volume Cascade Impactor Model 65-800, Andersen Samplers Inc., 4215-C Wende11 Drive, Atlanta, Georgia 30336.

(d) The aerodynamic equivalent diameter ( $A E D)$ is the diameter of a hypothetical particle of density $1 \mathrm{~g} / \mathrm{cm}^{3}$ with aerodynamic behavior identical to that of the actual particle. For spherical particles, $A E D=$ diameter $\times \sqrt{\text { specific gravity. }}$ 


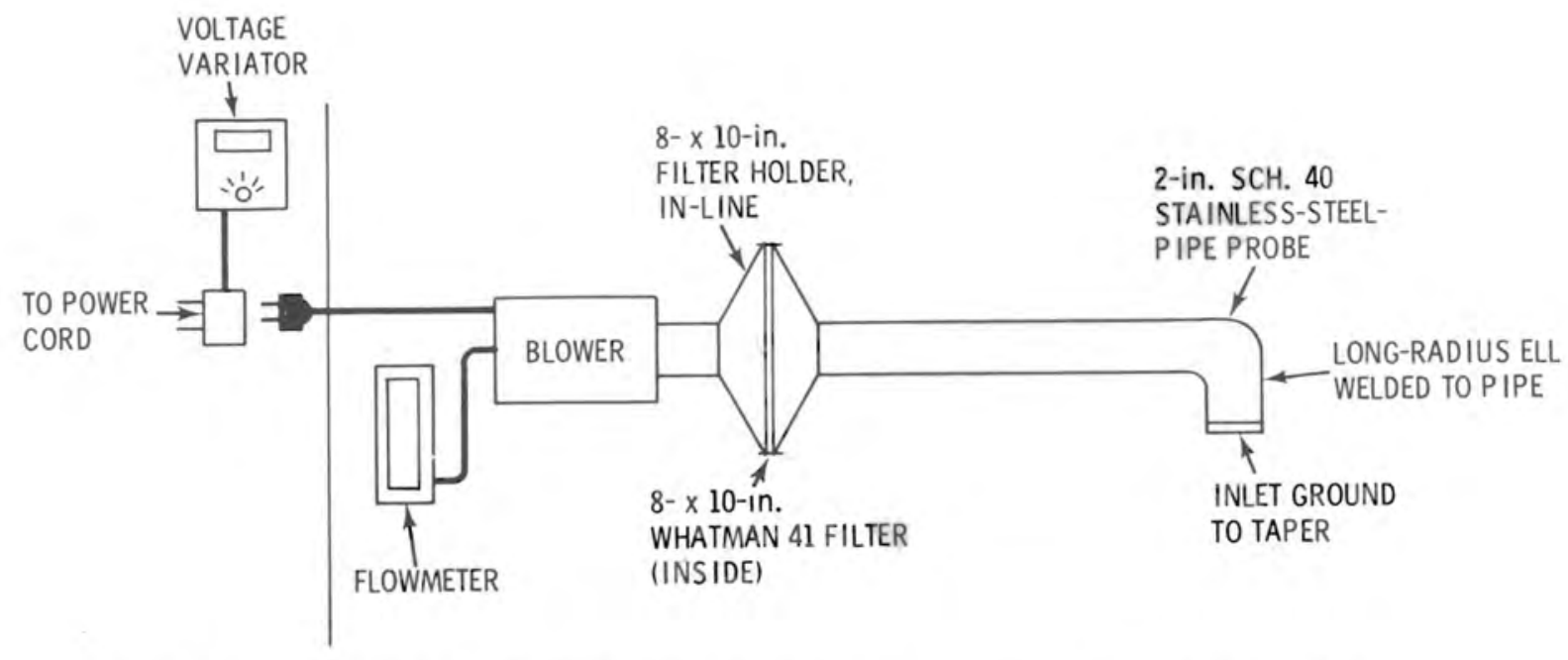

FIGURE 2. Diagram of Total-Particulate Sampler for Target Area

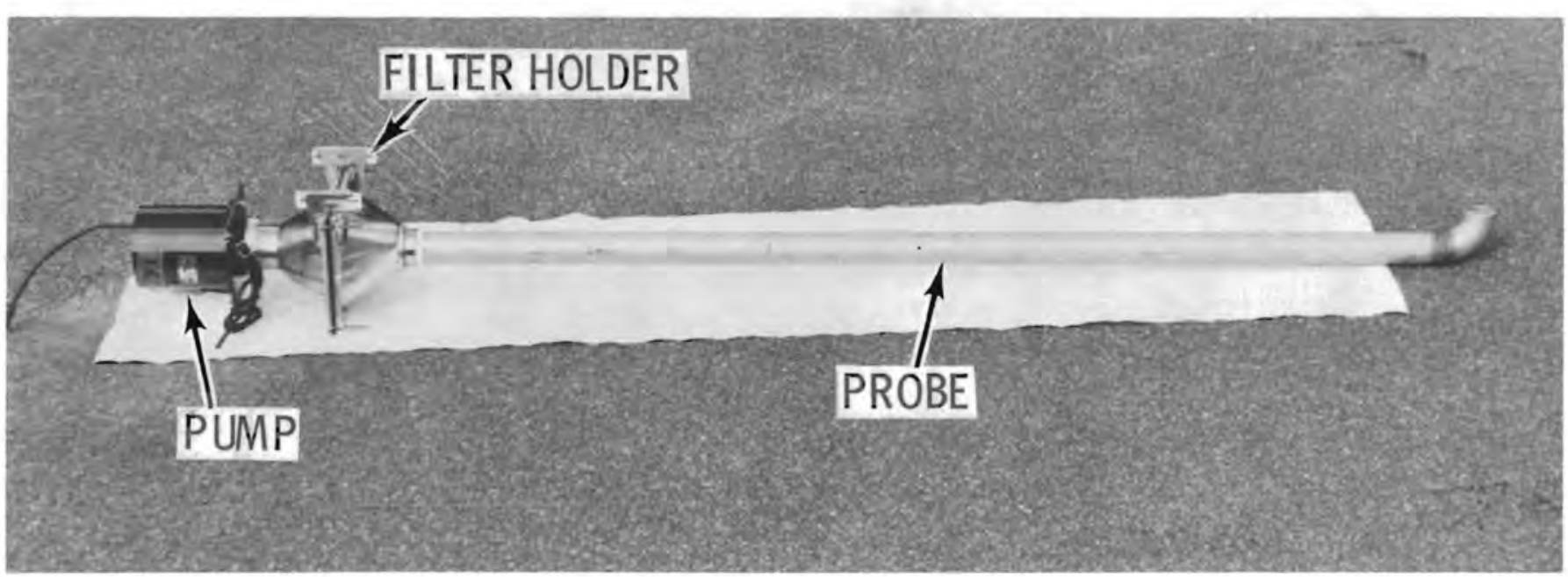

FIGURE 3. Assembled Total-Particulate Sampler for Target Area 


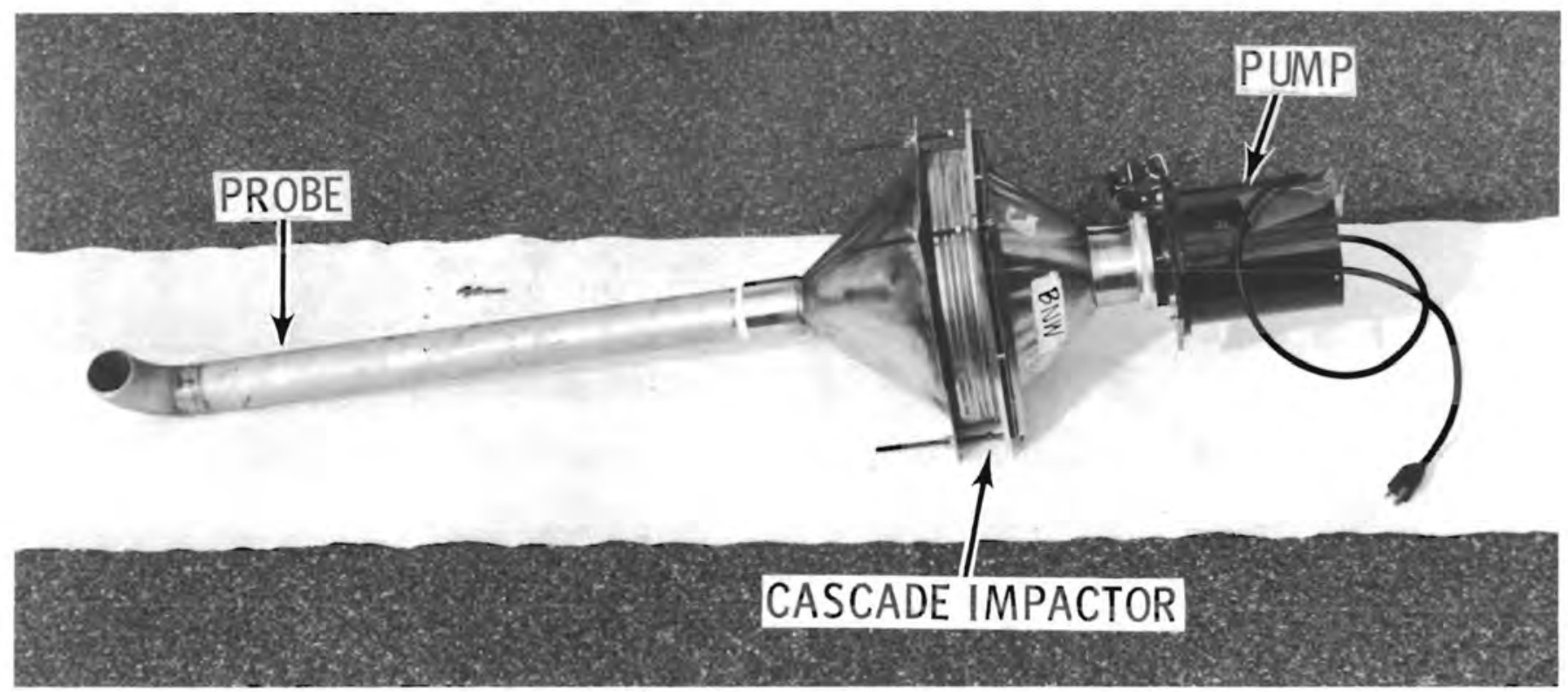

FIGIJRE 4. Assembled High-Volume Cascade Impactor for Target Area 


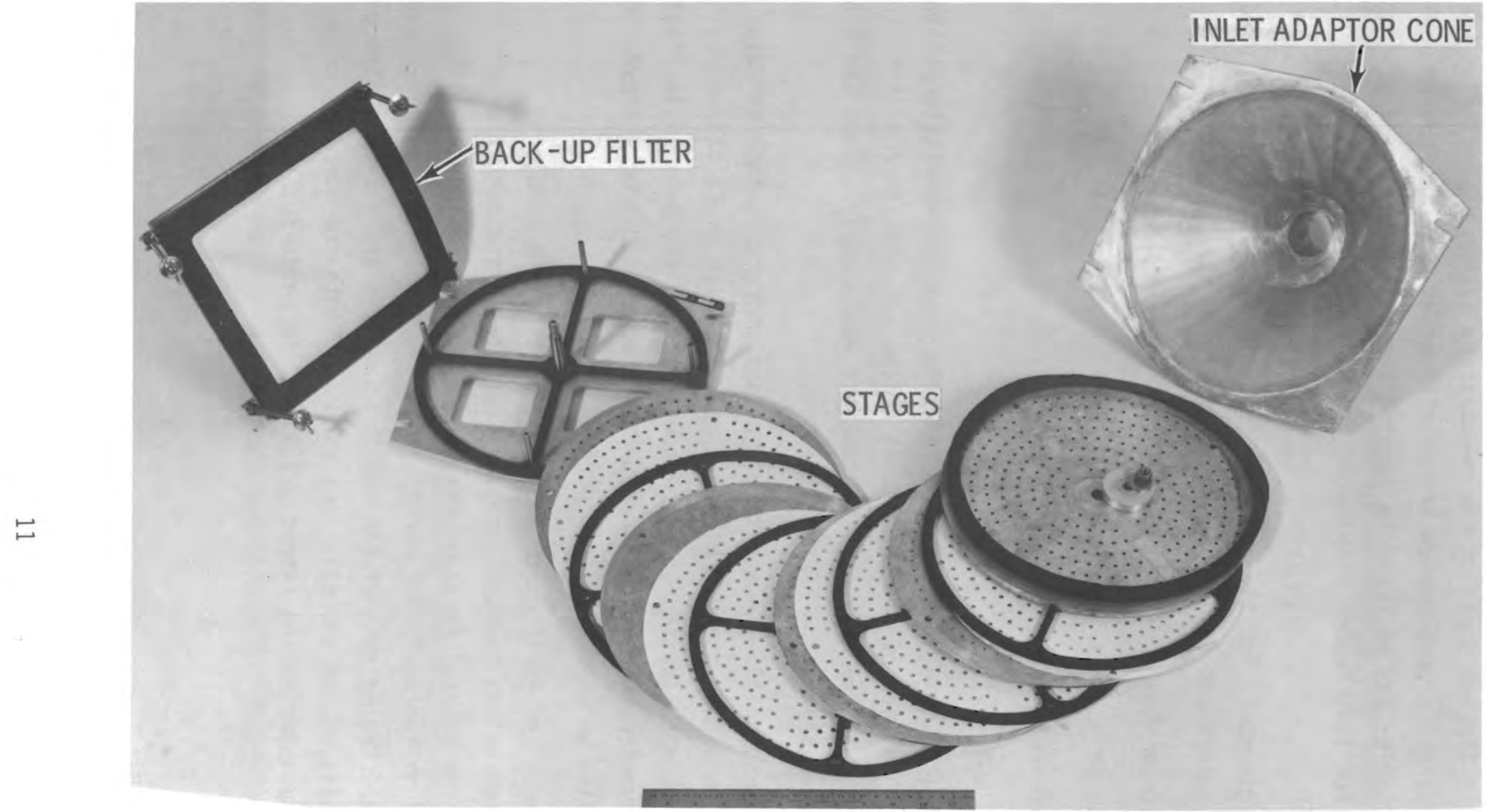

FIGURE 5. Exploded View of Anderson Model 65-800 Four-Stage High-Volume Cascade Impactor 
Measuring particle size by its AED is useful becauses inhaled particles are deposited in different parts of the respiratory system depending on their aerodynamic behavior. A good review of definitions of what are considered "respirable" particles can be found in Aerosol Technology in Hazard Evaluation. ${ }^{(4)}$ For this report respirable particles will be defined as those $\leq 3.3 \mu \mathrm{m}$ AED.

The cutoff diameters for the impactor (four fractionating stages) used in this study were determined using glass-fiber media substrates and are:

- Stage 1--7.0 $\mu \mathrm{m}$ AED

- Stage 2--3.3 $\mu \mathrm{m}$ AED

- Stage 3--2.0 $\mu \mathrm{m}$ AED

- Stage 4--1.1 um AED

It was felt (following consultation with the impactor manufacturer) that the thickness and texture of the Whatman 41 filter was similar enough to the glass-fiber media that the same cutoff diameters would apply. Time and funds did not permit a recalibration of the impactor.

The flow rates for all the samplers were set using a voltage variator to control the vacuum blower speed. Flow was measured with small flowmeters calibrated against a calibrated orifice made to fit on the 8- x 10-in. filter holder. The flowmeters were recalibrated during spot checks or whenever the adjusting mechanism was knocked loose during a run.

Figure 6 shows the location of the total-particulate samplers $\left(T_{1}-T_{6}\right)$ and high-volume cascade impactors (I1-I2) in the target area; the probes were set about $2 \mathrm{ft}$ above the tops of the target plates. The samplers mounted on the bombproof had 61-ft probes; those on the film-frame had $2 \frac{1}{2}-\mathrm{ft}$ probes. Photographs of the mounted samplers are shown in Figures 7 , 8, and 9. Examples of the abbreviations used to denote the samplers shown in these figures and later in the report are listed in Table 1. 
TI TOTAL-PARTICULATE SAMPLER N0.1

I2 HIGH-VOLUME CASCADE IMPACTOR N0.2

LI LUNDGREN CASCADE IMPACTOR NO.I

10-ft-HIGH

ROOFED CATCHER

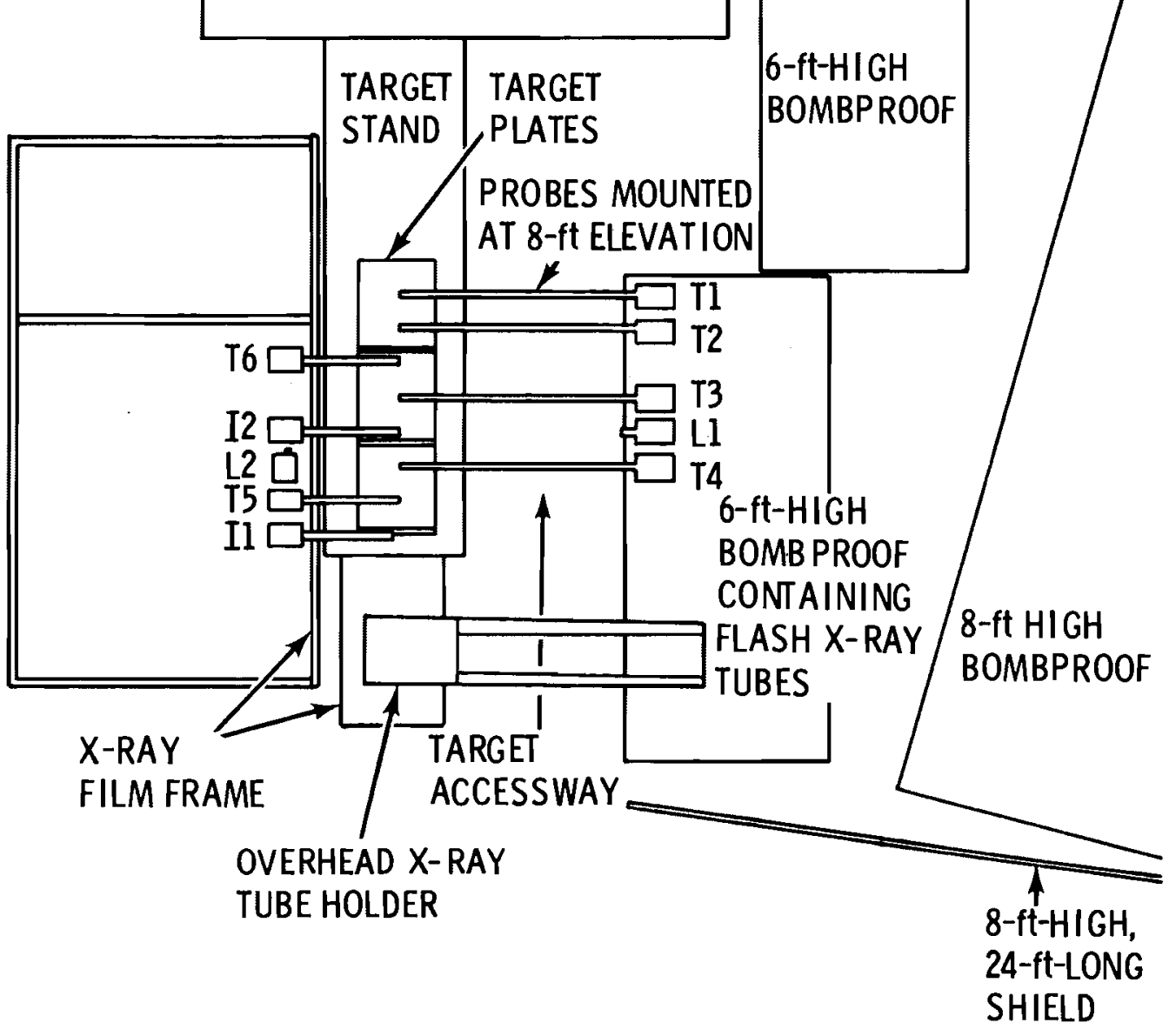

FIGURE 6. Plan of Sampler Array in the Target Area of the Ford's Farm Range 


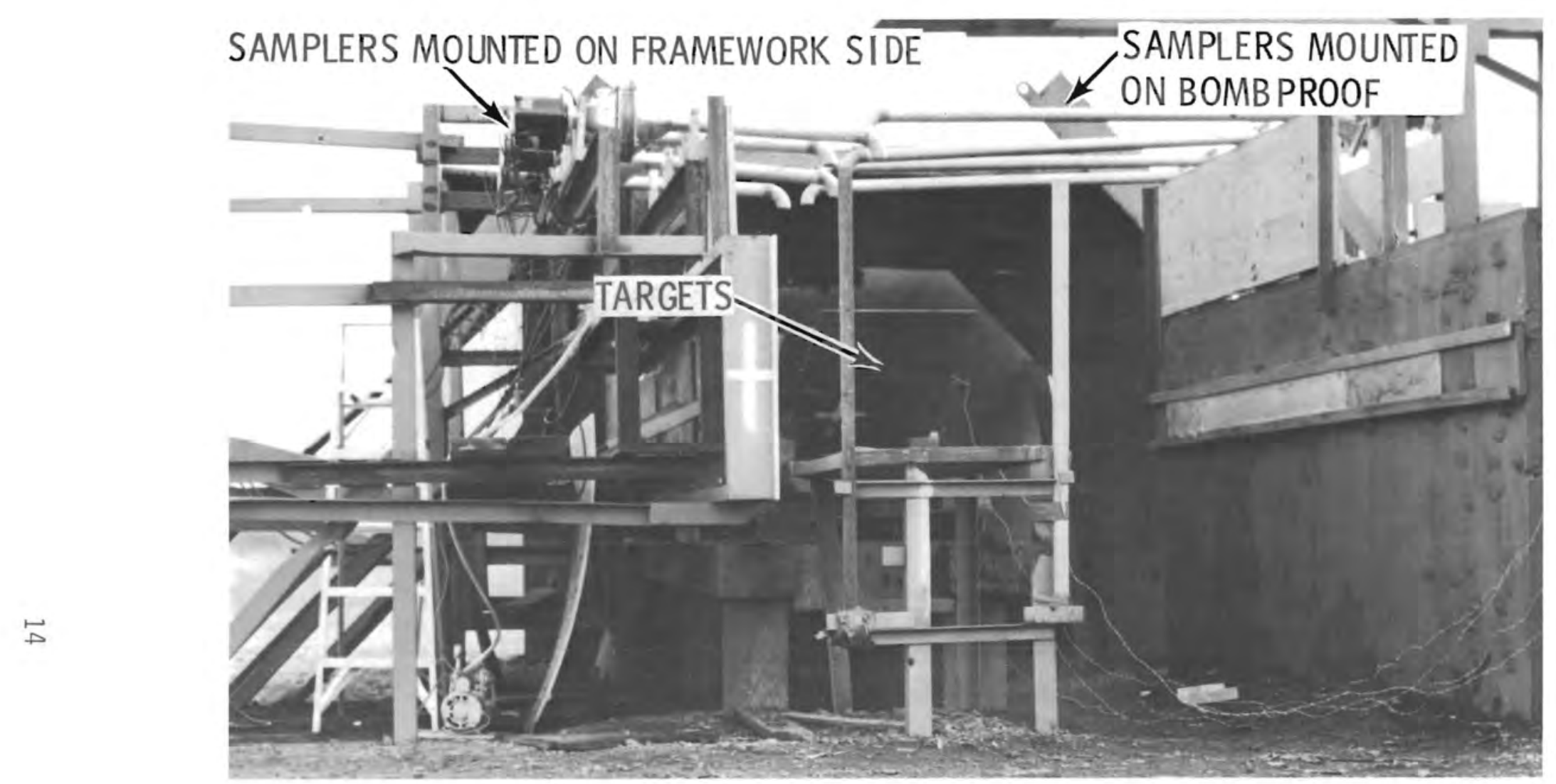

FIGURE 7. Target Showing Probes of Samplers Tl-T6 and I1, I2. (Probes are positioned about $8 \mathrm{ft}$ above grade.) 


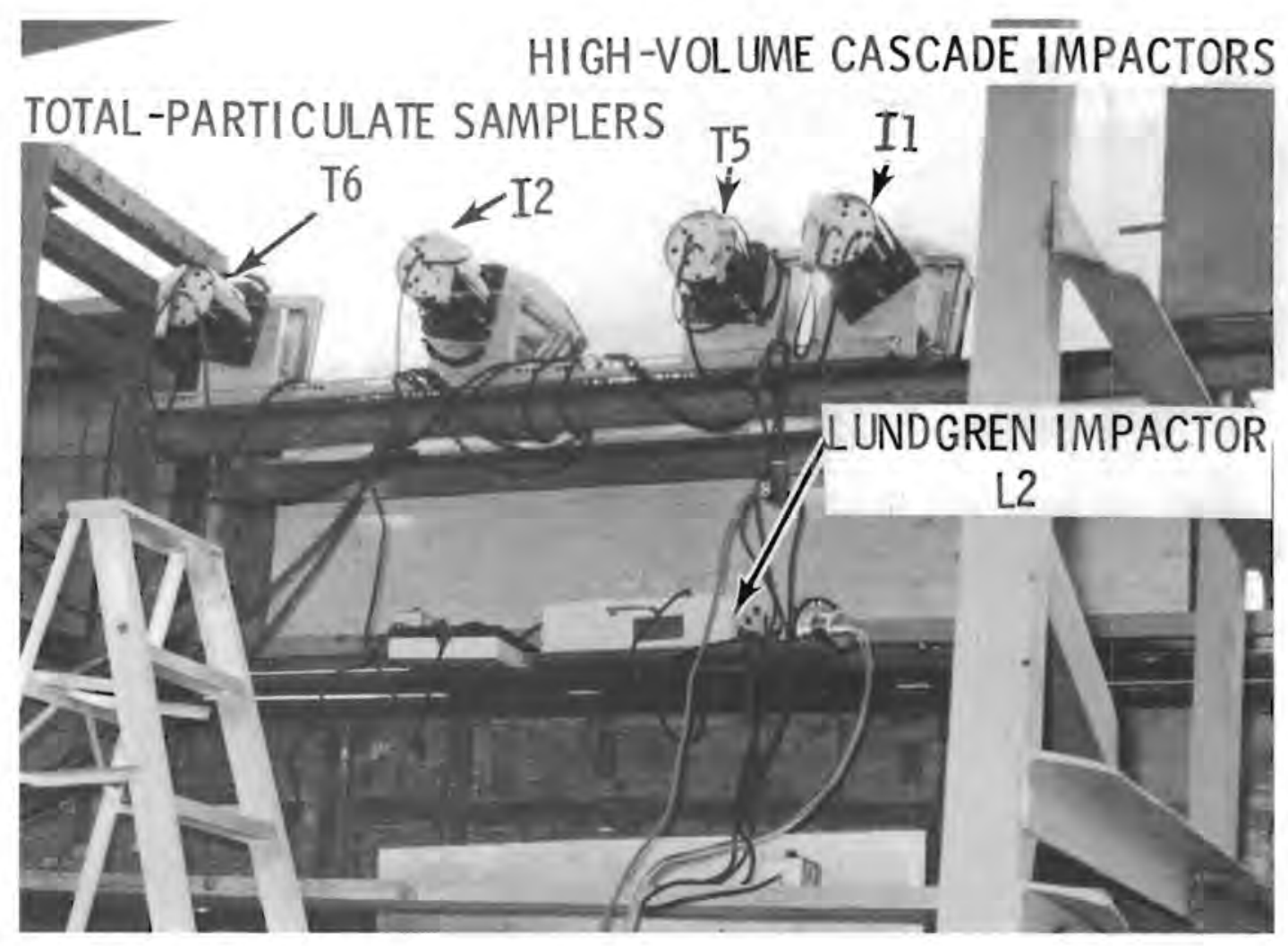

FIGURE 8. Rear of Film Frame Showing Samplers I1, I2, T5, T6, and L2.

TABLE 1. Sampler Abbreviations

T1 - 8- x 10-in. total-particulate sampler No. 1

I2 - High-volume cascade impactor No. 2

L2 - Lundgren impactor No. 2

S3 - Staplex total-particulate sampler No. 3

Isokinetic sampling(a) was not attempted in this study The authors expected the velocity and direction of air in the sampling area to vary rapidly, and it was impractical to control the sampling rate as rapidly. Therefore, the size distribution of the collected samples is probably not ideally representative of the airborne particulates.

(a) That is, maintaining an air velocity in the probe nozzle identical to the velocity of the approaching air, one of the measures required to assure that the size distribution of particles in the sample is identical to that in the air being sampled. 


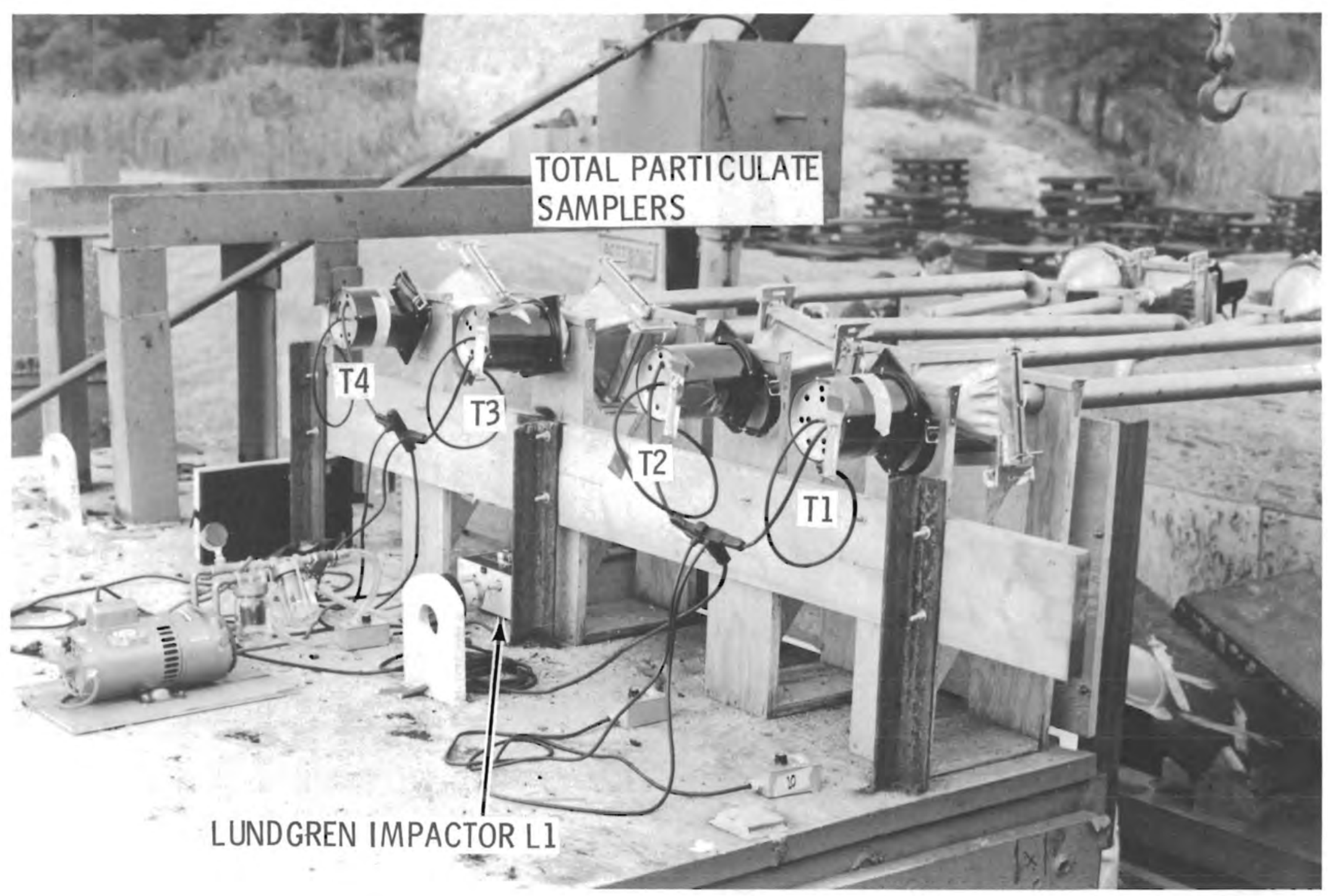

FIGURE 9. Rear View of Samplers Mounted on Bombproof 


\subsubsection{Upwind/Downwind Air Sampling}

Upwind and downwind air sampling was attempted within a 150-ft radius of the targets and at selected locations in the Industrial Area at Aberdeen Proving Grounds. All samplers were located in clearings and placed 4 to $6 \mathrm{ft}$ above grade. The samplers used were high-volume cascade impactors and totalparticulate samplers with $4-i n$. diameter and $8-\times 10-i n$. filters.

Two high-volume cascade impactors were set up for each run, one located upwind and one downwind from the target area. This equipment was identical to that used in the target area, except that 1) there were no inlet probes, and 2) the impactors were mounted with the plane of the jet plates horizontal and the intake side facing up.

Two total-particulate samplers with $8-x$ 10-in. filters were set up for each run, one upwind and one downwind from the target area. These samplers were identical to the target area's total-particulate samplers except that they were 1) mounted so that the filter was oriented horizontally and 2) had no inlet probe. The samplers were mounted on aluminum shelters, with Whatman 41 filters exposed to the atmosphere. Flow rate was controlled and calibrated as in the other tests.

High-volume total-particulate samplers with 4-in.-diameter filters ${ }^{(b)}$ were provided by Army Armament Research and Development Command (ARRADCOM). Three to five of these samplers were deployed for each run: one was located at the Human Engineering Laboratory (HEL) field and one at the Mile Test Loop (MTL) in the Industrial Area as indicated in Figure 10. The others were located in the upwind and downwind sampler groups. During the course of the experiments, some sampling was conducted by the Army at the Building 938 and Michaelsville locations, also shown in Figure 10. The deployment of the Staplex samplers varied from run to run and will be described in Appendix A.1.

Each Staplex unit had a built-in flowmeter, and three of these units had marked flow calibrations for Whatman 41 filters. These units, designated S1, S2, and S3, were marked as follows:

(b) The Staplex Company, 777 Fifth Avenue, Brooklyn, New York 11232. 


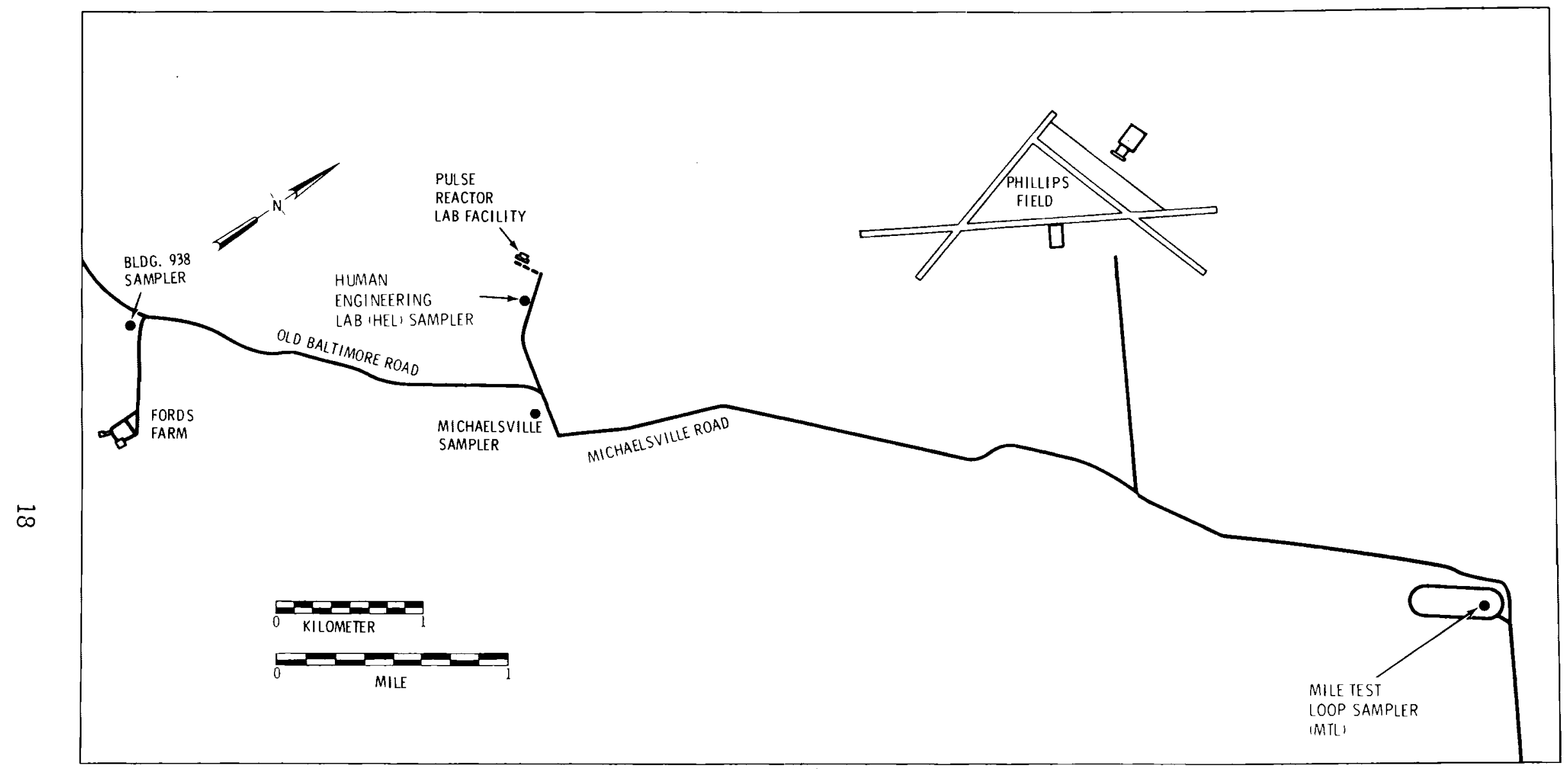

FIGURE 10. Position of Auxiliary Samplers Relative to Ford's Farm Firing Range (to scale) 


$\begin{array}{cc}\text { Unit } & \text { Flow Rate, cfm } \\ \text { S1 } & 24.75 \\ \text { S2 } & 26.1 \\ \text { S3 } & 25.88\end{array}$

The flow rates of the other units were read from their flowmeters without a calibration check.

The upwind and downwind sampler groups used for Run 1 are shown in Figures 11 and 12 .

\subsubsection{Cloud Dimensioning}

The measurements of cloud dimensions and rise time were made from high-speed motion pictures provided by the U.S. Army Testing and Evaluation Command (TECOM). Still photography and some color movie footage were also provided.

The high-speed motion pictures were taken in black and white using two tracking cameras separated by an included angle of about 57 degrees and located about $200 \mathrm{~m}$ from the target area (see Figure 1). The measurements made from these films aided in determining the source term for airborne uranium. The total airborne uranium was approximated from the concentrations measured in the target area and from the size of the cloud.

\subsubsection{Meteorological Data Collection}

Meteorological support for this project was provided by the U.S. Army Environmental Hygiene Agency (AEHA). A mobile meteorological system was located approximately $500 \mathrm{~m}$ from the target area in an open field (see Figure 1).

The windspeed, wind direction, and standard deviation of the wind direction were measured at $10 \mathrm{~m}$ above grade. Solar radiation and ambient temperature were also measured. The stability category was estimated using the Brookhaven Stability Class system. ${ }^{(5)}$ All meteorological data were reported as 5 -min averages for the periods from about $30 \mathrm{~min}$ before to $60 \mathrm{~min}$ after each test firing for which target area and upwind/downwind samplers were operated. 0therwise, the meteorological data were reported as 1-hr averages 


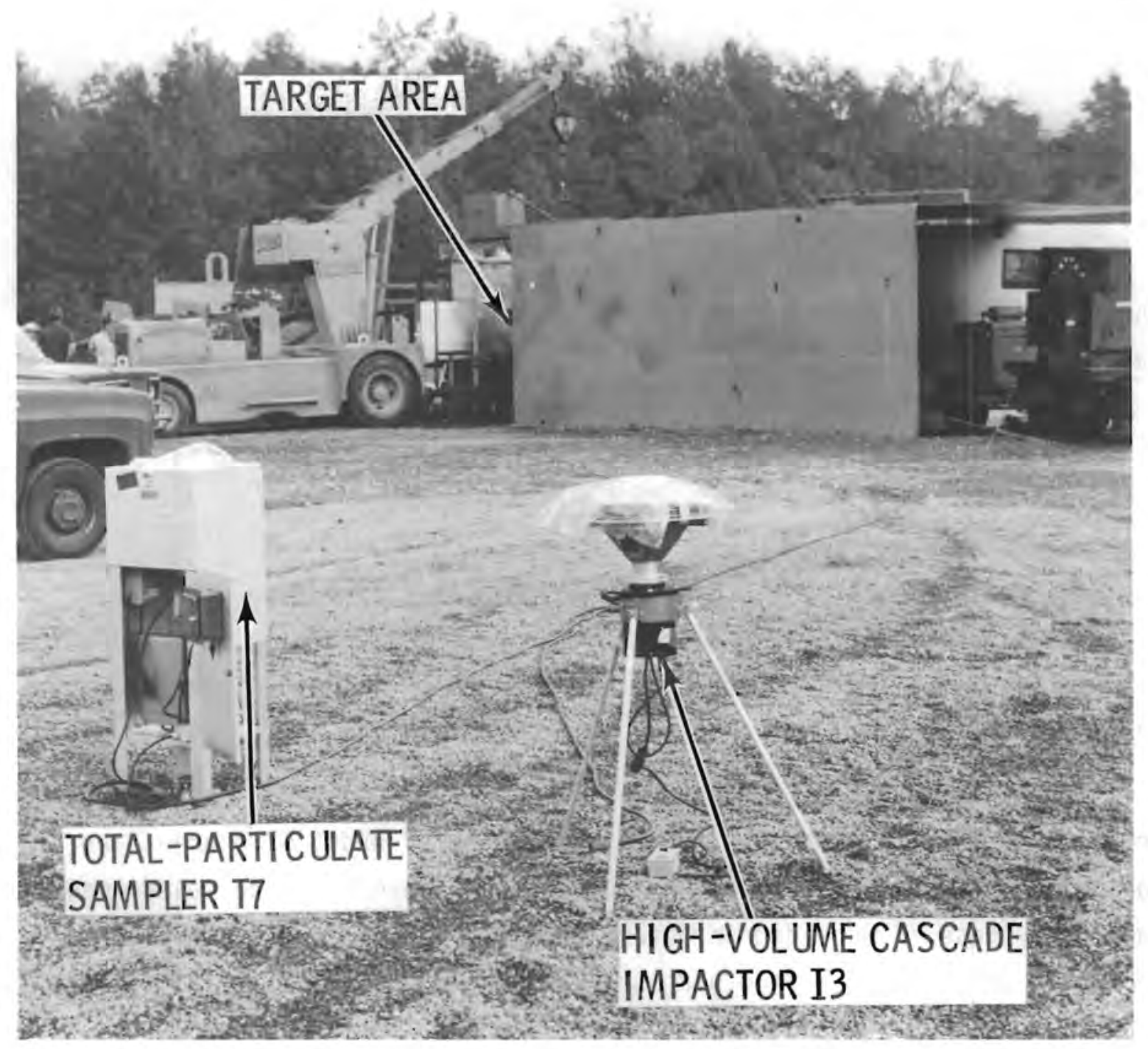

FIGURE 11. Upwind Samplers Located about $80 \mathrm{ft}$ from Target (Run 1)

for all time periods between October 4, 1977 (1430 hours) and October 9, 1977 (1000 hours). Appendix A.2 contains meteorological data extracted from the AEHA report.

\subsubsection{Target-Area Airborne-Uranium Dispersion Rate}

The rate of dispersion of airborne uranium in the target area was determined using Lundgren Cascade Impactors ${ }^{(a)}$. The principle of aerodynamic fractionation of airborne particles is the same as discussed earlier; however, features of this impactor make it useful for this

(a) Lundgren Impactor Model 4220, Environmental Research Corp. St. Pau1, Minnesota; now marketed by Sierra Instruments, Inc. 


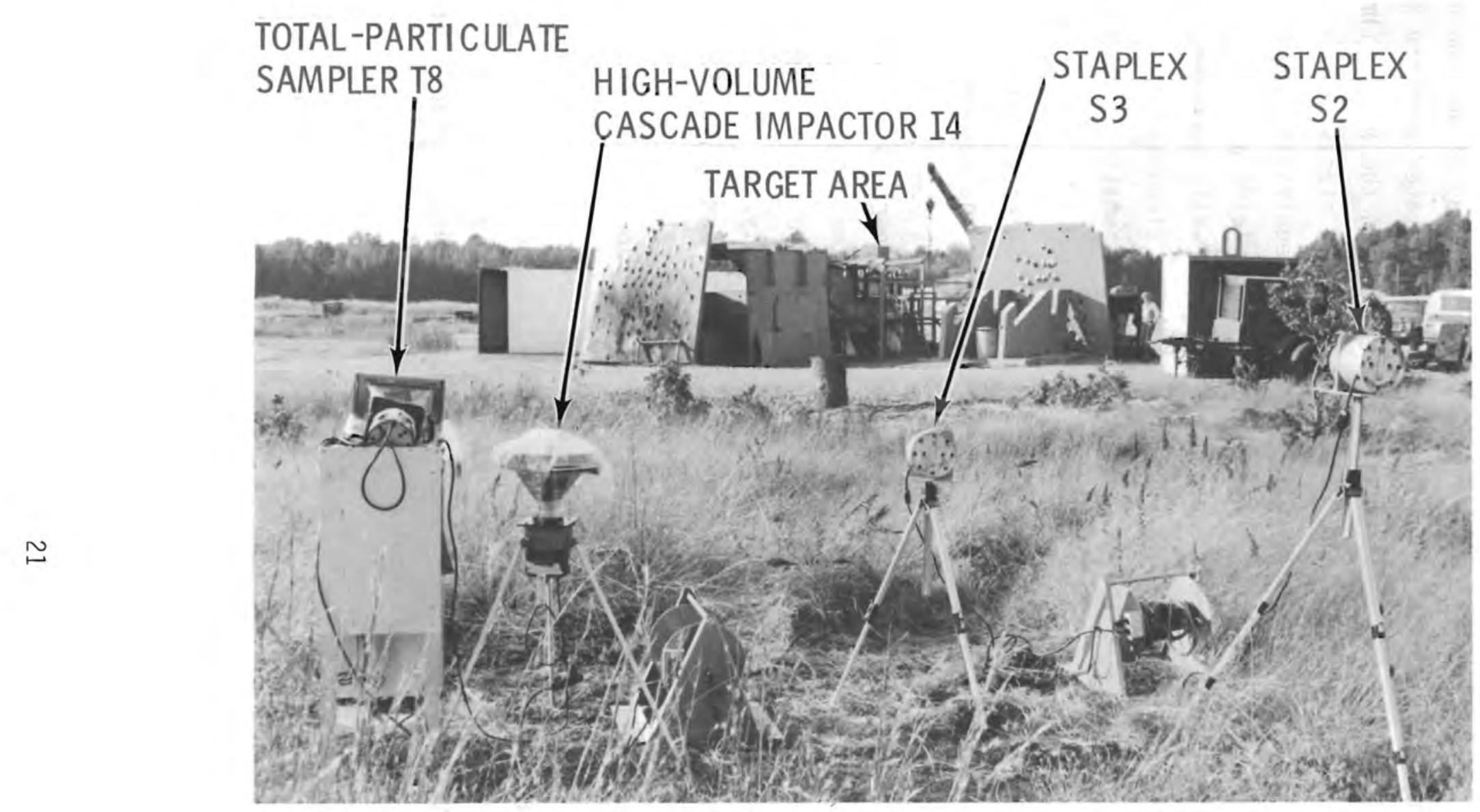

FIGURE 12. Downwind Samplers Located about $145 \mathrm{ft}$ from Target (Run 1) 
experiment. Instead of a circular plate with many jets at each stage, the Lundgren impactor employs a single rectangular jet at each stage. The impaction substrate is a thin rectangular film of mylar instead of Whatman 41 filter. The mylar film is wrapped around a cylinder that rotates past the jet at selectable speeds. Thus, the location of the particles on the mylar film can be related to the time of sampling. There are four such stages in the Lundgren impactor, each with a characteristic aerodynamic equivalent cutoff diameter ${ }^{(a)}$. A backup filter follows the four stages and yields a time-integrated rather than a time-dependent sample. An MF-Millipore membrane filter (b), with a high collection efficiency for submicron airborne particles, was used as a back-up filter. Figure 13 is a schematic drawing of the Lundgren impactor.

A thin coating of grease was rubbed onto the mylar substrates after they were mounted on the cylinders to increase particle adhesion and decrease large particle bounce. This practice was satisfactory for all but the fourth stage. The clearance between the cylinder and jet of the fourth stage was so small that, in some cases, the coating rubbed and smeared the deposited particles. The stretch of the mylar substrate contributed to the problem because the substrate did not always fit the cylinder tightly.

The vacuum source for the impactor was a sliding vane pump. A photograph of the assembled sampler is shown in Figure 14. The flow rate was set at $3 \mathrm{cfm}$ as indicated on the impactor's built-in calibrated flowmeter.

The impactors were located in areas close to the targets where personnel perform most of their tasks. Lundgren LI was located on the bombproof and sampled from the target accessway (the walkway between the targets and the bombproof) at a 6-ft elevation above grade. Lundgren, L2, was located on the framework where the $X$-ray film was mounted (see Figure 6 ).
(a) Stage 1--9.4 $\mu \mathrm{m}$ AED
Stage 2--2.8 $\mu \mathrm{m}$ AED
Stage 3--0.9 $\mu \mathrm{m}$ AED
Stage 4--0.26 $\mathrm{mm}$ AED
(b) MF-Millipore is a filter made of mixed cellulose esters. 

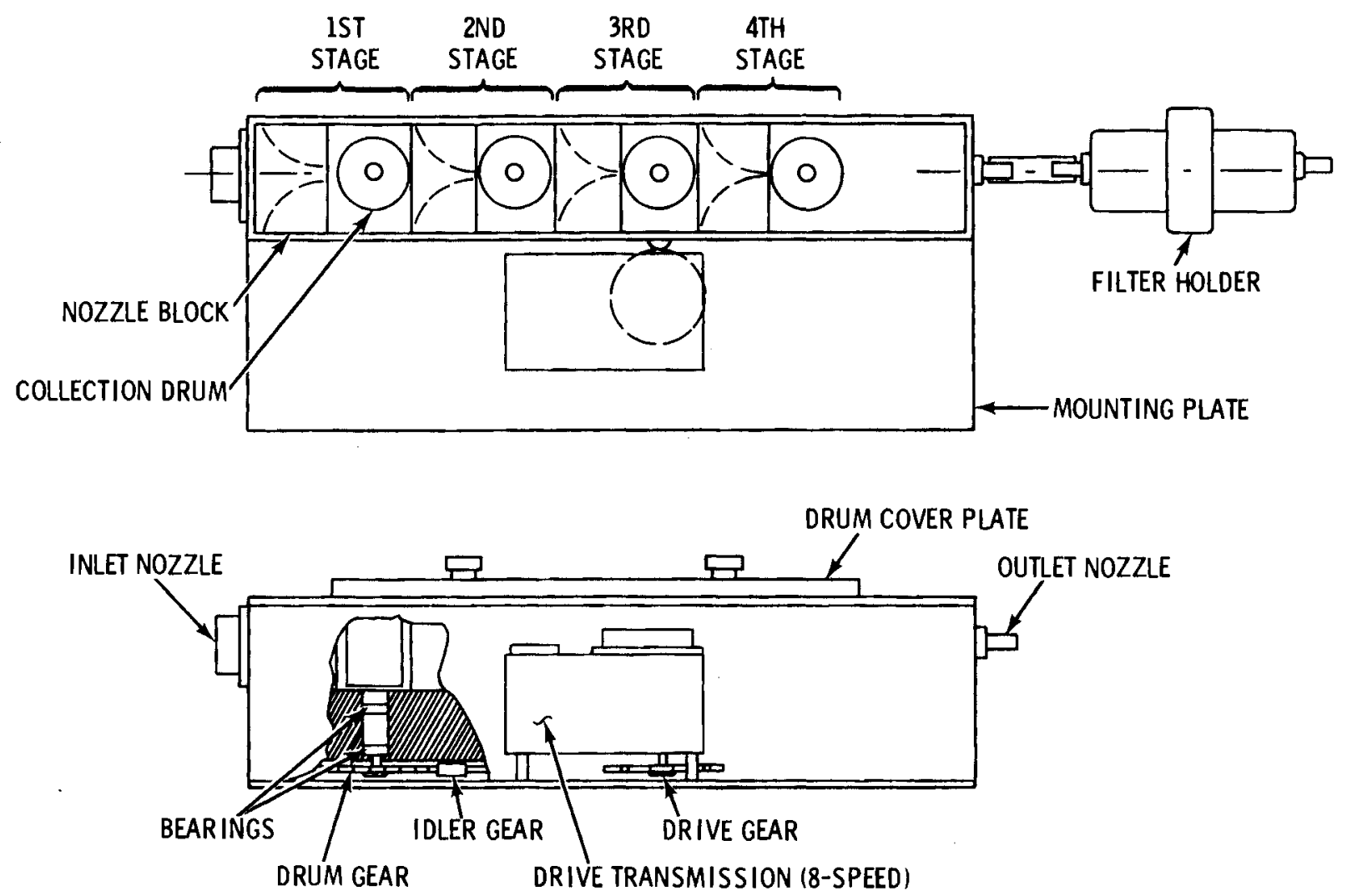

FIGURE 13. Schematic Diagram of Lundgren Impactor

\subsubsection{Fallout Collection}

Two plans were used to collect fallout. One was to collect sufficient fallout for the identification of uranium oxides. For this purpose, stainless-stee 1 trays, $8 \times 11$ in., were set out for a test firing, then covered and moved during the changing of targets. These trays were located where small fragments of depleted uranium had been found. The layout of the trays is shown in Figure 15. The samples from this experiment will be referred to as the "dry fallout" samples.

The second plan was designed to estimate the amount of uranium fallout within a 50-ft radius of the targets. Three-quart Pyrex trays containing water were used to collect the fallout. (The water made it easier to transfer the collected particles to sample jars.) The tray layout is shown in Figure 16. The area included in a 50-ft radius from the center of the middle target was divided into three annular and one circular region, all of equal area. The two inner regions were divided radially into sixths. A tray was 


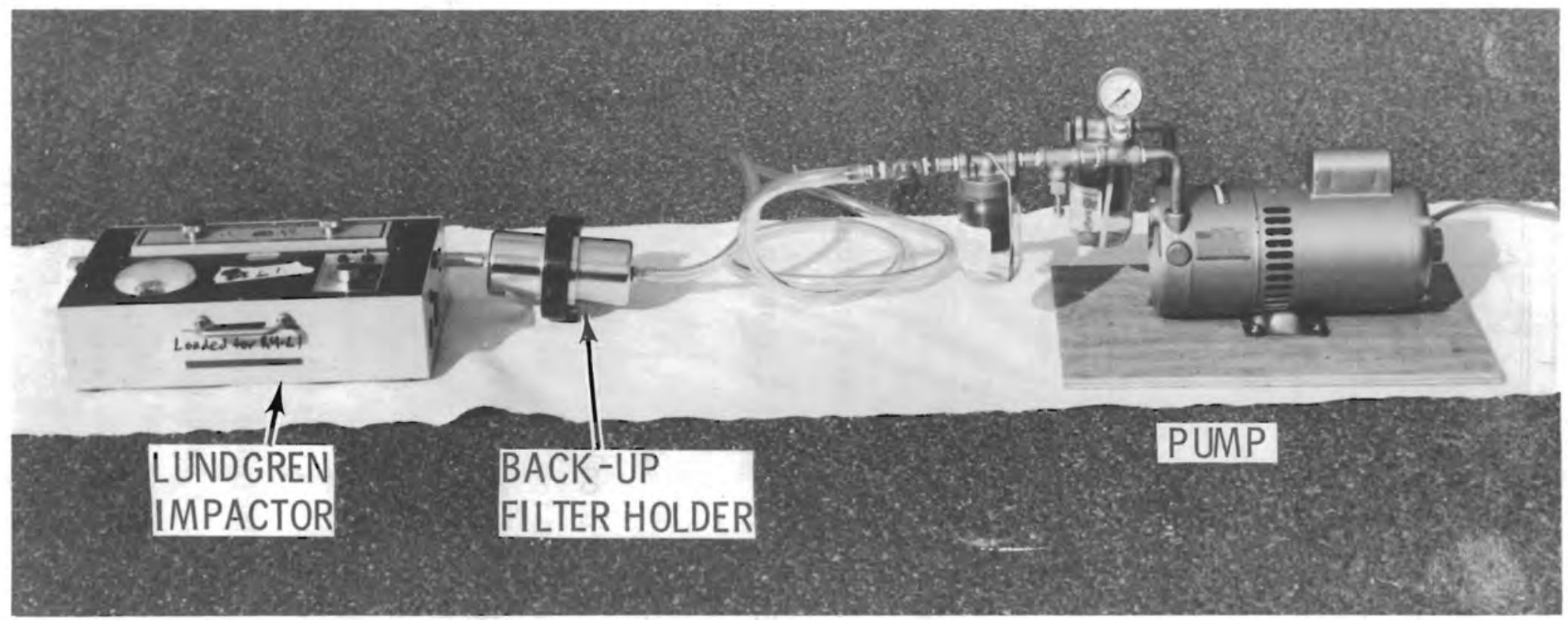

FIGURE 14. Assembled Lundgren Impactor Sampler 


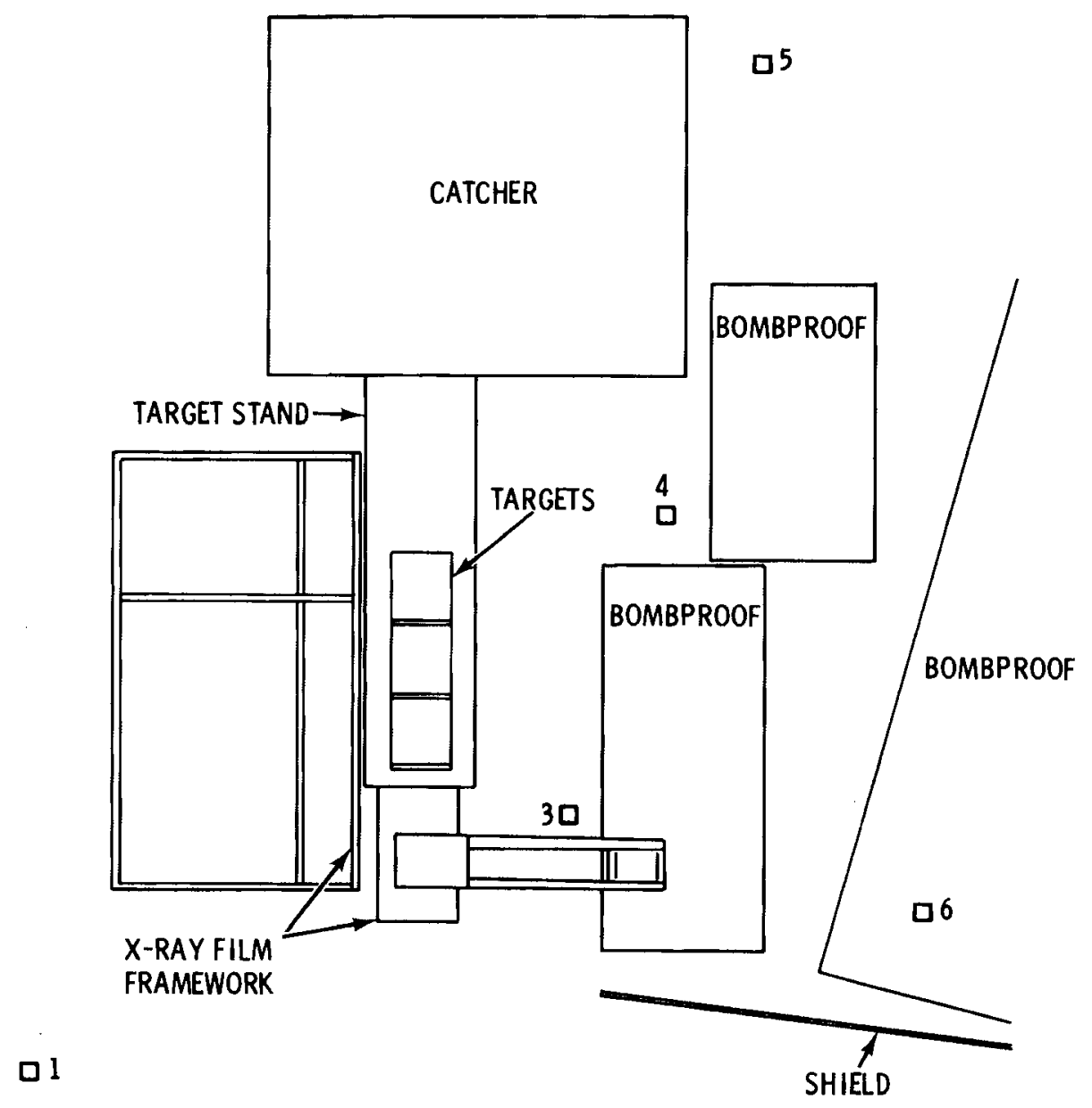

FIGURE 15. Approximate Locations of Dry Fallout Trays

located in each of the 12 areas, and the amount of fallout collected in each tray was considered representative of the $327-\mathrm{ft}^{2}$ area. The two outer regions were divided radially into quarters. A tray was located in each of the eight equal areas to represent the $490-\mathrm{ft}^{2}$ area. Each tray was located in the centroid of its region. The equation for the region radial boundaries is included in Figure 16. The samples from this experiment will be referred to as the "wet fallout" samples.

\subsection{EXPERIMENTS}

The experiments performed during the test firings will be outlined in this section. Details concerning the operation of air samplers are discussed in Appendix A.1. 


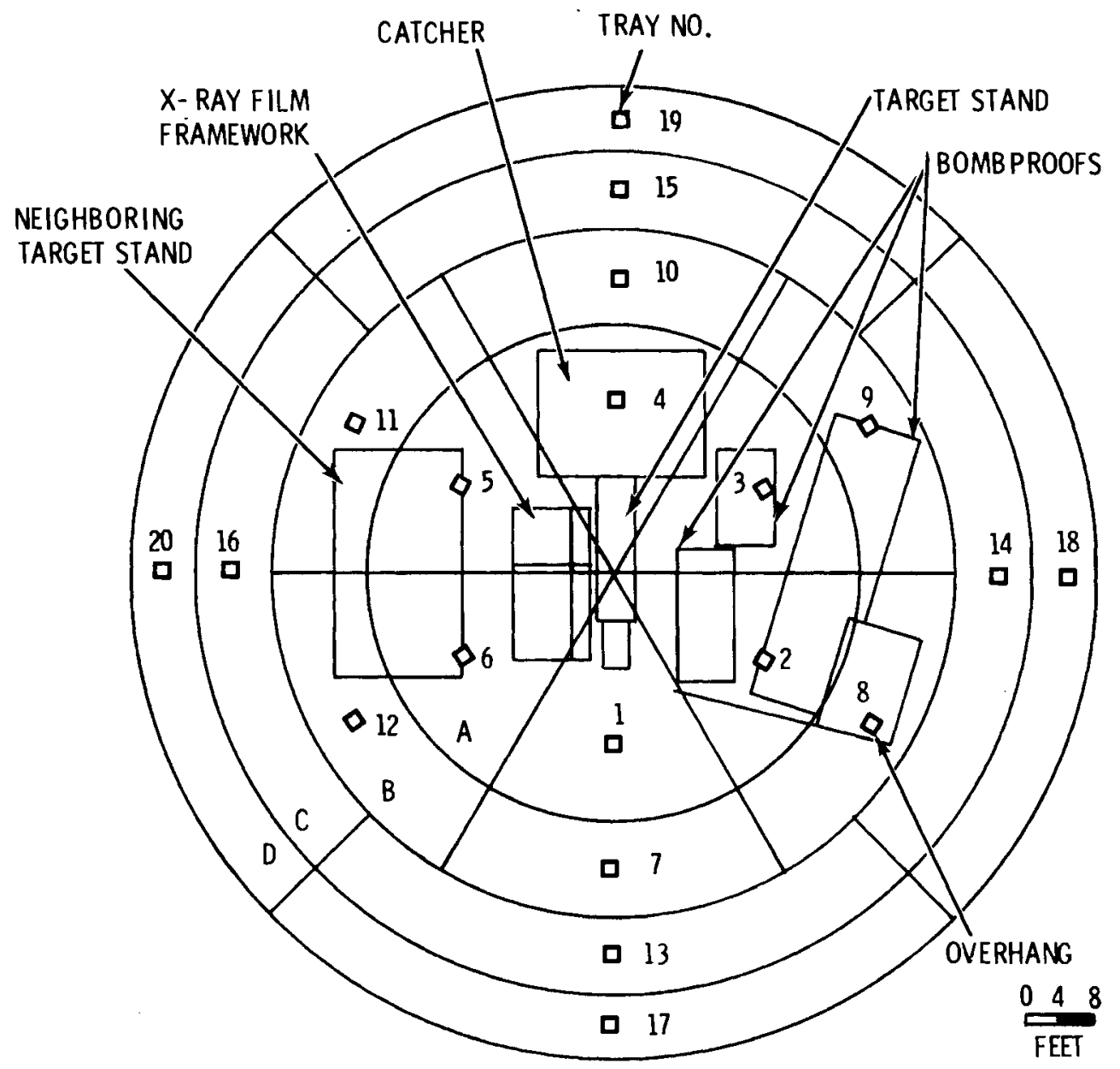

TRAYS 2, 3,4,8 AND 9 ON STRUCTURES

AREA BOUNDARY RADII $\mathrm{R}_{\mathrm{N}} \sqrt{\frac{\mathrm{na}}{\pi}}$

$$
\begin{aligned}
& R_{A}=25 \mathrm{ft} \\
& R_{B}=35.4 \mathrm{ft} \\
& R_{C}=43.3 \mathrm{ft} \\
& R_{D}=50 \mathrm{ft}
\end{aligned}
$$

口 21 BY STORAGE BUILDINGS UPRANGE

口 22 IN LAB, CONTROL

FIGURE 16. Layout of Water-Filled Fallout Trays 


\subsubsection{Air Sampling}

The air sampling experiments were repeated five times. The equipment was set up at the firing range while the range crew prepared the targets for the test firing. After the samplers were in place, the $X$-ray crew mounted the $X$-ray films. The samplers were started and set to their required flow rates, and all personnel took cover in the bombproofs near the gun (see Figure 1). After the firing, personnel were required to wait 15 min before entering the target area. After the waiting period, the air sampler flow rates were checked before being shut off at the desired times.

Generally, after the shot the upwind/downwind and Lundgren impactor samplers were operating at their set flow rates. If they were to be left on for an extended time, they required only minor adjustment. However, the target-area total-particulate and high-volume impactor samplers were all found operating at drastically reduced flow rates after the shot. The flowmeters could not be read in most cases because the flow was below scale (below $5 \mathrm{cfm})$. Therefore, the airflow and sampling duration of these air samplers can only be estimated.

The upwind and downwind sampler groups were located 90 to $150 \mathrm{ft}$ from the target stand. It was difficult to judge wind direction because it changed frequently and the wind speed was low $(<5 \mathrm{mph})$. In some cases, the wind shifted $180^{\circ}$ between the time the equipment was set up and the time the round was fired. The samplers at HEL and MTL were set up and operated for most runs. They were operated unattended for up to $12 \mathrm{hr}$.

The operation of the air samplers during each test firing is detailed in Appendix A.1. Figures showing the arrangement of upwind/downwind samplers with respect to the targets and the observed meteorological conditions for each test firing are also found in Appendix A.1.

\subsubsection{Fallout Sampling}

"Dry fallout" was collected in stainless-steel trays (see Figure 14) on October 6 and 7, 1977, during the nine test firings listed in Table 2. On 
TABLE 2. Firing Times During Which Fallout Was Collected

\begin{tabular}{|c|c|c|c|c|}
\hline \multicolumn{3}{|c|}{ Dry Fallout } & \multirow{2}{*}{\multicolumn{2}{|c|}{$\begin{array}{l}\text { Wet Fal lout } \\
\text { October } 8 \\
\end{array}$}} \\
\hline Oct & er 6 & 0ctober 7 & & \\
\hline 0951 & 1421 & 1401 & 0850 & 1451 \\
\hline 1056 & 1505 & 1508 & 1048 & 1339 \\
\hline 1143 & 1722 & & 1203 & 1603 \\
\hline 1330 & & & & \\
\hline
\end{tabular}

October 6 , the trays were out for seven test firings in rainy conditions. The wet material collected was scraped off the trays and combined into one sample; paper towels used to wipe the trays were added to the sample. The trays were then cleaned for the next day.

On 0ctober 7, the trays were set out in the same pattern as before but for only two test firings. This time the material collected was dry and was brushed off the trays and again combined into one sample. The samples collected on both days contained wood chips and soil.

The water-filled fallout trays were set out on October 8 according to the pattern shown in Figure 15 and during the firings listed in Table 2. The contents of each tray were washed into labeled plastic jars.

\subsection{SAMPLE ANALYSIS}

Four types of sample analyses were completed for this study: 1) total uranium content by gamma spectroscopy, alpha counting or fluorometry; 2) total uranium by $X$-ray fluorescence; 3 ) uranium solubility in simulated lung fluid; and 4) uranium oxide analysis by $X$-ray diffraction and scanning electron microscope. The disposition of the various sample types into these analytical categories is summarized in Table 3. The procedures employed for handling air samples in the field are outlined in the following subsection. Then, further sample preparations and analytical methods are briefly described. Details for each procedure are found in the appendices. 
TABLE 3. Summary of Disposition of Samples

\begin{tabular}{|c|c|c|c|c|}
\hline & $\begin{array}{l}\text { 0xide Analysis \& Morphology } \\
\text { Electron Microscope (a) }\end{array}$ & $\begin{array}{l}\text { Total Uranjum } \\
\text { Analysis } \\
\end{array}$ & $\begin{array}{c}\text { Total Uranium } \\
\text { X-ray } \\
\text { Fluorescence (c) }\end{array}$ & Solubility (d) \\
\hline Target-Area Total Particulate & 1/16th Fraction of 6 Filters & $1 / 4$ Fraction Plus Probes & --- & Fraction of 5 Samples \\
\hline Other Total Particulate & --- & $1 / 4$ or $1 / 2$ Fractions & -- & \\
\hline $\begin{array}{l}\text { Target-Area High-Volume } \\
\text { Impactor }\end{array}$ & Fraction of 2 Impactors & $1 / 4$ Fractions Plus Swabs & --- & $\begin{array}{l}\text { Fractions of Same Im- } \\
\text { pactors Used for } \\
\text { 0xide Analysis, } \\
\text { Stages } 3,4 \text { and Filter }\end{array}$ \\
\hline Other High-Volume Impactor & --- & 1/4 Fractions Plus Swabs & -- & $\begin{array}{l}\text { Fraction of One } \\
\text { Impactor Stages } 3,4 \\
\text { and Filter }\end{array}$ \\
\hline Lundgren Backup Filter & --- & A11 & -- & -- \\
\hline Lundgren Substrates & -- & $-\cdots$ & Al1 & --- \\
\hline Dry Fallout & -- & Fractions & --- & -- \\
\hline Wet Fallout & --- & All & --- & -- \\
\hline $\begin{array}{l}\text { (a) Metallurgy Research and } A \\
\text { (b) U.S. Test ing, Richland Di } \\
\text { (c) Chemical Methods and Kine } \\
\text { (d) Inhalation Technology \& TC }\end{array}$ & $\begin{array}{l}\text { alytical \& Nuclear Research Se } \\
\text { ision. } \\
\text { ics Section, PNL. } \\
\text { xicology Section, PNL. }\end{array}$ & ions, PNL. & & \\
\hline
\end{tabular}




\subsubsection{Field Handling of Air Samples}

The filters from the total-particulate samplers were removed, folded, bagged and labeled. The probes were removed, washed repeatedly with distilled water, and swabbed with moistened cellulose tissue. The washings and swabs were combined as one sample.

For the target-area high-volume cascade impactors, the probe, inlet adaptor, and face of the first jet plate were washed and swabbed. This was termed the "probe" sample. For the other high-volume impactors, the face of the first jet plate was swabbed and the swabs were saved as a sample. From then on, the cascade impactors were all treated identically. The first jet plate was removed, and the perforated substrate beneath it was folded and bagged. The bottom of the first jet plate and the top of the second plate were swabbed, and swabs were added to the perforated substrate. This procedure was repeated for each successive stage and for the back-up filter.

The mylar substrates of the Lundgren impactors were removed from each drum, taped to cards and placed in containers so that the deposited materials would not contact other surfaces. The backup filter was folded and bagged. The holder for the backup filter was swabbed and the swabs were placed with the filter.

\subsubsection{Uranium Analysis Procedures}

Analyses for uranium in most samples were performed by United States Testing Company (UST) in Richland, Washington. The total-particulate, high-volume cascade impactor, Lundgren impactor backup filter, and fallout samples were analyzed for total uranium. The preparation of the samples for analysis is detailed in Appendix B.1.

Because of a lack of funds, not all of the upwind impactor samples were analyzed. However, it was felt that they would not add significantly to our findings because they were probably not located far enough upwind of the targets to give a true background uranium size distribution. Because of the diffusion from the rapidly expanding cloud following the impact of the ammunition, the upwind samplers were possibly contaminated (see pp. 44-46). 
UST used three methods to determine the uranium content of the samples: gamma spectroscopy, alpha counting and fluorometry. A simplified flow chart of the methods is shown in Figure 17.

Gamma counting was used only for samples that gave hand-held geiger counter readings distinguishable from background. The analysis for uranium was based on the assumption of equilibrium between thorium-234 and its parent uranium-238 and on the isotopic content of the ingot from which the penetrator was made.

Most of the filter, substrate and liquid suspension (probe wash and some "wet fallout") samples were processed through pyrosulfate fusion to ensure dissolution of all particulates. The uranium was then extracted from the solution with hexone. A portion of the extractant solution was plated on a planchet and subjected to an alpha-counting technique. Those samples for which the counting statistics were unacceptable were subjected to analys is by fluorometry. A portion of the hexone extractant was fused into a pellet of NaF-LiF for the fluorometric analysis.

\subsubsection{Lundgren Impactor Substrates}

The four Lundgren cascade impactor substrates from one impactor are shown in Figure 18. The dark bands are deposits of particles collected when the concentration of airborne particles was particularly high. Substrate 4 shows how the deposits on this stage were frequently smeared in the impactor.

Each substrate was cut vertically into segments (see Figure 18) representing intervals of sampling time. Each segment was then analyzed for uranium using an X-ray fluorescence technique. The uranium content of the four segments (for example, the four labelled "A") corresponding to the same time interval were summed, and a weighted amount of the uranium on the backup filter was then added to the sum to estimate the total uranium collected during the time interval. The details of sample preparation and some sample calculations are included in Appendices B.2 and B.3.

\subsubsection{Oxides}

The relative abundance of uranium oxides made airborne during the test firings was determined semi-quantitatively by $X$-ray diffraction analysis of portions of target-area total-particulate sample filters (one from each test 


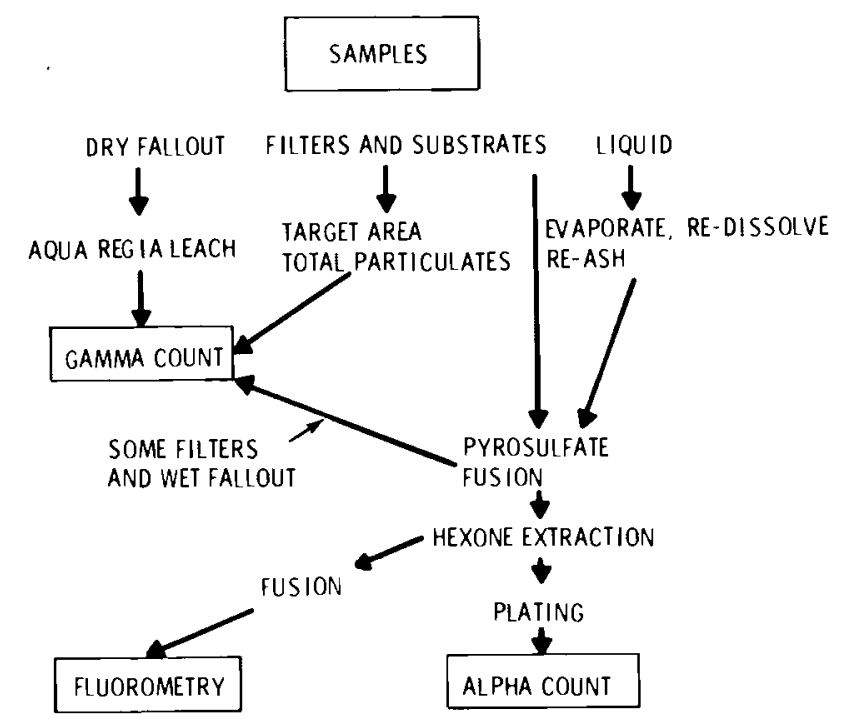

FIGURE 17. Simplified Flow Chart for Uranium Analysis

firing). The same analysis was made for fractions of the dry fallout. Qualitative identification of uranium oxides collected on the substrates of two of the target-area high-volume cascade impactors was also done by $X$-ray diffraction. The morphologies of selected particles from each of the above three types of samples were studied with a scanning electron microscope and the elemental compositions were determined by microprobe analysis. The details of sample preparation and analytical method are covered in Appendices B.4 and B.5.

\subsubsection{Solubility}

The solubility of uranium-containing particles in simulated lung fluid was investigated using airborne particulate samples collected in the target area and downwind. Portions of each of the total-particulate sample filters used for uranium oxide determinations were subjected to the solubility analysis. Fractions of the same target-area cascade impactor samples employed in the oxide analyses were also subjected to solubility analysis with the addition of one of the downwind impactor samples. Whereas all five of the substrates from an impactor were used for oxide analysis, only those 


$$
\begin{aligned}
& |3-L| S 1 \mid \\
& \beta_{3}-4-52= \\
& \text { R3-41-33 } \\
& \text { R3-4 } 54
\end{aligned}
$$


substrates representing respirable particles were used in the solubility analysis. It was reasoned that only respirable particles, approximately $3.3 \mu \mathrm{m}$ AED or smaller, would penetrate to and be retained in the pulmonary compartment of the lungs. Respirable particles were collected on the last two stages of the impactor and the backup filter (see page 12 and Table 9, page 53).

The solubilities of the materials collected on the samples were measured by immersing them in simulated lung fluid ${ }^{(6)}$ and extracting aliquots at selected times. The aliquots were analyzed for uranium using the fluorometry technique. The starting uranium content of the sample fractions was estimated from analysis of other portions of the same samples. The details of sample preparation and analytical procedure are covered in Appendices B.6 and B.7. 


\subsection{RESULTS}

In this section the results of the experiments and interpretation of the data are summarized. Other detailed data and sample calculations are referenced and included in the appendices.

\subsection{AIRBORNE PARTICLE SIZE}

\subsubsection{High-Volume Cascade Impactors}

The size distribution of the airborne uranium is reconstructed from the cascade impactor data by first summing the uranium collected on the stages and backup filter and calculating the percentage of the total mass found on the individual stages. Then, cumulative percentages for each stage are calculated starting with the backup filter and ending with the first stage. An example calculation is shown in Appendix C, Table C.1. The cumulative percent for the backup filter is plotted versus the aerodynamic equivalent cut-off of stage 4 and so on, until the cumulative percent of stage 2 is plotted versus the aerodynamic equivalent cut-off of stage 1. If this is done where the cumulative percent scale is expressed as probability and the particle-size scale is logarithmic, the size distribution frequently approximates a straight line and the aerodynamic particulate sizes are said to be "log-normally distributed." This condition turned out to be the case for all of the high-volume cascade impactor samples except for two of those located up/downwind of the targets. The individual plots are shown in Figure 19. From these plots the cumulative percent of the airborne uranium less than a given aerodynamic size (AED) can be estimated. The particle size corresponding to 50 cumulative percent of the uranium is the mass mean aerodynamic diameter (MMAD). Thus, half the mass of the airborne uranium is associated with particles smaller than the MMAD and half with larger particles. The MMAD and the slope of the line are sufficient to characterize the size distribution.

The analyses of impactor-stage swabs from four samples were not found to be consistent from impactor to impactor. Average fractions (swab $\div$ substrate) were calculated for each impactor stage and the resulting corrections applied 


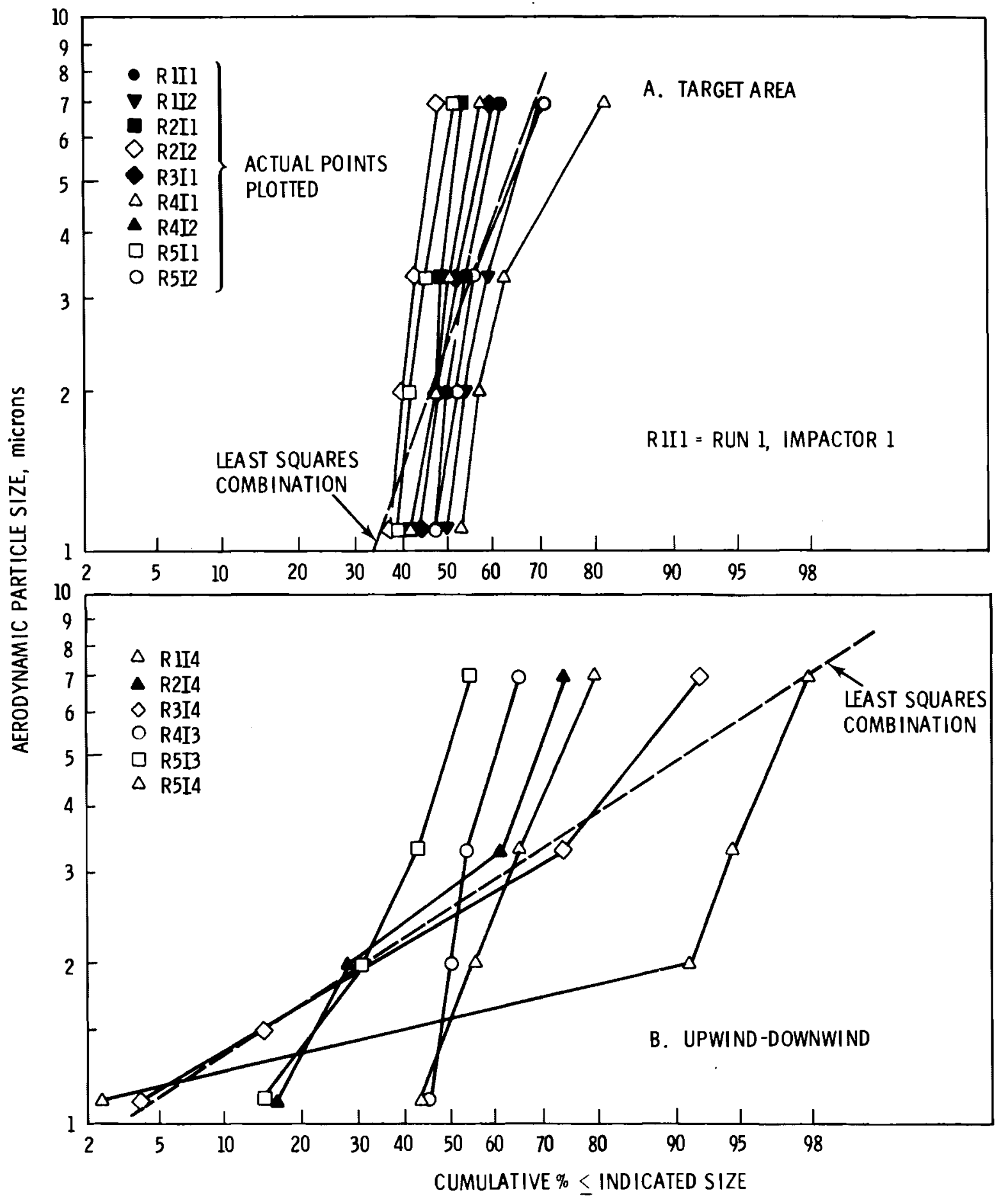

FIGURE 19. Size Distribution Plots for High-Volume Cascade Impactor 
to the impactors without swab analyses. The resulting size distributions were neither statistically nor numerically different from those calculated neglecting the swabs. Therefore, the swab analyses were disregarded because of their negligible effect and the uncertainty they would add.

Through the appropriate transformation of each plotted data point shown in Figure 19 least-squares-fitted size distributions were determined and are shown in Figure 20. The target-area size distribution was calculated both with and without the addition of the uranium content of the probe to the content of the first stage. It is reasonable to include the probe with the first stage (cut-off diameter $7 \mu \mathrm{m}$ ), as in Figure 19, for two reasons. First, particle deposition in the pipe is strongly dependent on particle size--the larger the particle the more readily it deposits. Second, one would not expect the MMAD in the target-area to be smaller than downwind from the targets because of the relatively large airborne particles in the impact region that would fall out within a short distance.

Figure 20 shows that the MMADs at the targets were similar to those about $100 \mathrm{ft}$ away. The figure also shows that at the targets the mass percentage of respirable uranium aerosol is smaller than at $100 \mathrm{ft}$ away (56\% vs. 70\%), indicating large particle fallout over the intervening distance.

It should be pointed out that the size distributions derived from the target-area high-volume impactors carry an uncertainty caused by the clogging of the impactors during the test firings. This is not the case for the up/downwind impactors or the Lundgren impactors (discussed in the following subsection). There was greater variability in the measured MMADs for the target-area impactors than for those up/downwind as shown in Figure 19.

\subsubsection{Lundgren Cascade Impactors}

The raw data for the Lundgren cascade impactors were reduced as discussed on page 31 and shown in Appendix B.3. The size distribution analysis using the data for the first impactor operating-time interval (which averaged about 5 min) is presented here. The size distributions resulting from the total operating times of the impactors were virtually identical because at least $89 \%$ of the airborne uranium measured was collected in the first time interval. 


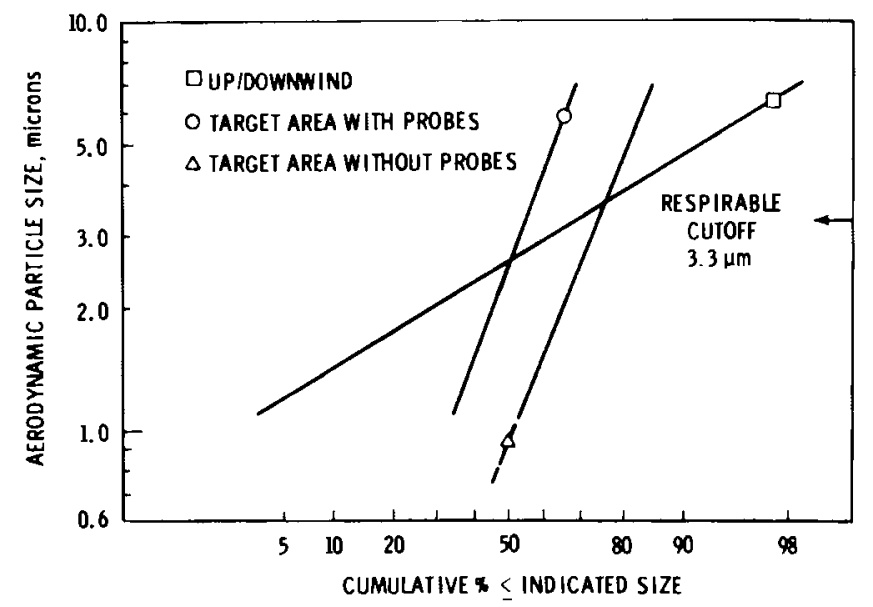

FIGURE 20. Combined High-Volume Impactor Airborne Uranium Size Distributions

The method of deriving size distributions was discussed earlier for the high-volume impactors (page 35) and an example is included in Appendix C, Table C.2.

The size distributions for each impactor sampling from the target accessway are shown in Figure 21 and from behind the $X$-ray film framework in Figure 22. The corresponding least-squares-fitted lines are also shown in Figures 21 and 22. There is noticeably less variability in these MMADs than in the high-volume impactor data--possibly because these impactors did not clog up.

Figure 23 shows the fitted size distributions from the Lundgren impactors superimposed over those from the high-volume impactors. The similarity of the distributions from the high-volume impactors (probes included) and the accessway Lundgren impactors confirms that uranium aerosol in the target area is coarser (a) than at a $110 \mathrm{ft}$ distance from the targets. Both the high-volume impactor (probes excluded) and the Lundgren impactor (behind the framework) distributions show a similar attenuation of large airborne particles by the probes and the framework. Table 4 summarizes the important size distribution data.

(a) Smaller percentage respirable on mass basis. 


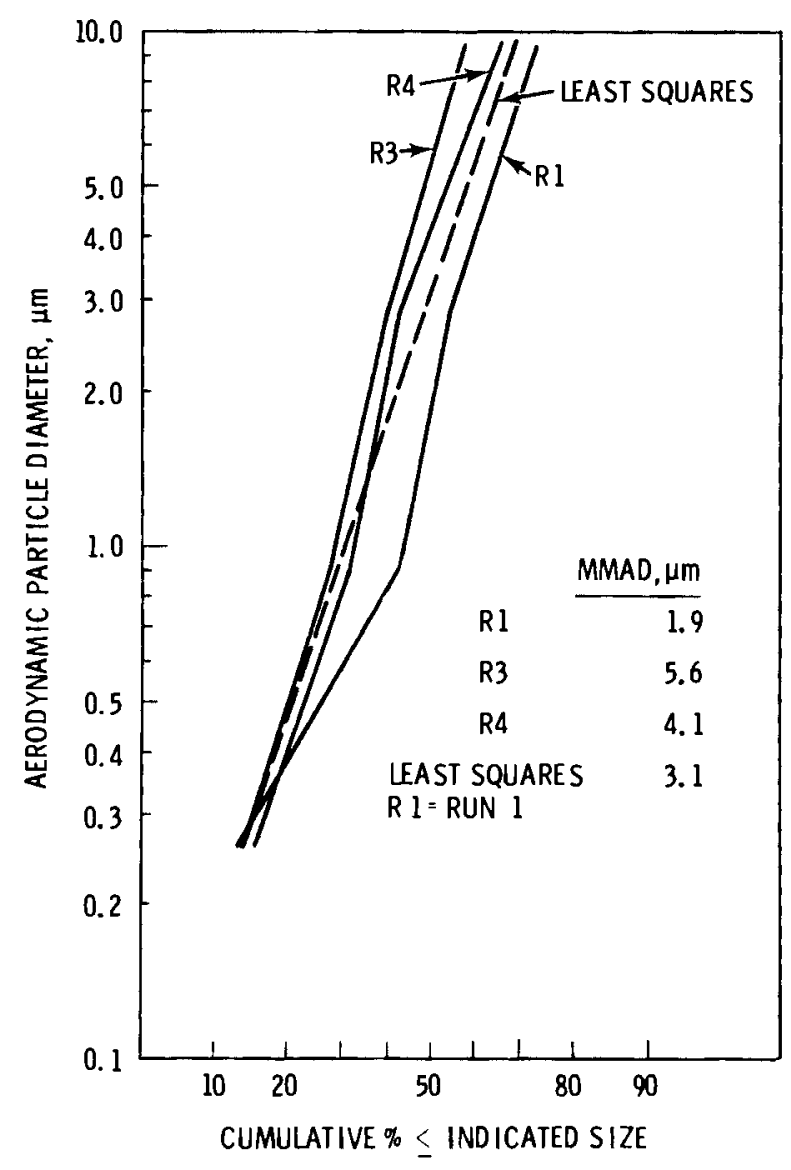

FIGURE 21. Size Distributions for all Lundgren Impactors Sampling from Target Accessway

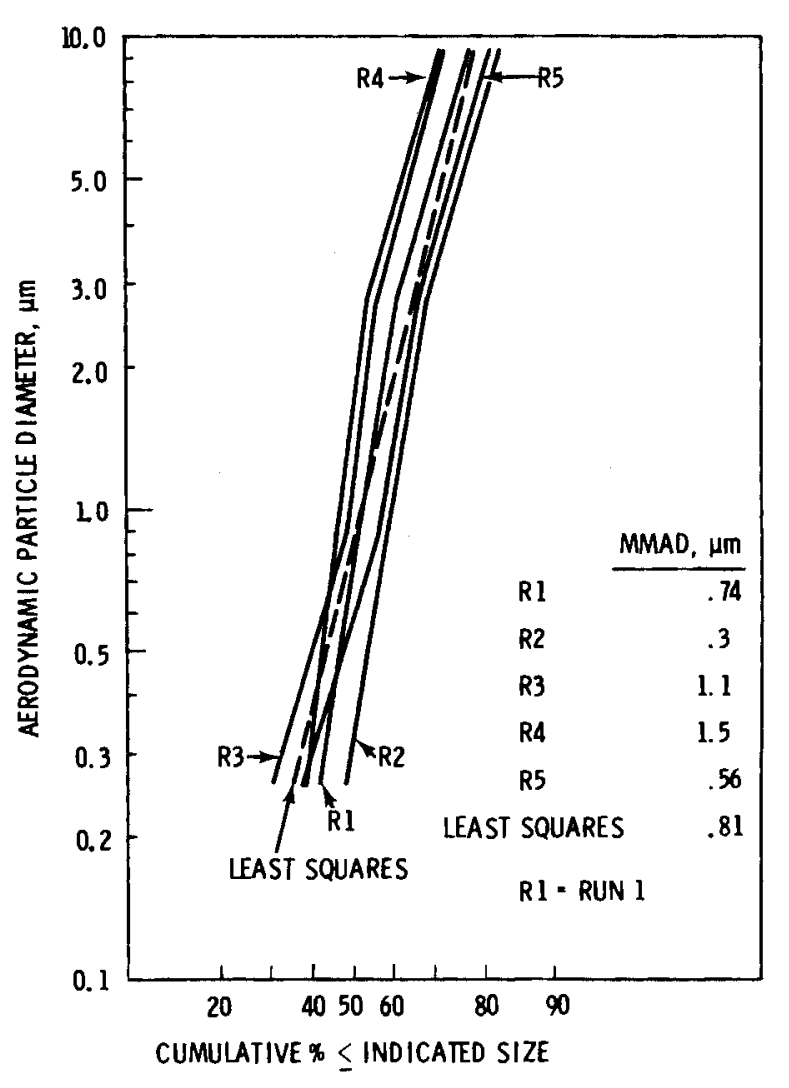




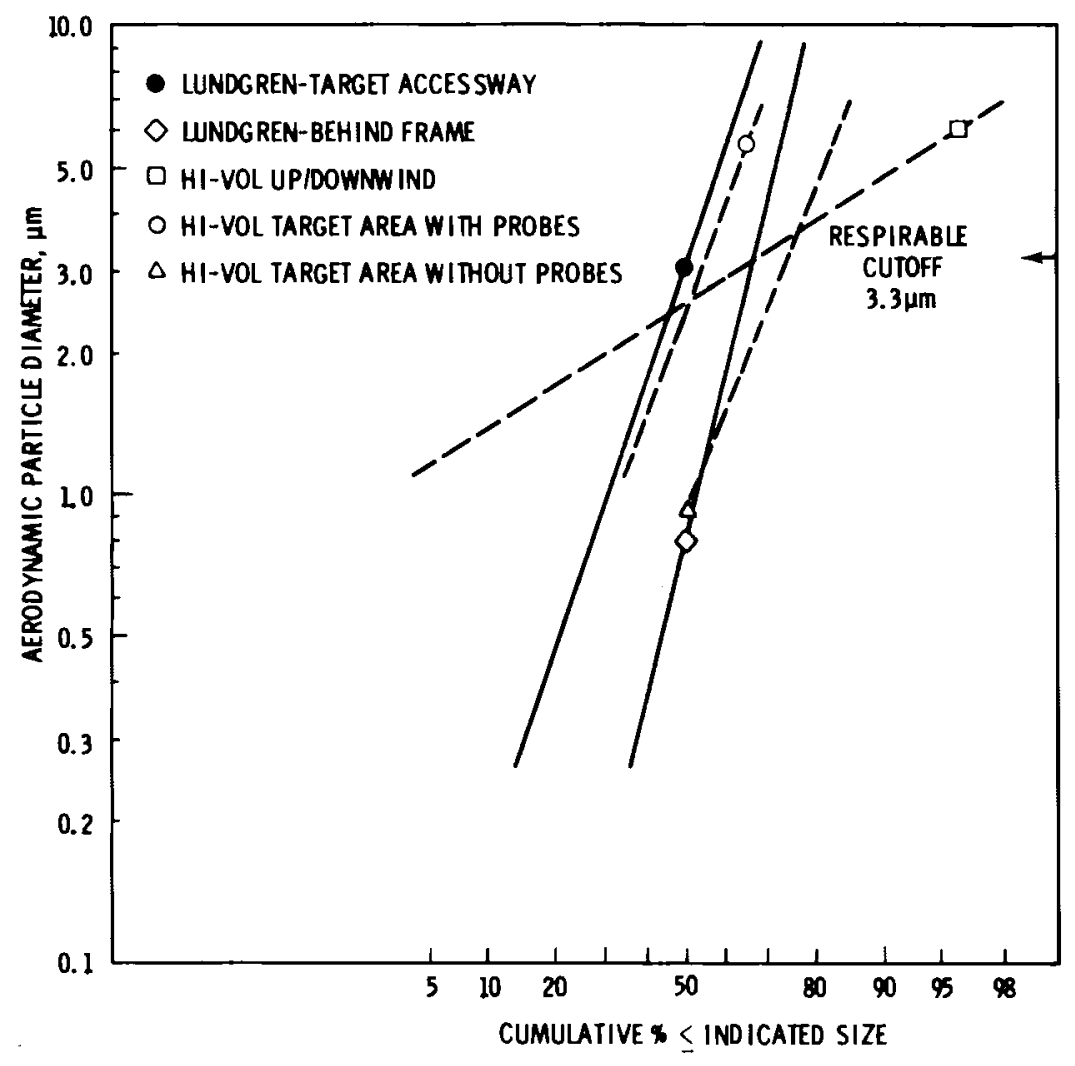

FIGURE 23. Airborne Uranium Size Distributions

TABLE 4. Size Distribution Summary

\begin{tabular}{l} 
Impactor \\
\hline High-Volume Impactor \\
High-Volume Impactor \\
Lundgren Impactor \\
Lundgren Impactor
\end{tabular}

\subsection{AIRBORNE URANIUM CONCENTRATION VERSUS TIME}

Data from the Lundgren impactor samples were used to estimate the target-area airborne uranium concentration variation with time. The reduction of data to determine the mass of uranium collected over time intervals was described on page 31 and in Appendix B.3. The average airborne uranium 
concentration over a time interval was calculated by dividing the mass by the sampler flowrate and time. Examples of these calculations are shown in Appendix D, Table D.1. The resulting concentrations for each time interval are tabulated in Table D.2.

The measured change in airborne depleted uranium concentration with time is summarized in Figure 24. The two envelopes enclose the data points obtained by sampling from the target accessway and behind the X-ray film frame during the usual 15-min post-shot waiting period(a) and usual targetchanging activity. The two lines indicate the measured concentrations at the same locations and while no target-changing activity occurred. (This latter condition was studied for only one run). The measured concentrations in the accessway were generally higher than behind the film frame. All measurements were made at breathing level, 5 to $6 \mathrm{ft}$ elevation. Note that the measured concentrations were higher when target changing proceeded as usual than when suspended. (b) The measurements show some increase in concentration as the target-changing activity gets underway. This may be caused by mechanical resuspension of uranium from the soil or other surfaces. For comparison, the maximum permissible concentrations $\left(M P C_{a}\right)$ set in the code of Federal Regulations $^{(c)}$ for occupational exposure to airborne depleted uranium are noted in the figure for both soluble and insoluble uranium compounds.

\subsection{CLOUD VO:UME}

The volumes of the clouds generated by the impacts of penetrators were estimated from the tracking films provided by TECOM. To estimate cloud volume, the image of a cloud (at its greatest size and before significant

(a) The time interval personnel are required to wait before re-entering the target area.

(b) The sharper drop in concentration during the 15-min waiting period shown by the two lines may be caused by a higher wind speed than experienced during the other runs (2.7 to $5.5 \mathrm{mph}$ versus calm to $3.8 \mathrm{mph}$ ).

(c) The $M P C_{a}$ for insoluble uranium is derived from the value given for natural uranium in 10 CFR 20 using the specific activity of $3.6 \times 10^{-7} \mathrm{Ci} / \mathrm{g}$ for depleted uranium. The $10 \mathrm{CFR} 20 \mathrm{MPC}$ a for soluble mixtures of uranium isotopes where the abundance of $235 \mathrm{U}<5 \%$ is used herein. (7) 


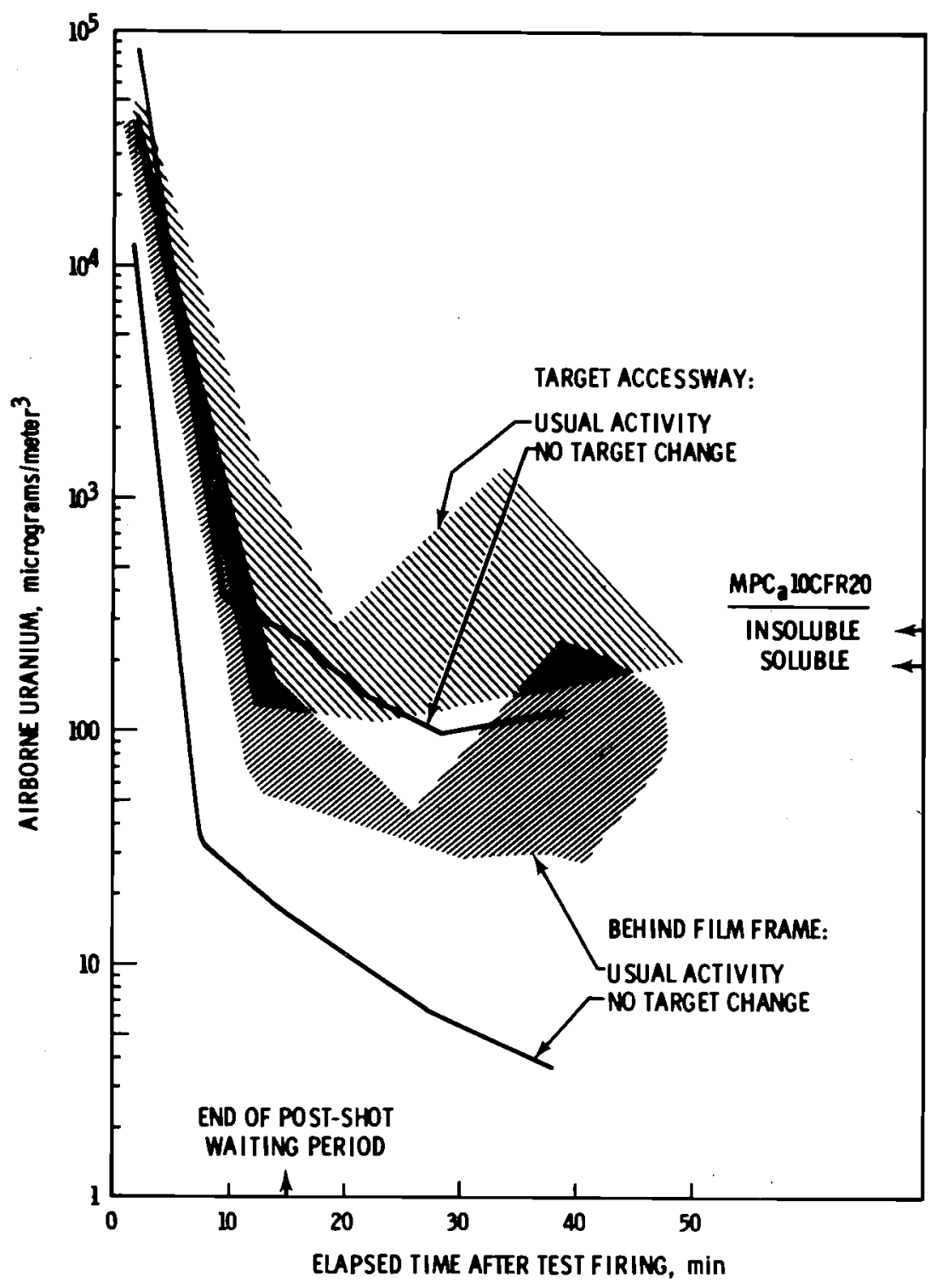

FIGURE 24. Airborne Depleted Uranium Concentration Versus Time

drifting) was projected onto paper, and the cloud and features of the target stand were outlined. A length scale was obtained from features of known dimension. Each cloud outline was divided into units of simple geometric shape (parallelograms and circles) and key dimensions were measured. Volumes were computed assuming the horizontal cross sections were circular. Computations were made for the views of each cloud from two cameras separated by a $57^{\circ}$ included angle. Because of the distortion caused by this positioning, a true estimate of depth of each cloud was not possible. The 
estimated cloud volumes from the two camera angles were averaged; results are given in Table 5. Both films for Run 5 were overexposed and deleted from the analysis.

TABLE 5. Estimated Cloud Volumes, $\mathrm{m}^{3}$

\begin{tabular}{|c|c|c|c|}
\hline Run & Camera No. 22 & Camera No. 25 & Average Volume \\
\hline 1 & $1600^{(a)}$ & 1370 & 1500 \\
\hline 2 & 827 & 1120 & 1000 \\
\hline 3 & 556 & 2750 & 1700 \\
\hline 4 & 970 & 2840 & 1900 \\
\hline
\end{tabular}

(a) Photographic images were slightly overexposed. The value given is a best estimate.

\subsection{TOTAL AIRBORNE URANIUM PARTICULATES}

The results of the total particulate samples collected in the target area are discussed first and the results for environmental total-particulate samplers follow.

\subsubsection{Target-Area Total Airborne Uranium}

The total exposure (mass $x$ time/vol) to airborne uranium in the target area was calculated for each run by dividing the total uranium collected by the total volume flowrate of the samplers. Sample calculations are included in Appendix E.

The airborne concentration can be calculated from the total exposure, given the time interval during which the material of interest was sampled. The total mass airborne can then be computed from the cloud volume. Estimating the sampling interval during which the bulk of the airborne material would have passed the probes and estimating the volume of the cloud sampled are the greatest uncertainties in this analysis. The assumption of a homogeneous concentration within the visible cloud and the plugging of samplers add to the uncertainty. 
The tracking films of the clouds did not cover a long enough period of time to observe when the visible smoke dissipated from the target area. However, they did show the very rapid growth $(10 \mathrm{sec})$ of the cloud to a very large size. The color movie of Run 4 showed that the most dense cloud moved out of the target area in less than $16 \mathrm{sec}$ (the view of the camera was changed to follow the smoke as it drifted across the range.) The width of the initial deposits on the Lundgren impactor substrates indicates that the deposits were collected in less than a minute although the substrate rotation speed was not fast enough to resolve the time any finer than that.

It would not be reasonable to assume that the total-particulate samplers operated at full flow and instantly plugged when the cloud dispersed from the target area. From examination of the color movie from Run 4 and the Lundgren impactor substrates, the samplers probably plugged in less than $15 \mathrm{sec}$ after the shot. The study has assumed, then, that the samplers operated at full flow for $5 \mathrm{sec}$ and that the flow decreased linearly to zero at $10 \mathrm{sec}$, which is equivalent to assuming a sampling interval of $7.5 \mathrm{sec}$ at $50 \mathrm{cfm}$ for each sampler. The calculated airborne uranium concentration and mass for each run are shown in Table 6 based on these assumptions. The average fraction of the penetrator as airborne particulates was $70 \%$. This result, however, suffers from the uncertainties mentioned in this subsection and from the likelihood that some of the particulates sampled are resuspended from the soil and target stand. It cannot be stated conclusively how much of the respirable particulates came from the penetrator impact or from material resuspended by the concussion. Of the roughly $2.4 \mathrm{~kg}$ of airborne depleted uranium generated during a test firing, about half of that is respirable particulates based on the size distribution discussed earlier (see Table 4).

\subsubsection{Environmental Airborne Uranium}

The analysis of environmental airborne uranium was based on the total particulate (T7, T8) and cascade impactor (I3, I4) samples collected at a distance of 80 to $150 \mathrm{ft}$ from the target, and the total particulate samples 
TABLE 6. Total Airborne Uranium Assuming $7.5 \mathrm{sec}$ Sampling Interval at $50 \mathrm{cfm}$

\begin{tabular}{|c|c|c|c|c|c|}
\hline Run & $\begin{array}{l}\text { Exposure } \\
\mathrm{mg} \mathrm{min} / \mathrm{m}^{3}\end{array}$ & $\begin{array}{c}\text { Concentration(a) } \\
\mathrm{mg} / \mathrm{m}^{3}\end{array}$ & $\underset{\substack{\text { Cloud } \\
\mathrm{m}^{3}}}{(b)}$ & $\begin{array}{c}\text { Airborne(c) } \\
\mathrm{g}\end{array}$ & $\begin{array}{l}\text { Approximate } \\
\text { Mass \% of }(\mathrm{d}) \\
\text { Penetrator }(\mathrm{d})\end{array}$ \\
\hline 1 & 150 & 1200 & 1500 & 1800 & 53 \\
\hline 2 & 153 & 1220 & 1000 & 1220 & 36 \\
\hline 3 & 215 & 1720 & 1700 & 2924 & 87 \\
\hline \multirow[t]{2}{*}{4} & 231 & 1850 & 1900 & $\frac{3515}{9,459}$ & 104 \\
\hline & & & \multicolumn{2}{|c|}{ Ave $=2,365$ or } & $70 \%$ \\
\hline
\end{tabular}

(a) Concentration $=\left[\frac{\mathrm{mg} \times \mathrm{min}}{\mathrm{m}^{3}}\right] \times\left[\frac{1}{0.125 \mathrm{~min}}\right]$

(c) $\mathrm{g}=$ cloud, $\mathrm{m}^{3} \times \frac{\mathrm{mg}}{\mathrm{m}^{3}} \times \frac{\mathrm{g}}{1000 \mathrm{mg}}$

(d) $\frac{\mathrm{c}}{3365 \mathrm{~g}} \times 100$

collected outside the Ford's Farm Firing Range. These offsite samples were collected at the Human Engineering Lab (HEL) field, Mile Test Loop (MTL) and Building 938 at Michaelsville as shown in Figure 10. Most of the samples from the Staplex samplers at Ford's Farm were not analyzed because of cost factors. Airborne uranium concentration was calculated by dividing the mass of uranium collected by the flow rate and collection time. For the samplers at Ford's Farm, the assumed collection time was the elapsed time the samplers operated after the shot was fired. For the samplers at HEL and MTL, the actual operating time was used for the calculations.

Table 7 summarizes the concentration at each location and indicates whether the sampler was located downwind, upwind or crosswind. It was not always known for certain whether the HEL and MTL samplers were downwind or upwind because the wind direction varied considerably as shown in Appendix A.2. 
TABLE 7. Environmental Airborne Uranium Concentrations

\begin{tabular}{|c|c|c|c|}
\hline $\begin{array}{l}\text { Run/Firing } \\
\text { Time } \\
\end{array}$ & $\begin{array}{c}\text { Approximate } \\
\text { Orientation of } \\
\text { Sampler } \\
\end{array}$ & $\begin{array}{l}\text { Operating } \\
\text { Time, min }\end{array}$ & $\begin{array}{c}\text { Concentration } \\
\mu \mathrm{g} / \mathrm{m}^{3} \\
\end{array}$ \\
\hline \multirow[t]{6}{*}{$1 / 1803$} & T8 Downwind & 20 & 15 \\
\hline & I4 Downwind & 20 & 690 \\
\hline & S4 Downwind & 20 & 8.9 \\
\hline & S3 Downwind & 20 & 5.8 \\
\hline & T7 Upwind & 20 & 12 \\
\hline & MTL Crosswind & 446 & 0.44 \\
\hline \multirow[t]{2}{*}{$2 / 0951$} & I4 Crosswind & 15 & 82 \\
\hline & MTL Crosswind & 112 & 0.14 \\
\hline \multirow[t]{4}{*}{$3 / 1722$} & T8 Downwind & 16 & 1.8 \\
\hline & I4 Downwind & 16 & 110 \\
\hline & HEL Crosswind & 180 & 0.091 \\
\hline & T7 Upwind & 16 & 4.5 \\
\hline $4 / 1401$ & $T 7$ Downwind & 94 & 39 \\
\hline \multirow[t]{4}{*}{$\& 1508$} & I3 Downwind & 94 & 93 \\
\hline & MTL Downwind & 287 & 0.045 \\
\hline & HEL Downwind & 346 & 0.053 \\
\hline & T8 Upwind & 94 & 0.40 \\
\hline \multirow[t]{6}{*}{$5 / 0850$} & T7 Crosswind & 19 & 4.5 \\
\hline & I3 Crosswind & 19 & 80 \\
\hline & T8 Downwind & 19 & 100 \\
\hline & I4 Downwind & 19 & 250 \\
\hline & MTL Upwind & 395 & 0.022 \\
\hline & HEL Upwind & 309 & 0.046 \\
\hline Oct. $7-8^{(a)}$ & B 1dg 938 & 1270 & 0.43 \\
\hline 0ct. $7-8^{(a)}$ & Michaelsville & 1293 & 0.41 \\
\hline
\end{tabular}

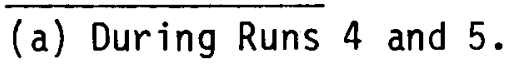


The table also includes the concentration measured by the Army at Building 938 and Michaelsville with routine environmental samplers (see Figure 10).(a)

Table 7 shows that the concentrations at the locations distant from Ford's Farm (see Figure 10) were lower than at the range and well below the MPC for nonoccupational exposures set at $7 \mu \mathrm{g} / \mathrm{m}^{3}$ for soluble airborne particles and $10 \mu \mathrm{g} / \mathrm{m}^{3}$ for insoluble. ${ }^{(6)}$ The agreement between adjacent pairs of samplers at Ford's Farm--T7, 13, and T8, 14--was not good. These adjacent samplers were only as far as $15 \mathrm{ft}$ apart. It is possible that one and not the other adjacent sampler caught the edge of the plume although the impactors always gave higher readings. Some Ford's Farm downwind concentrations exceeded the occupational MPC.

\subsection{FALIOUT}

The quantities collected during the wet and dry fallout experiments and the mass associated with a few fragments of depleted uranium are discussed in this subsection.

\subsubsection{Wet Fallout}

The estimated amount of fallout collected in each sector shown in Figure 16 was calculated by multiplying the quantity found in each tray by the sector area and dividing by the area of the tray. Figure 25 shows the estimated quantity of uranium in each sector.

The total quantity estimated within $50 \mathrm{ft}$ of the target center for six test firings is $2157 \mathrm{~g}$ uranium or $359 \mathrm{~g}$ per test firing. Therefore, about $11 \%$ of a penetrator could be accounted for on the ground or structures within a 50-ft radius; however, some fallout collected may have been resuspended ground contamination. The amount of fallout in the immediate target vicinity was probably underestimated as a result of the fact that no fallout tray was

(a) In this case, the ${ }_{3}$ samples were alpha-counted by the Army and the result reported as $\mu \mathrm{C} i / \mathrm{m}^{3}$. The concentration in Table 7 assumes this was all depleted uranium. 


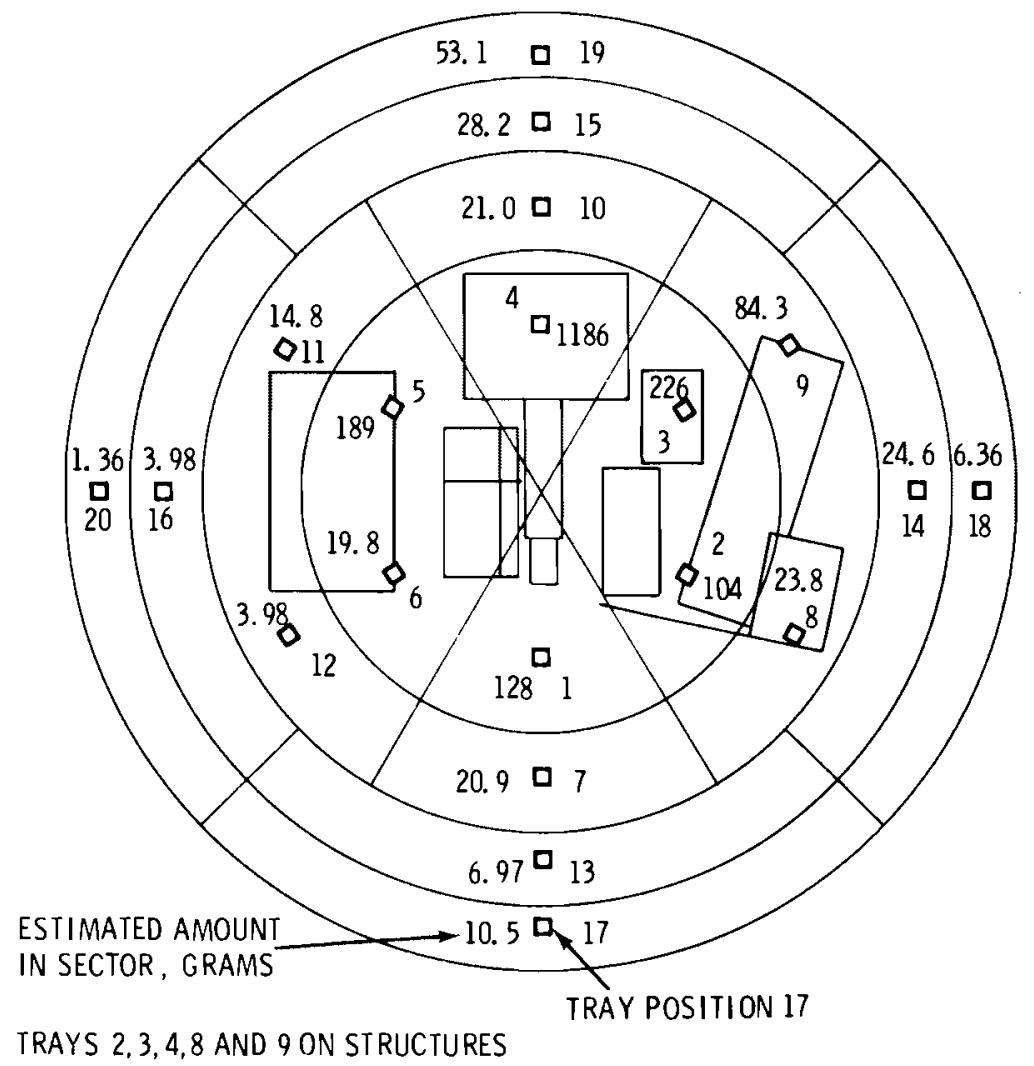

FIGURE 25. Estimated Amount of Uranium Fallout in Sectors Within $50 \mathrm{ft}$ of Target Center

closer than $10 \mathrm{ft}$ to the targets. Using a figure of $360 \mathrm{~g}$ per firing, $36 \mathrm{~kg}$ of depleted uranium would be deposited with a $50-\mathrm{ft}$ radius $\left(730 \mathrm{~m}^{2}\right)$ after 100 firings. This estimate does not include the larger fragments discussed later. Also, there is likely to be some fallout outside the $50-\mathrm{ft}$ radius as we 11 .

\subsubsection{Dry Fallout}

The dry fallout trays collected material from nine test firings, a total of $169 \mathrm{~g}$ of fallout, dirt and wood chips. Small samples of the collected 
materials were submitted for uranium analysis. The collected fallout material contained $19 \%$ uranium by weight. These samples were collected mainly for the identification of uranium oxides as detailed later.

\subsubsection{Fragments}

Over months, large fragments of penetrators have been collected during the test firing program. These large fragments were picked up and stored in a container near the catcher. Undoubtedly, many fragments were not picked up. Most of the large fragments are identifiable as being from the tail section of the penetrator.

Two large fragments, some smaller ones and some powder were picked up off the ground and selected from the fragment storage container. The fragments were irregular in shape and gray in color with a greenish-yellow tinge. Polished metal surfaces were evident from the machining operations. The machined "flutes" of the penetrator were easily recognized on the two largest fragments. These two fragments weighed 124 and $194 \mathrm{~g}$ each $(3.7 \%$ and $5.8 \%$ of a $3.365 \mathrm{~kg}$ penetrator).

\subsection{URANIUM OXIDES}

Uranium is a pyrophoric metal and, at elevated temperatures, can ignite and oxidize rapidly. $(7,8,9,10)$ Four uranium oxides have been established-$\mathrm{UO}_{2}, \mathrm{U}_{4} \mathrm{O}_{9}, \mathrm{U}_{3} \mathrm{O}_{8}$, and $\mathrm{UO}_{3}$--plus a large number of non-stoichiometric uraniumoxygen combinations. $(12)$ The most commonly encountered oxides are $\mathrm{UO}_{2}$ (which by $X$-ray diffraction pattern must be considered $\mathrm{UO}_{2+x}$ where $x$ is less than 0.33 ) and $\mathrm{U}_{3} \mathrm{O}_{8}$. For the test firing conditions, it was anticipated that all the depleted uranium made airborne would be in the form of oxides.

Inhalation and deposition of uranium oxides in the deep lung can pose two hazards. If the material is insoluble, the lung tissue is subjected to internal irradiation. If the material is soluble, the chemical toxicity affects the kidneys. (13) Uranium is soluble in body fluids (interstitial lung fluid, blood serum, etc.); the rate at which uranium goes into solution 
depends upon its starting oxidation state and surface area. (14) Thus, knowledge of the solubility of the airborne material is important in deciding which limitation to impose--that based upon irradiation or chemical toxicity.

Identification and relative abundance of uranium oxides present in selected samples of airborne material collected over the targets during test firings and in dry fallout material was performed by comparison with American Society for Testing Materials diffraction patterns for these compounds and integration of the area of the identifying peaks. Elemental analysis by $X$-ray fluorescence micro-probe were also performed to determine the amount of other material that might be involved with the airborne depleted uranium. Photomicrographs using a scanning electron microscope (SEM) were obtained as part of the particle selection process for the elemental analysis and are presented as an indication of the morphology of the airborne particles.

\subsubsection{Total Particulate Samples}

The relative abundance of $\mathrm{UO}_{2}: \mathrm{U}_{3} \mathrm{O}_{8}$ in the airborne material collected over the target during each firing was determined from the total particulate sample with the highest measured uranium mass from each run. The estimated relative abundances determined are listed in Table 8 . The crystalline phase in all the samples appears to be a relatively homogeneous mixture of $\mathrm{UO}_{2}$ and $\mathrm{U}_{3} \mathrm{O}_{8}$ and elemental analysis of individual particles indicates $1 \%$ to $5 \%$ by weight of iron and tungsten are present.

TABLE 8. Relative Abundance of Uranium 0xides in Target Area Samples

\begin{tabular}{ccc} 
Run Sample & $\begin{array}{c}\mathrm{U}_{2} \\
\text { Weight Percent }\end{array}$ & $\begin{array}{c}\mathrm{U}_{3} \mathrm{O}_{8} \\
\text { Weight Percent }\end{array}$ \\
\cline { 2 - 3 } $1-\mathrm{T} 2$ & 25 & 75 \\
$2-\mathrm{T} 1$ & 28 & 72 \\
$3-\mathrm{T} 2$ & 30 & 70 \\
$4-\mathrm{T} 3$ & 27 & 73 \\
$5-\mathrm{T} 2$ & 29 & 71
\end{tabular}


Figure 26 shows photomicrographs of individual particles at two magnifications- $-1200 \times$ and $3000 x$. At $3000 x$, the particles appear to be roughly spherical and composed of many small particles ranging from 0.03 to $0.1 \mathrm{~m}$ in diameter.

\subsubsection{High-Volume Cascade Impactor Samples}

The oxide forms present in various size fractions of airborne material collected over the target were determined for two runs ( 3 and 4 ). The mass of material was insufficient for a quantitative estimate, but the oxides are listed in the order of estimated abundance in Table 9. Analysis of individual particles indicates that the principal constituents are uranium and iron with minor quantities of tungsten, aluminum, and silicon. The ratios of uranium to iron are also listed in Table 9 and range from 5:1 to 13:1 with the ratio increasing with decreasing size (20\% to $8 \%$ iron). Much higher U:Fe ratios (100:1 to 20:1) were observed for the total particulate samples. A possible explanation is the loss of a portion of smaller particles during the high air-velocity flow (when the particle concentrations are highest) as a result of non-isokinetic sampler flow.

Most of the particles examined using the scanning election microscope were dark spheres, but some samples also contained amorphous particles ranging from yellow to reddish orange. Analysis indicates that their major constituents are iron and tungsten with essentially no uranium. Figure 27 consists of photomicrographs at various magnifications of the material found on the stages and backup filter of high-volume cascade impactor I2 during Run 3.

\subsubsection{Dry Fallout Samples}

Uranium dioxide was the predominant uranium compound observed in the dry fallout material analyzed with only trace quantities of $U_{3} \mathrm{O}_{8}$ found. Analysis of individual particles showed uranium to be the principal cation present with some silicon, iron, and tungsten. Figure 28 shows photomicrographs of individual particles observed at two magnifications and indicates the coarse nature of the material. 


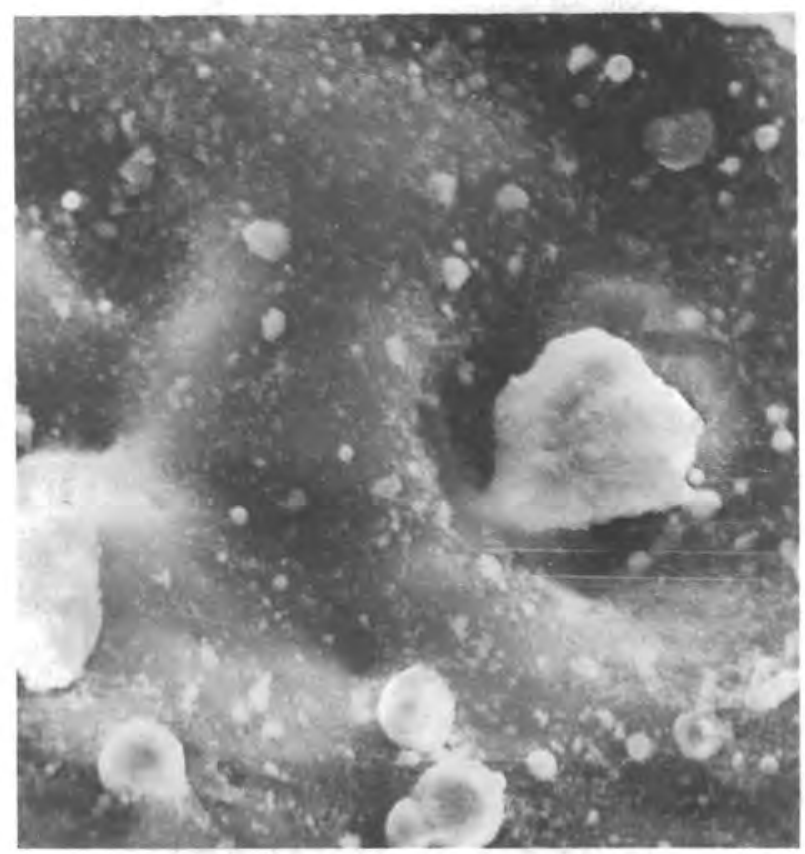

a. Showing some spherical particles $1200 \mathrm{x}$.

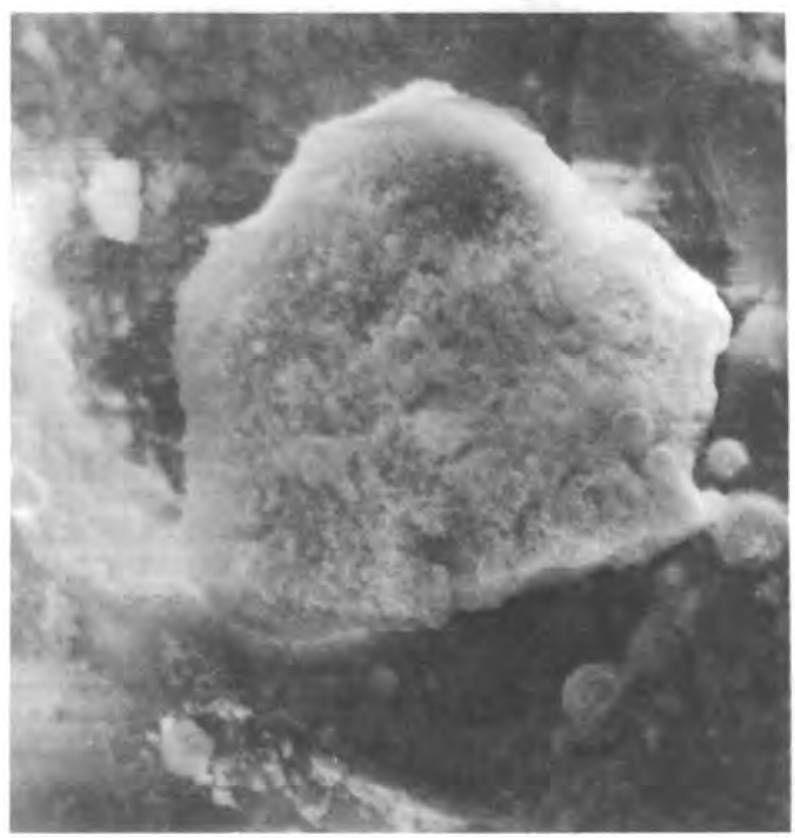

b. This particle is made of fine crystalline uranium oxides $3000 x$.

FIGURE 26. Scanning Electron Micrographs of Particles Collected on Filter Paper 
TABLE 9. Characteristics of Material Collected in a Target Area High-Volume Cascade Impactor During Runs 3 and 4

Size Range $\mu \mathrm{m} \quad \underline{U}$ :Fe wt ratio(a) $\underline{U \text { Compounds Identified(b) }}$

Run 3-I2
$>7.0$
$5.4 \pm 0.4$
3.3 to 7.0
$9.6 \pm 9.7$
$\mathrm{UO}_{2}, \mathrm{U}_{3} \mathrm{O}_{8}$
2.0 to 3.3
$8.7 \pm 0.5$
$\mathrm{UO}_{2}, \mathrm{U}_{3} \mathrm{O}_{8}$
1.1 to 2.0
$7.8 \pm 0.4$
$\mathrm{UO}_{2}, \mathrm{U}_{3} \mathrm{O}_{8}$
$<1.1$
$12.8 \pm 0.4$
$\mathrm{UO}_{2}, \mathrm{U}_{3} \mathrm{O}_{8}$
$\mathrm{U}_{3} \mathrm{O}_{8}$

Run I2

$>7.0$
3.3 to 7.0
2.0 to 3.3
1.1 to 2.0
$<1.1$

$5.2 \pm 0.6$

$\mathrm{UO}_{2}, \mathrm{U}_{3} \mathrm{O}_{8}$

$6.0 \pm 0.7$

$\mathrm{UO}_{2}, \mathrm{U}_{3} \mathrm{O}_{8}$

$6.6 \pm 0.5$

$\mathrm{UO}_{2}, \mathrm{U}_{3} \mathrm{O}_{8}$

$8.2 \pm 0.2$

$\mathrm{UO}_{2}, \mathrm{U}_{3} \mathrm{O}_{8}$

$12.8 \pm 0.4$

$\mathrm{U}_{3} \mathrm{O}_{8}, \mathrm{UO}_{2}$

(a) Average of four measurements \pm standard deviation.

(b) The compounds are listed in order of estimated abundance.

\subsection{SOLUBILITY}

The solubility in simulated lung fluid of airborne depleted uranium collected over the target during these test firings was measured for eight specimens. The eight specimens were the total particulate sample from each run containing the highest mass of uranium plus the "respirable fraction" (last two stages and backup filter) from one high-volume cascade impactor from Run 3 and two high volume cascade impactors from Run 4. The samples from the cascade impactors were included to ascertain if a difference in solubilities existed for the finer size fraction. Impactor Run 4-I3 was not in the target area (as were the other two impactors) but in a "downwind" location (see Figure 19). The experimentally measured solubilities are summarized in 


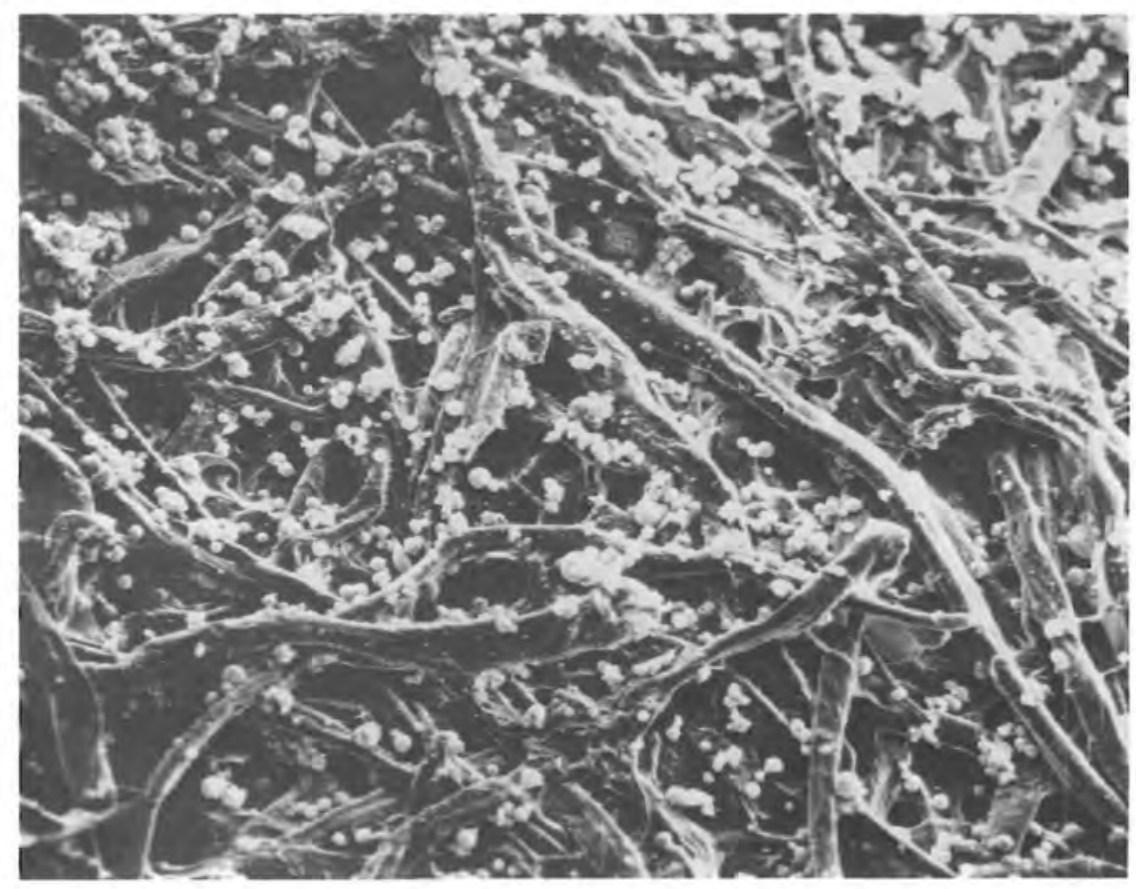

a. Stage $1,200 \times$ magnification

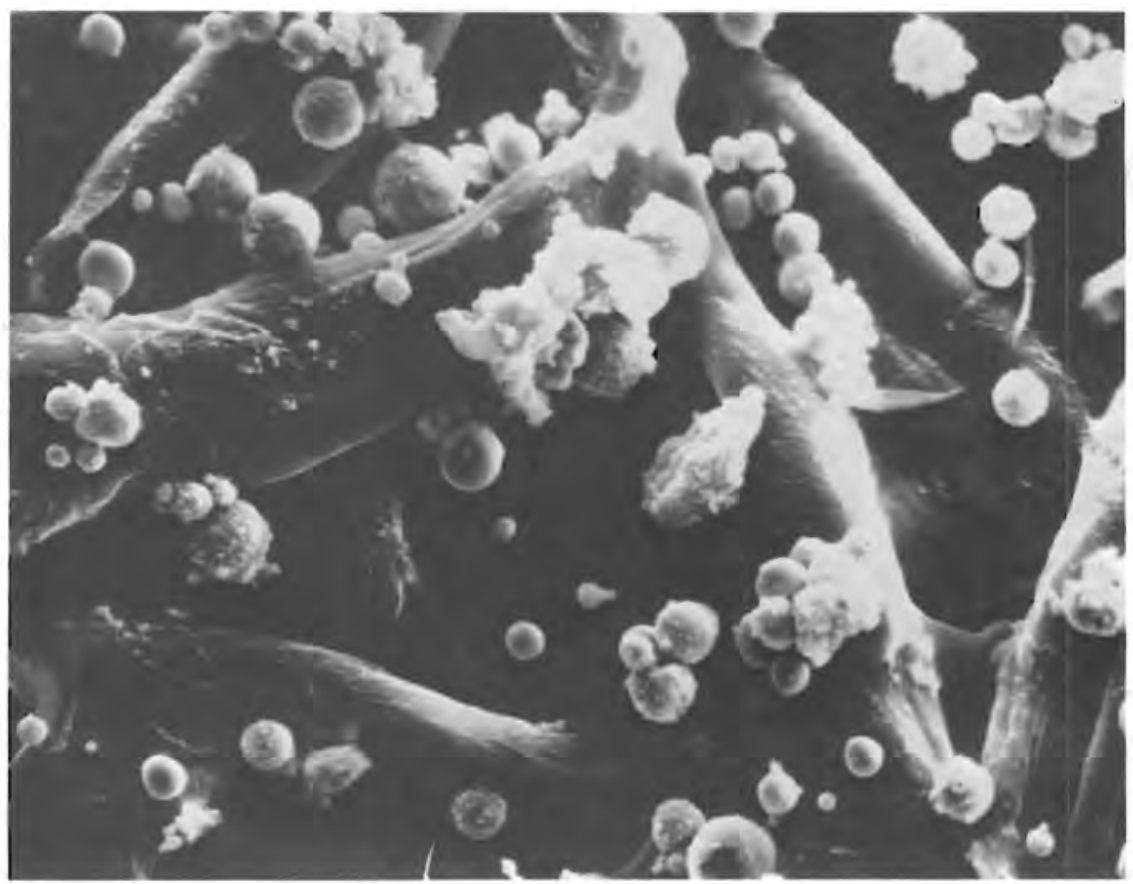

b. Stage 1, $1000 \times$ magnification

FIGURE 27. Scanning Electron Microscope (SEM) Photomicrographs of Materials Collected in a Target Area High-Volume Cascade Impactor During Run 3 


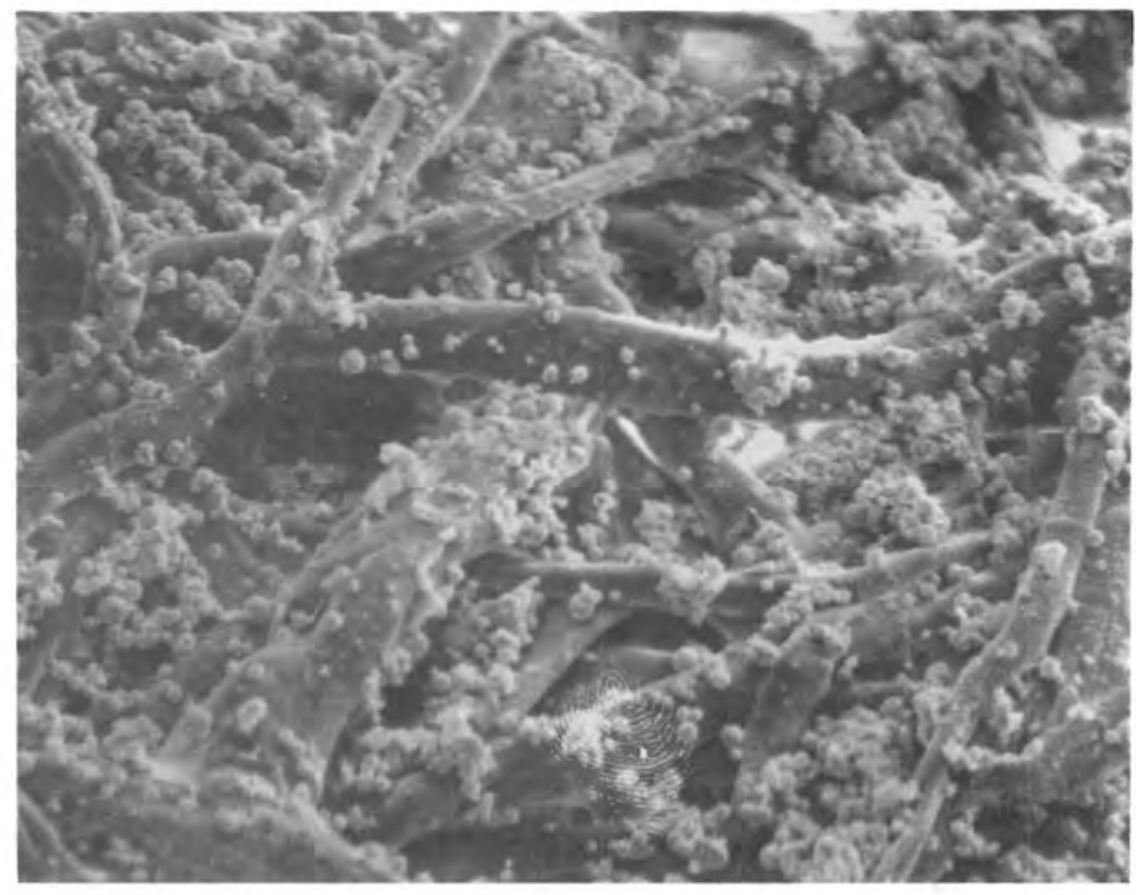

c. Stage 2, $500 \times$ magnification

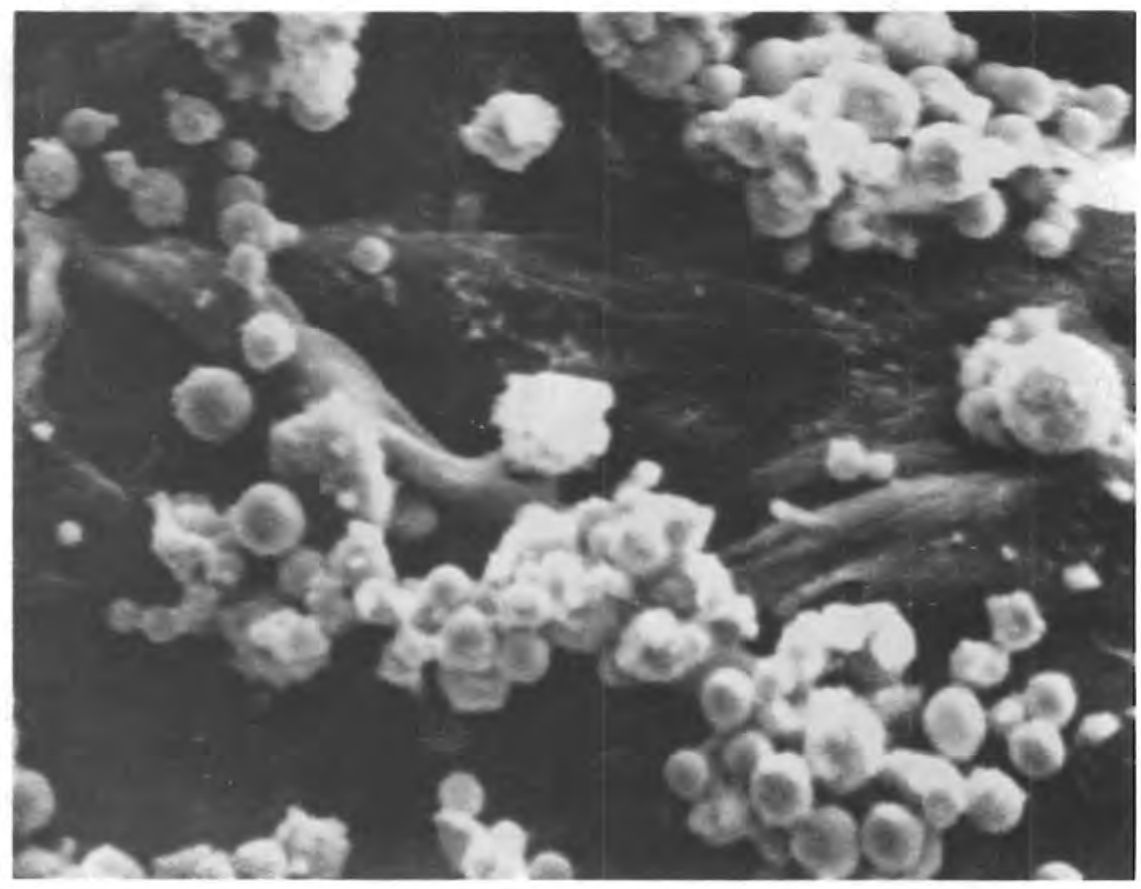

d. Stage 2, $2000 \times$ magnification

FIGURE 27. SEM Photomicrographs of Materials Collected in a Target Area High-Volume Cascade Impactor During Run 3 (contd.) 


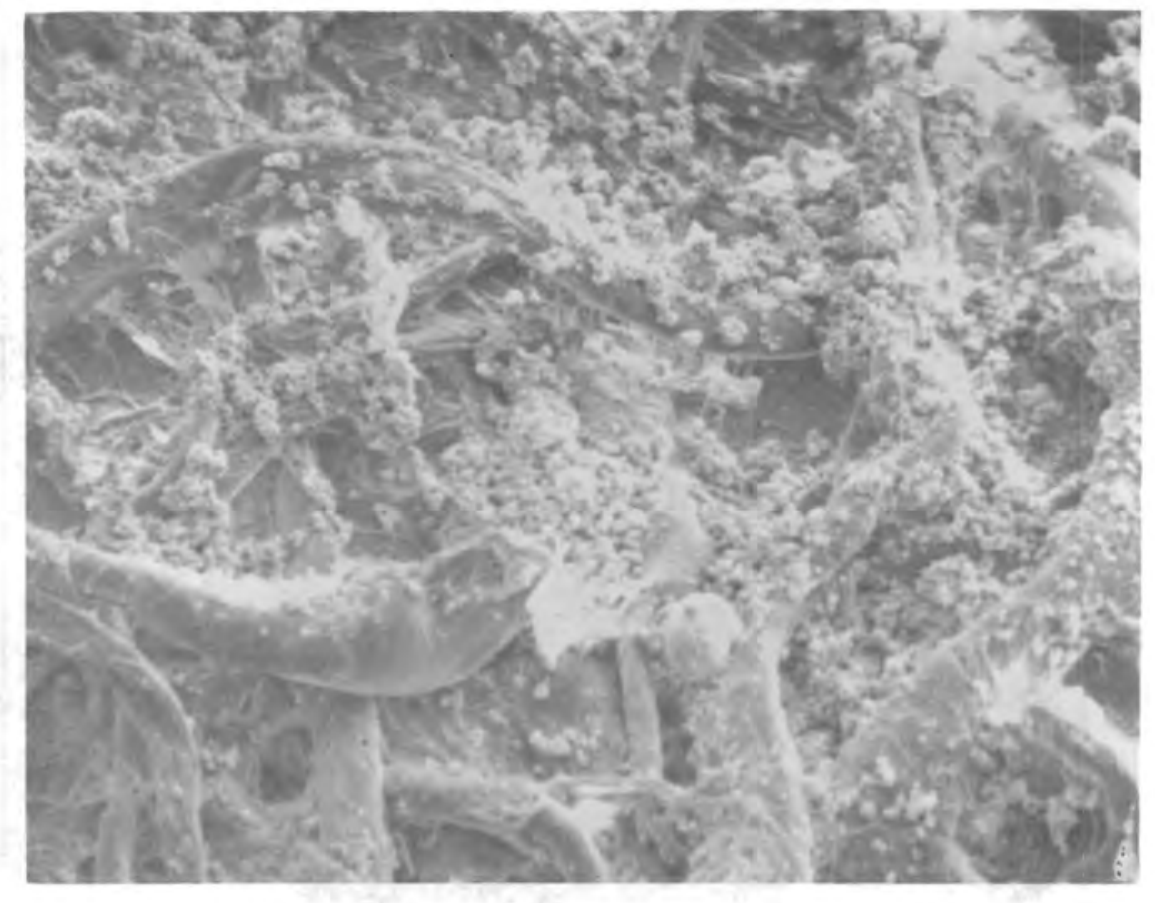

e. Stage 3, $500 \times$ magnification

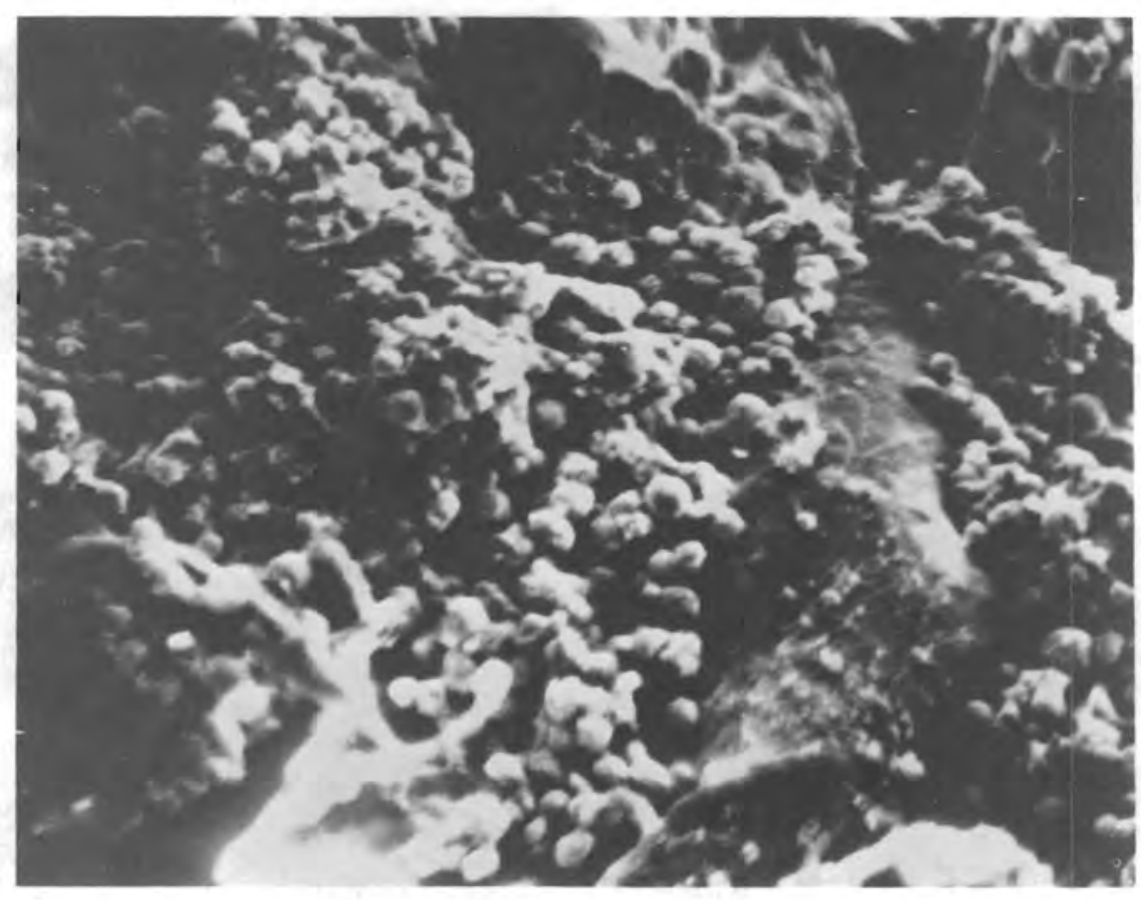

f. Stage 3, $2000 \times$ magnification

FIGURE 27. SEM Photomicrographs of Materials Collected in a Target Area High-Volume Cascade Impactor During Run 3 (contd.) 


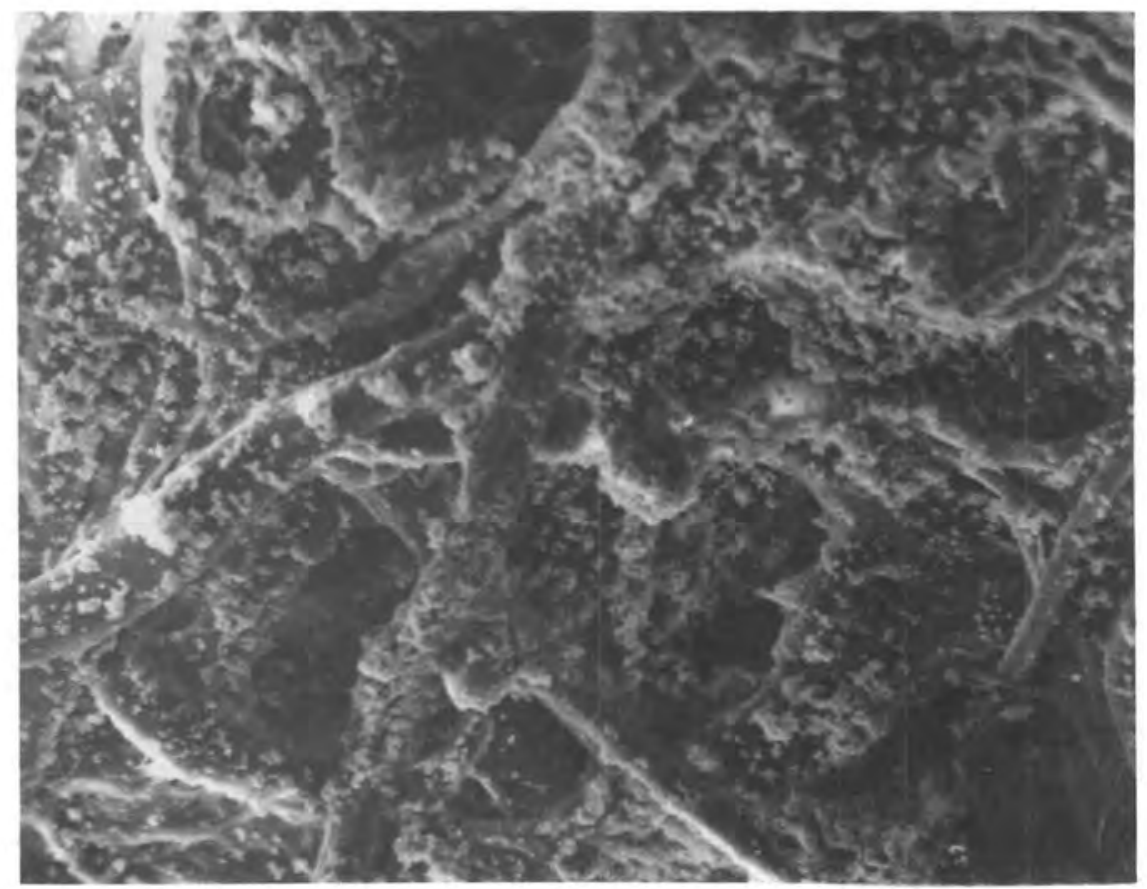

g. Stage $4,500 \times$ magnification

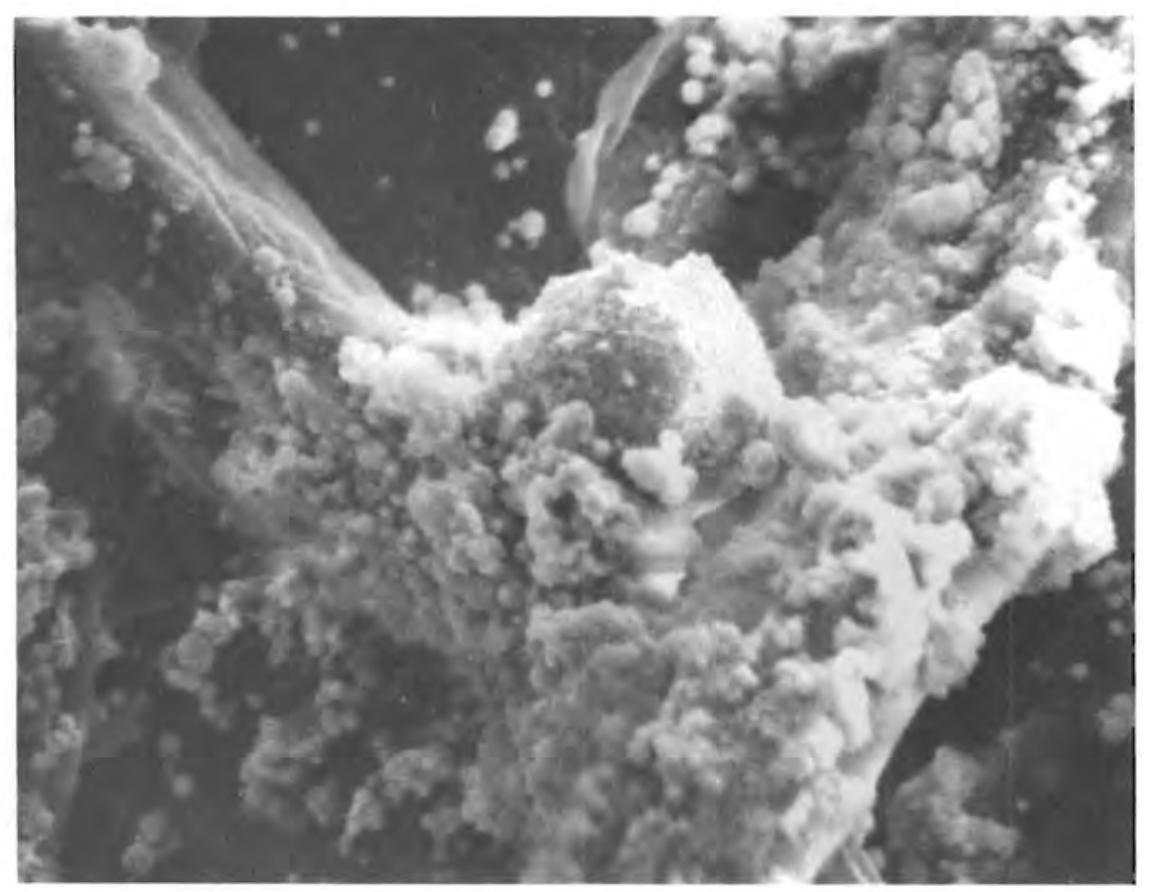

h. Stage $4,2000 \times$ magnification

FIGURE 27. SEM Photomicrographs of Materials Collected in a Target Area High-Volume Cascade Impactor During Run 3 (contd.) 


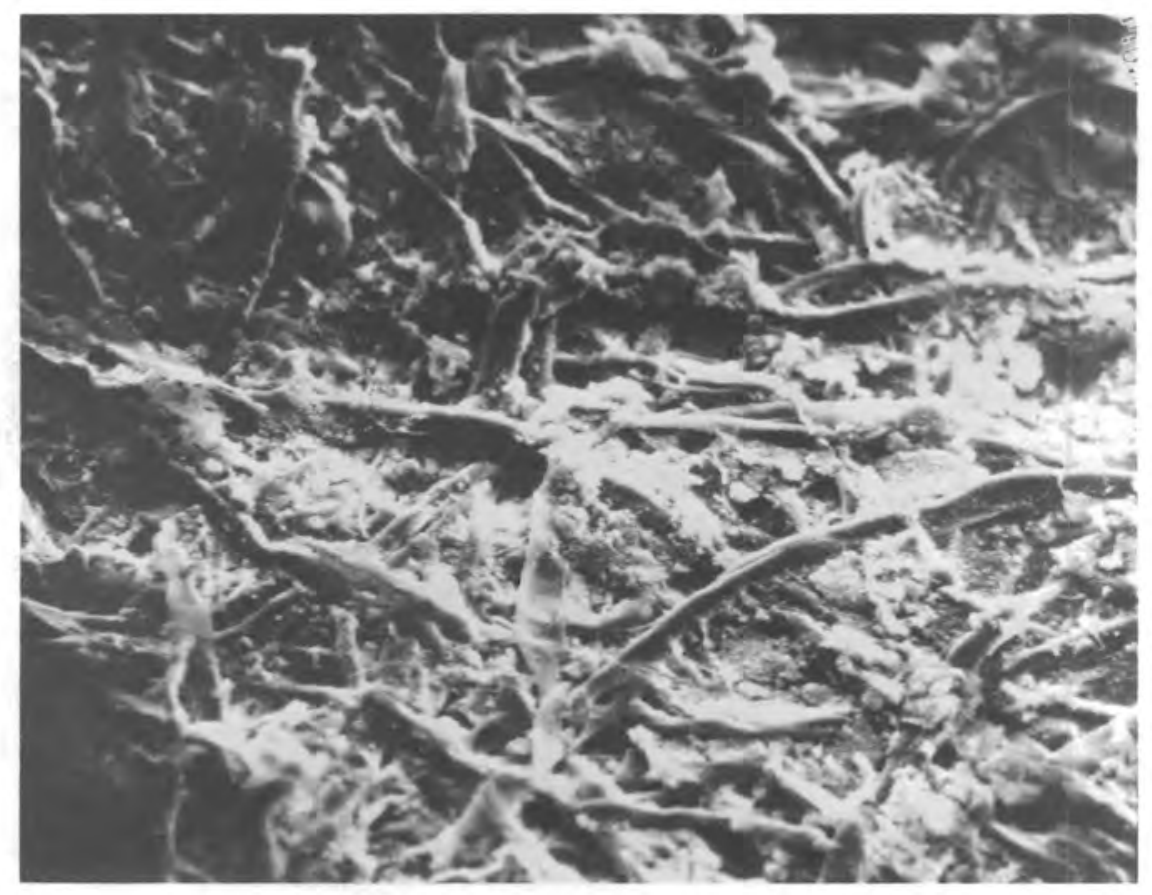

i. Backup filter $200 \mathrm{X}$ magnification

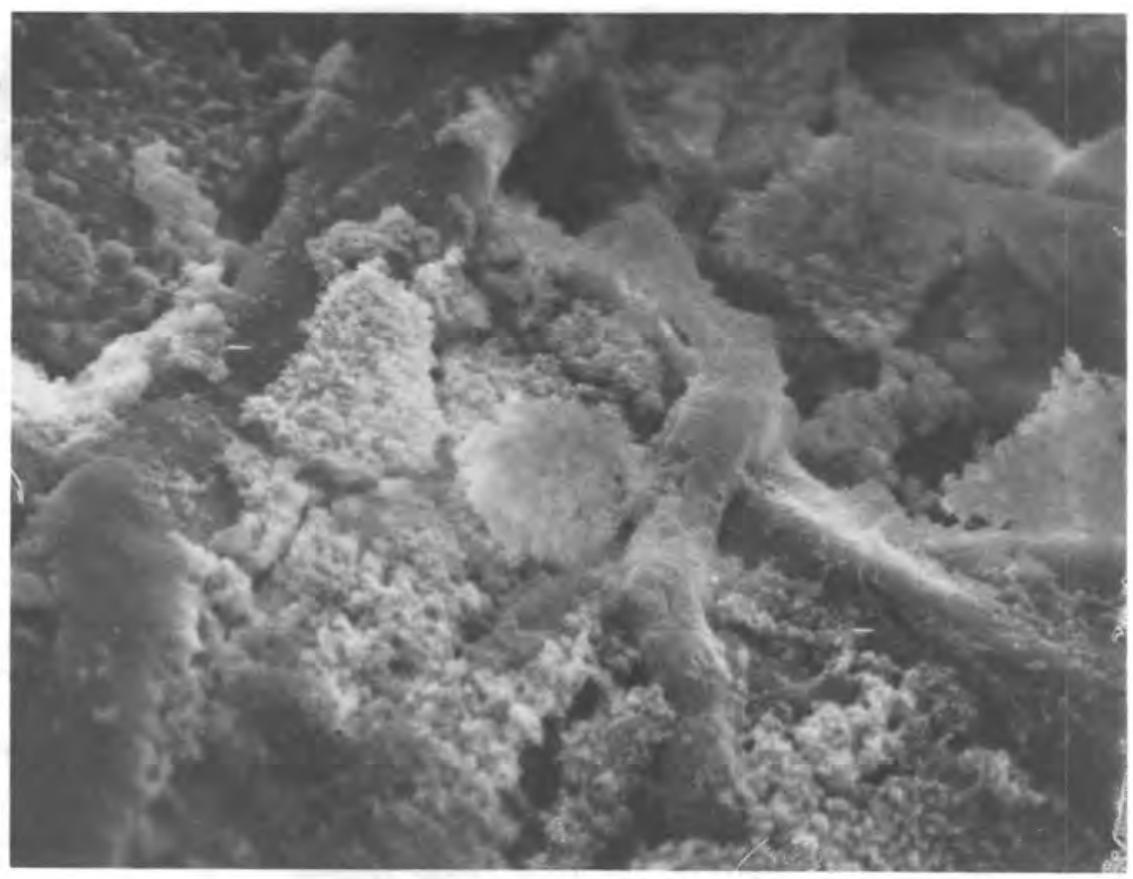

j. Backup filter $1000 \mathrm{X}$ magnification

FIGURE 27. SEM Photomicrographs of Materials Collected in a Target Area High-Volume Cascade Impactor During Run 3 


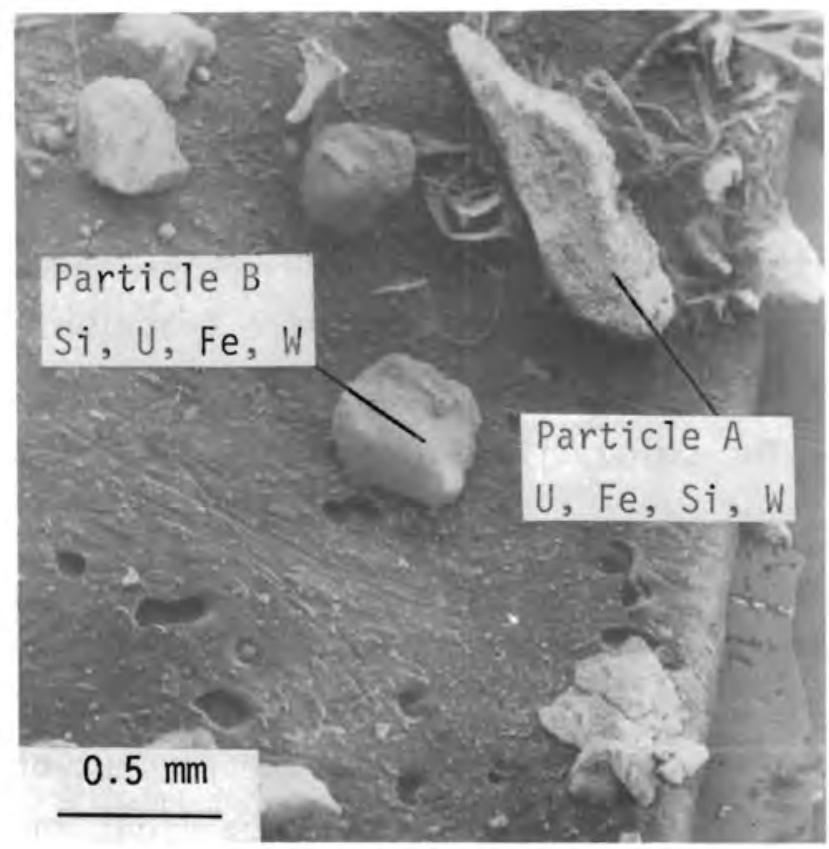

a. Showing particle distribution and chemical compositions

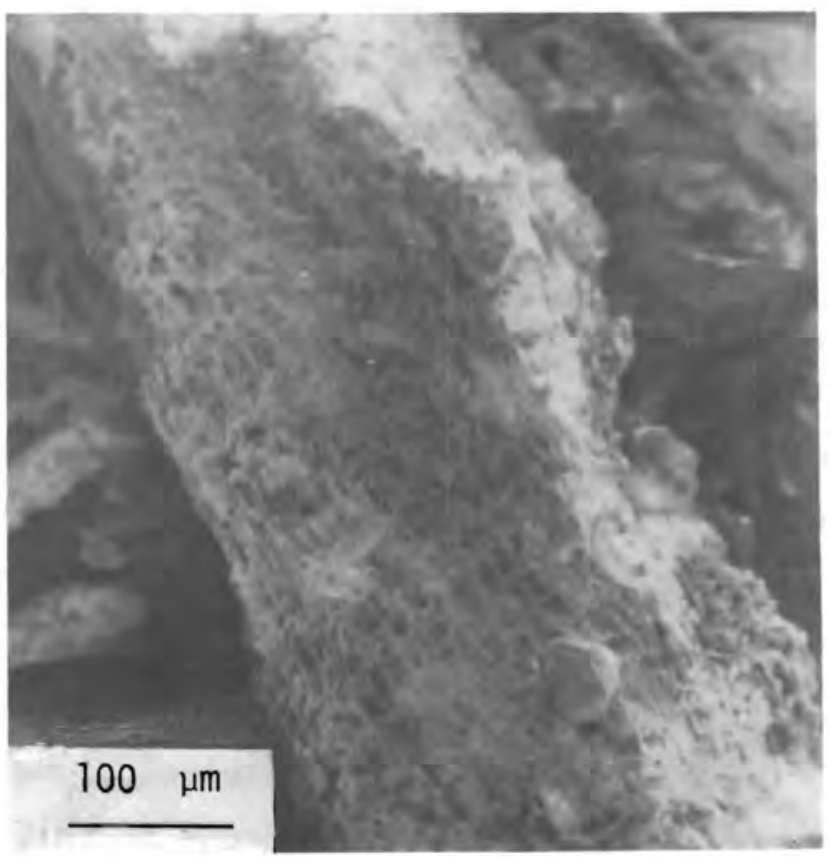

b. Enlargement of Particle A showing some spherical particles and fine crystalline uranium oxide

FIGURE 28. Scanning Electron Micrographs of Sample Fallout 
Table 10. The table shows that some uranium is soluble within the first week and that the remainder is essentially insoluble.

The 7-day apparent solubility of the uranium in the finer size fraction averaged $43 \%$ (see Table 10, respirable samples) and is two to three times greater than the airborne depleted uranium collected in the total particulate samplers. Table 9 appears to indicate that the fraction of $\mathrm{U}_{3} \mathrm{O}_{8}$ increases with decreasing size (on $1 \mathrm{y}_{3} \mathrm{U}_{8}$ was found in the smallest size fraction in impactor Run 4-I3). The solubility of $\mathrm{U}_{3} \mathrm{O}_{8}$ in carbonate solution (e.g., lung fluid, etc.) is $700 \mu \mathrm{g} / \mathrm{ml}$. The difference in solubility cannot be explained completely by the difference in solubility of $\mathrm{U}_{3} \mathrm{O}_{8}$ and $\mathrm{UO}_{2}$. Even if $\mathrm{UO}_{2}$ is considered insoluble, from $26 \%$ to $35 \%$ of the material on the total particulate sample should dissolve in 7 days since they are $23 / 4$ $\mathrm{U}_{3} \mathrm{O}_{8}$ (see Table 8). Figure 29 is a plot of the percent of material dissolved in 7 days versus the mass of uranium present in the sample and indicates solubility may be influenced by the mass packing of material on the filter sample. Another possible explanation for the decrease of solubility of the material collected on the total particulate samples may be the presence of extraneous material coating some of the particles or inhibiting the dissolution of part of the uranium.

\subsection{DOWNWIND DOSE}

It was the intent of the study to provide some examples of downwind dose calculations to illustrate the influence of distance and stability class. The calculations were made but the measured solubilities for the airborne depleted uranium in the respirable fraction indicated a significant toxicological hazard that was not within the scope of this project. Providing a calculational methodology to indicate the potential radiological hazard without providing a means of assessing the damage as a result of chemical toxicity might lead to the inference that radiological hazard is more significant. Such a decision is beyond the scope of this project and has not been investigated. The example calculations are not included so as to not mislead the reader but are available. 
TABLE 10. Measured Solubilities of Airborne Depleted Uranium in Simulated Lung Fluid

Percent of Uranium

Run Sample

Run 3-I2(b)

Run 4-I2(b)

Run $4-I 3(b)$

Run 1-T2

Run 2-T1

Run 3-T2

Run $4-\mathrm{T3}$

Run $5-\mathrm{T} 2$ into Solution in 7 Days

$$
\begin{aligned}
& 47+10 \\
& 34+8.0 \\
& 49+14 \\
& 16+3 \\
& 13+3 \\
& 18+4 \\
& 11+3 \\
& 15+4
\end{aligned}
$$

Approximate Dissolution Rate after 7 Days, (Percent Extracted per Day $(a, c)$

(a) A negative value indicates uranium lost or reabsorbed.

(b) Respirable fraction only.

(c) \pm Estimated Standard Error

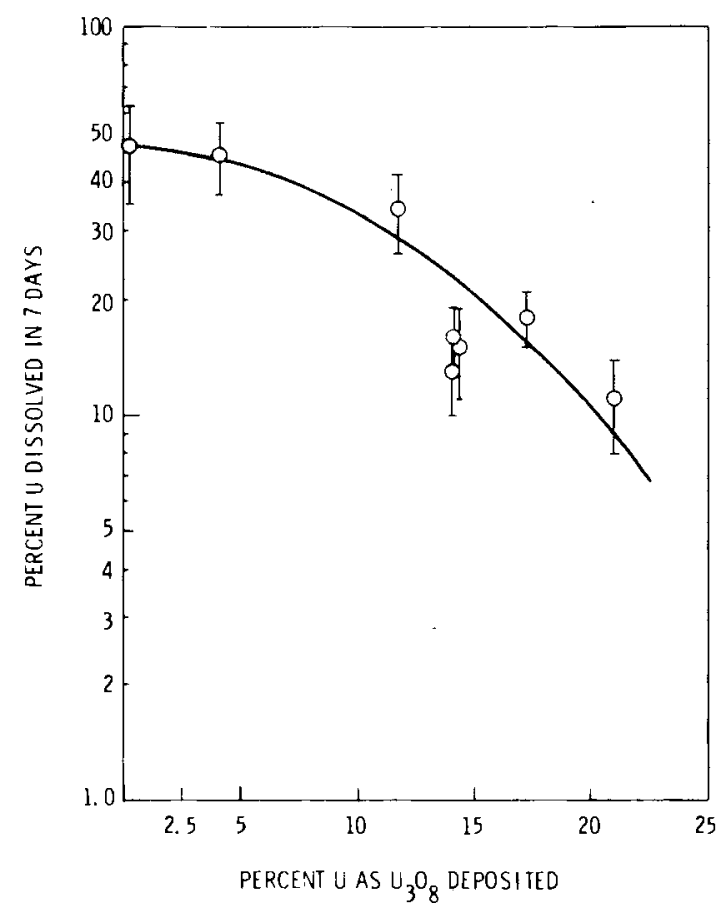

FIGURE 29. Percent Uranium Soluble in Seven Days Versus Mass of Uranium (as $\mathrm{U}_{3} \mathrm{O}_{8}$ ) in Sample 


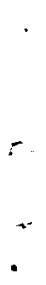




\subsection{REFERENCES}

1. R. L. Gilchrist, G. B. Parker and J. Mishima, Radiological and

Toxicological Assessment of an External Heat (Burn) Test of the $105 \mathrm{~mm}$ Cartridge, APFSDS-T, XM-774. PNL-2670, Pacif ic Northwest Laboratory, Richland, WA 99352, March 1978.

2. R. L. Gilchrist, W. T. Bartlett and G. W. R. Endres, Radiation Dose Rate Measurements Associated With the Use and Storage of XM-774 Ammunition. PNL-2947, Pacific Northwest Laboratory, Richland, WA 99352, 1979.

3. W. C. Hanson, J. C. Elder, H. J. Ettinger, L. W. Hantel and J. W. Owens, Particle Size Distribution of Fragments from Depleted Uranium Penetrators Fired Against Armor Plate Targets. LA-5654, Los ATamos Scientific Laboratory, Los Alamos, NM, October 1974.

4 Thomas T. Mercer, Aerosol Technology in Hazard Evaluation. Academic Press, New York, NY, pp. 287-293, 1973.

5. F. A. Gifford, "Turbulent Diffusion - Typing Schemes: A Review," Consequences of Effluent Release. R. L. Shoup, ed., Nuclear Safety. 17, 68-76, Jan.-Feb. 1976.

6. 0. R. Moss, "Simulants of Lung Interstitial Fluid." Health Phys., 36 , $447-448,1979$.

7. Code of Federal Regulations. Title 10, chapter 1, part 20, appendix B. Superintendent of Documents, U.S. Government Printing office, Washington DC, pp. 168-169, January 1977 .

8. E. M. Mouradian and L. Baker, Jr., "Burning Temperatures of Uranium and Zirconium in Air." Nuclear Science and Engineering. 15:388-394, 1963.

9. L. Leibowitz, L. Baker, Jr., J. G. Schnizlein, L. W. Mishler and J. D. Bingle, "Burning Velocities of Uranium and Zirconium in Air." Nuclear Science and Engineering. 15:395-403, 1963.

10. L. Baker, Jr., J. G. Schnizlein and J. D. Bingle, "The Ignition of Uranium." Journal of Nuclear Materials. 20:22-38, 1966.

11. L. E. Musgrave, "A Theory of Burning Curve Ignition of Nuclear Metals." Journal of Nuclear Materials. 43:155-163, 1972.

12. H. C. Hodges, J. N. Stannard and J. B. Hursh, eds., Uranium, Plutonium, Transplutonium Elements. Springer-Verlag, New York, 1973.

13. E. J. Bennellicke, A Review of the Toxicology and Potential Hazards of Natural, Depleted, and Enriched Uranium. AHSB-RP-R58, Authority Health and Safety Branch, United Kingdom Atomic Energy Authority, U.K., 1966. 
14. H. B. Wilson, H. E. Stockinger and G. E. Sylvester, "Acute Toxicity of Carnolite Ore Dust." Archives of Industrial Health. 7:301-309, Apri1 1953. 


\section{PLACEMENT AND OPERATION OF SAMPLERS}

RUN 1--OCTOBER 4, 1977, ROUND FIRED 1803

When the samplers were shut-off, the flowmeters of target-area samplers T1-T6, I1, and I2 read below scale. The other air samplers were operating as set except that $T 7$ read $35 \mathrm{cfm}$ and $\mathrm{I} 3$ read about $22 \mathrm{cfm}$.

\section{( $~ 145 \mathrm{ft} \mathrm{FROM}$}

FRONT TARGET)

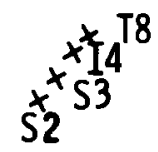

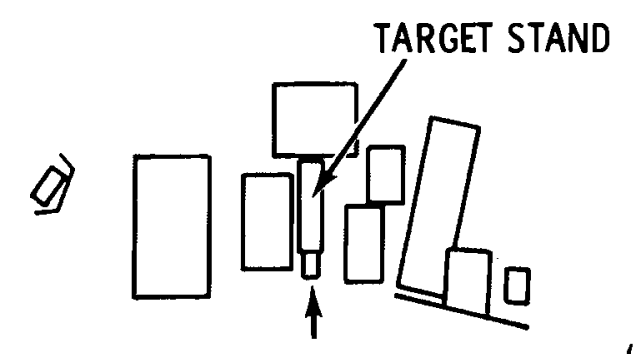

$\times$ SI AT MTL

Tl-T6, Il, I2, Ll, L2

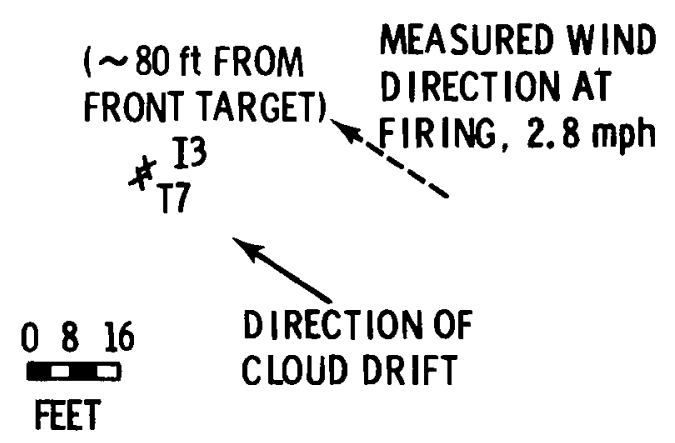

FIGURE A.1.1. Sampler Placement Run 1, October 4, 1977 
TABLE A.1.1. Sampler Operation, Run 1, October 4, 1977

\begin{tabular}{|c|c|c|c|c|}
\hline Sampler & $\begin{array}{l}\text { Time } \\
\text { on } \\
\end{array}$ & $\begin{array}{l}\text { Time } \\
\text { off } \\
\end{array}$ & $\begin{array}{c}\text { Duration } \\
\text { (min) }\end{array}$ & $\begin{array}{l}\text { Assumed Average } \\
\text { Flowrate, cfm }\end{array}$ \\
\hline$T 1-T_{6}(a)$ & 1758 & 1823 & $?^{(e)}$ & 50 \\
\hline $\mathrm{T7}$ & 1758 & 1823 & 25 & 42 \\
\hline T8 & 1758 & 1823 & 25 & 50 \\
\hline $\mathrm{I} 1,^{(\mathrm{b})} \mathrm{I2}$ & 1758 & 1823 & $?$ & 20 \\
\hline I3, I4 & 1758 & 1823 & 25 & 20 \\
\hline$L 1, L 2^{(c)}$ & 1758 & 1852 & 54 & 3 \\
\hline S2 & 1758 & 1823 & 25 & 26 \\
\hline S3 & 1758 & 1823 & 25 & 26 \\
\hline$s 1^{(d)}$ & 1217 & 1517 & 446 & 25 \\
\hline S1 & 1519 & 1945 & & \\
\hline
\end{tabular}

\footnotetext{
(a) T6: Total Particulate Sampler \#6.

(b) I1: High-Volume Cascade Impactor \#1.

(c) L2: Lundgren Impactor \#2.

(d) S1: Staplex Sampler \#1.

(e) Time not accurately known due to sampler clogging or other malfunction
}

RUN 2--OCTOBER 6, 1977, ROUND FIRED 0951

This run was performed during a light rain. The fuse burned out on impactor L1, and the impactor was removed from the area. Power to the upwind samplers was lost, probably because the addition of sampler S5 overloaded the circuit. The cloud formed into a mushroom shape, rose about 100 to $150 \mathrm{ft}$, and drifted over the trees east of the target, missing the downwind samplers. 

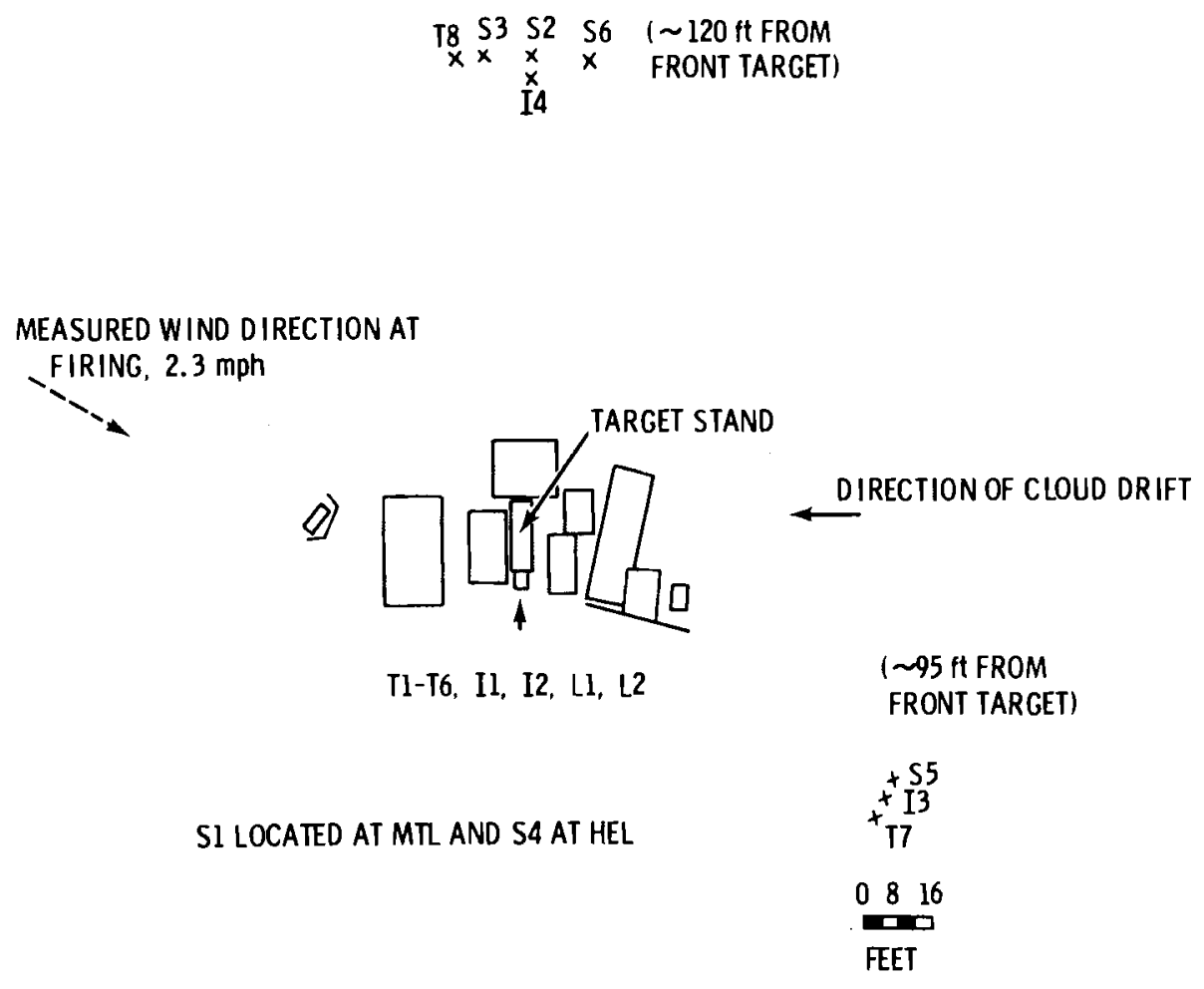

FIGURE A.1.2. Sampler P1acement Run 2, October 6, 1977

TABLE A.1.2. Sampler Operation, Run 2, October 6, 1977

\begin{tabular}{|c|c|c|c|c|}
\hline Sampler & $\begin{array}{l}\text { Time } \\
\text { on } \\
\end{array}$ & $\begin{array}{l}\text { Time } \\
\text { off }\end{array}$ & $\begin{array}{c}\text { Duration } \\
\text { (min) }\end{array}$ & $\begin{array}{l}\text { Assumed Average } \\
\text { Flowrate, cfm }\end{array}$ \\
\hline T1-T6 & 0940 & 1006 & $?$ & 50 \\
\hline T8 & 0940 & 1006 & $?$ & $?$ \\
\hline $\mathrm{I1}, \mathrm{I} 2$ & 0940 & 1006 & $?$ & 20 \\
\hline I4 & 0940 & 1006 & 26 & 20 \\
\hline L2 & 0940 & 1010 & 30 & 3 \\
\hline S1 & 0823 & 1015 & 112 & 25 \\
\hline S2 & 0940 & 1006 & 26 & 26 \\
\hline S3 & 0940 & 1006 & 26 & 26 \\
\hline$\$ 4$ & 0750 & $?$ & $?$ & 24 \\
\hline S6 & 0940 & 1006 & 26 & 35 \\
\hline
\end{tabular}

A. 3 
RUN 3--OCTOBER 6, 1977, ROUND FIRED 1722

At startup, sampler 78 read $45 \mathrm{cfm}$ and all the others were set as before in run 2. The cloud rose in a mushroom shape and extended to 150 to $200 \mathrm{ft}$. The cloud drifted at approximately $2 \mathrm{mph}$ over the trees east of the target. The part of the cloud closest to the ground passed through the downwind sampler group. After the shot, the sampler flowmeters read as set initially except for T1-T6, I1, I2, which read below scale or zero. The Lundgren impactors were allowed to run during the preparations for the next firing.

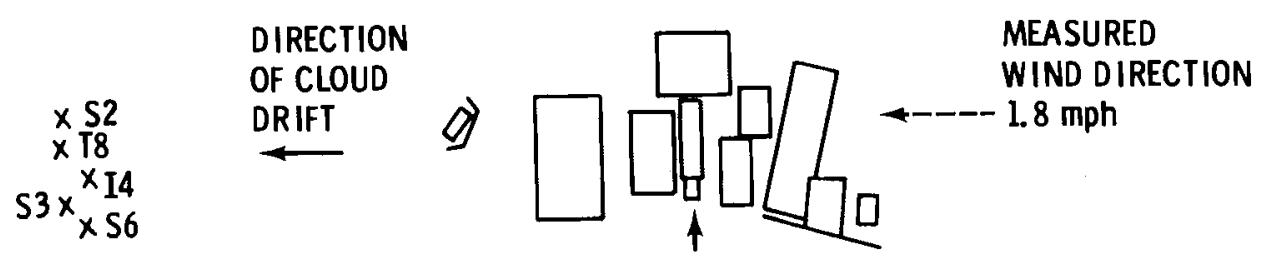

$\sim 124$ ft FROM

Tl-T6, Il, I2, Ll, L2 FRONT TARGET

S4 AT HEL

0816

$\times{ }^{x} \times 13$

$\sim 94 \mathrm{ft} \mathrm{FROM}$

FRONT TARGET

FEET

FIGURE A.1.3. Sampler Placement Run 3, October 6, 1977 
TABLE A.1.3. Sampler Operation, Run 3, October 6, 1977

\begin{tabular}{|c|c|c|c|c|}
\hline Sampler & $\begin{array}{l}\text { Time } \\
\text { on } \\
\end{array}$ & $\begin{array}{l}\text { Time } \\
\text { off } \\
\end{array}$ & $\begin{array}{c}\text { Duration } \\
\text { (min) }\end{array}$ & $\begin{array}{l}\text { Assumed Average } \\
\text { Flowrate, cfm }\end{array}$ \\
\hline T1-T6 & 1716 & 1738 & $?$ & 50 \\
\hline $\mathrm{T7}$ & 1716 & 1738 & 22 & 50 \\
\hline T8 & 1716 & 1738 & 22 & 45 \\
\hline $\mathrm{I} 1, \mathrm{I} 2$ & 1716 & 1738 & $?$ & 20 \\
\hline I3, I4 & 1716 & 1738 & 22 & 20 \\
\hline L1, L2 & 1716 & 1800 & 44 & 3 \\
\hline S2 & 1716 & 1738 & 22 & 26 \\
\hline S3 & 1716 & 1738 & 22 & 26 \\
\hline S6 & 1716 & 1738 & 22 & 35 \\
\hline S4 & 1515 & 1815 & 180 & 24 \\
\hline
\end{tabular}

RUN 4--OCTOBER 7, 1977, ROUND 5 FIRED 1401 and 1508

The first round was fired at $1401 \mathrm{hr}$, and the cloud drifted at about 4 mph over samplers I3 and T7 (which were initially the upwind samplers). The authors intended to operate the Lundgren impactors and upwind/downwind samplers undisturbed for an hour with none of the usual activity in the target area. The air sampling crew entered the target area at $1416 \mathrm{hr}$ to shut off some of the samplers and adjust the others. At this time, T8 read $48 \mathrm{cfm}$ (it had initially read $43 \mathrm{cfm}$ ). Samplers T1-T6, I1, and I2 read below scale and were shut off. All the remaining samplers were operating at their initial flow rate.

The air sampling crew returned to the target area at $1440 \mathrm{hr}$ and turned off the Lundgren impactors, which were still operating at $3 \mathrm{cfm}$. The upwind/downwind samplers were left on for the next round. The target area samplers were removed and the usual preparations for a shot commenced. The second round was fired at $1508 \mathrm{hr}$. The cloud drifted over samplers T7 and I3. The upwind/downwind samplers were turned off at $1536 \mathrm{hr}$. 
$\sim 124 \mathrm{ft} \mathrm{FROM}$

FRONT TARGET

\section{MEASURED WIND DIRECTION,}

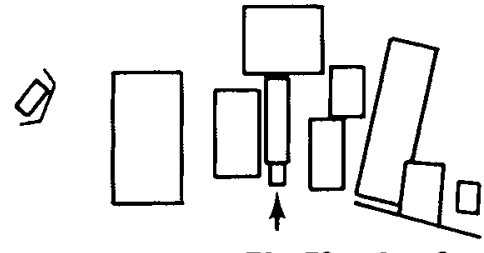

T1-T6, Il, I2, L1, L2

\section{* measured \\ WIND DIRECTION, FIRST ROUND, \\ 4. $1 \mathrm{mph}$}

DIRECTION OF CLOUD DRIFT, FIRST AND SECOND ROUNDS

SECOND ROUND, $2.7 \mathrm{mph}$

S4 AT HEL

$$
x_{T 7}^{x{ }^{13}}
$$

Sl AT MTL

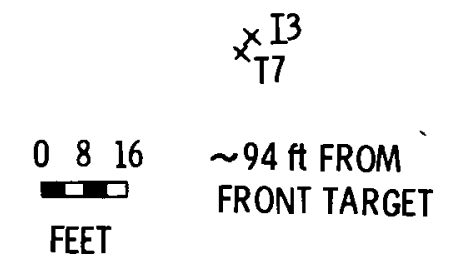

FIGURE A.1.4. Sampler Placement Run 4, October 7, 1977

TABLE A.1.4. Sampler Operation, Run 4, October 7, 1977

\begin{tabular}{|c|c|c|c|c|}
\hline Sampler & $\begin{array}{l}\text { Time } \\
\text { on }\end{array}$ & $\begin{array}{l}\text { Time } \\
\text { off }\end{array}$ & $\begin{array}{c}\text { Duration } \\
\text { (min) }\end{array}$ & $\begin{array}{l}\text { Assumed Average } \\
\text { Flowrate, cfm }\end{array}$ \\
\hline T1-T6. & 1352 & 1417 & $?$ & 50 \\
\hline $\mathrm{T7}$ & 1352 & 1535 & 103 & 50 \\
\hline T8 & 1352 & 1535 & 103 & 46 \\
\hline $\mathrm{I} 1, \mathrm{I} 2$ & 1352 & 1417 & $?$ & 20 \\
\hline $\mathrm{I} 3, \mathrm{I} 4$ & 1352 & 1535 & 103 & 20 \\
\hline L1, L2 & 1352 & 1440 & 48 & 3 \\
\hline S2, S3 & 1352 & 1535 & 103 & 26 \\
\hline S6 & 1352 & 1535 & 103 & 35 \\
\hline S1 & 1458 & 1945 & 287 & 25 \\
\hline S4A & 1251 & 1612 & 201 & 24 \\
\hline$S 4 B$ & 1655 & 1920 & 145 & 24 \\
\hline
\end{tabular}


RUN 5--OCTOBER 8, 1977, ROUND FIRED 0850

The cloud drifted to the northwest of the target and over samplers $T 7$ and I3. The back-up filter holder for impactor L1 was found disconnected from the impactor, possibly because of the concussion of the round, and was reconnected at $0908 \mathrm{hr}$; however, the samples from L1 may be of little value.

The flow rates of most upwind/downwind samplers remained as set. The flow rates of samplers $\mathrm{TI}-\mathrm{T6}$, I1, and I2 were essentially zero after the samplers became plugged with particulates. The flow rate of sampler L2 had crept up to $4 \mathrm{cfm}$ and was adjusted back down to $3 \mathrm{cfm}$ at $0914 \mathrm{hr}$. The flow rates of samplers 18 and $I 4$ had decreased to 40 and $15 \mathrm{cfm}$, respectively, by the time they were turned off.

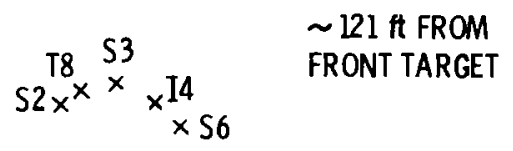

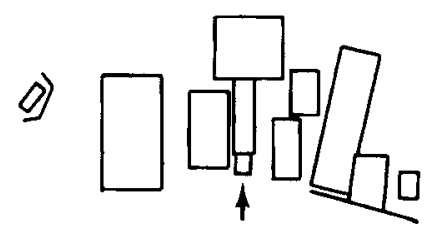

T1-T6, Il, I2, L1, L2

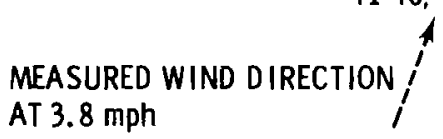

S4 LOCATED AT HEL AND SI AT MTL

FIGURE A.1.5. Sampler Placement Run 5, October 8, 1977

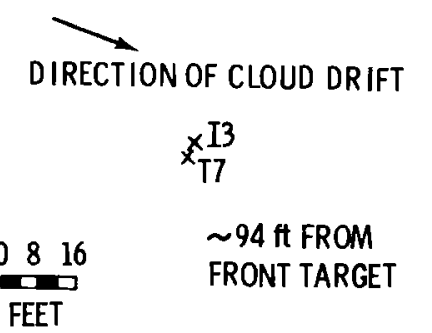

EET 
TABLE A.1.5. Sampler Operation, Run 5, October 8, 1977

\begin{tabular}{|c|c|c|c|c|}
\hline Sampler & $\begin{array}{l}\text { Time } \\
\text { on } \\
\end{array}$ & $\begin{array}{l}\text { Time } \\
\text { off }\end{array}$ & $\begin{array}{c}\text { Duration } \\
\text { (min) } \\
\end{array}$ & $\begin{array}{l}\text { Assumed Average } \\
\text { Flowrate, cfm }\end{array}$ \\
\hline $\mathrm{T} 1-\mathrm{T} 6$ & 0843 & 0909 & $?$ & 50 \\
\hline $\mathrm{T7}$ & 0843 & 0909 & 26 & 50 \\
\hline T8 & 0843 & 0909 & 26 & 45 \\
\hline $\mathrm{I} 1, \mathrm{I} 2$ & 0843 & 0909 & $?$ & 20 \\
\hline I3, I4 & 0843 & 0909 & 26 & 20 \\
\hline L1 & 0843 & 0930 & $?$ & 3 \\
\hline L2 & 0843 & 0930 & 47 & 3 \\
\hline S2, S3 & 0843 & 0909 & 26 & 26 \\
\hline S6 & 0843 & 0909 & 26 & 35 \\
\hline S1 & 0650 & 1325 & 395 & 23 \\
\hline S4 & 0723 & 1232 & 309 & 24 \\
\hline
\end{tabular}


APPENDIX A.2

METEOROLOGICAL DATA EXTRACTED FROM REPORT

FURNISHED BY U.S. ARMY ENVIRONMENTAL HYGIENE AGENCY, AGP, MD, DATED NOVEMBER 15, 1977

TABLE A.2.1. AEHA Meteorological Data for Time Periods October 4, 1977 to October 9, 1977

\begin{tabular}{|c|c|c|c|c|c|}
\hline Date & Time(a) & $\begin{array}{l}\text { Wind } \\
\text { Speed } \\
\text { (mph) }(b)\end{array}$ & $\begin{array}{l}\text { Wind } \\
\text { Direction }\left({ }^{\circ}\right)\end{array}$ & Sigma $\left({ }^{\circ}\right)$ & $\begin{array}{c}\text { Stability } \\
\text { Class } \\
\end{array}$ \\
\hline \multicolumn{6}{|c|}{ October 4, 1977} \\
\hline \multirow{12}{*}{$\begin{array}{l}\text { Run } 1 \text {, } \\
\quad \text { Round } 1803\end{array}$} & \multirow[t]{12}{*}{$1800-1900$} & 2.8 & 283 & & B2 \\
\hline & & 1.7 & 282 & & B2 \\
\hline & & 1.8 & 319 & & B2 \\
\hline & & 1.1 & 54 & & B2 \\
\hline & & 1.0 & 4 & & B2 \\
\hline & & CALM & & & \\
\hline & & CALM & & & \\
\hline & & CALM & & & \\
\hline & & CALM & & & \\
\hline & & CALM & & & \\
\hline & & CALM & & & \\
\hline & & CALM & & & \\
\hline
\end{tabular}

October 6, 1977

Run 2,
Round 0951

$0945-1040$

2.3

114

1.5

6

1.0

322

2.5

291

1.8

205

2.1

294

B1

1.0

293

B1

1.8

226

B1

1.3

315

B1

1.3

276

B1

CALM

(a) Wind data reported at 5-min intervals.

(b) Calm is indicated when the wind speed dropped below $1 \mathrm{mph}$. 
TABLE A.2.1. (Contd)

\begin{tabular}{|c|c|c|c|c|c|}
\hline Date & Time (a) & $\begin{array}{c}\text { Wind } \\
\text { Speed } \\
\text { (mph) }(b)\end{array}$ & $\begin{array}{l}\text { Wind } \\
\text { Direction }\left({ }^{\circ}\right)\end{array}$ & Sigma $\left({ }^{\circ}\right)$ & $\begin{array}{r}\text { Stabil } \\
\text { Clas } \\
\end{array}$ \\
\hline \multicolumn{6}{|c|}{ October 6, 1977} \\
\hline \multirow{12}{*}{$\begin{array}{l}\text { Run 3, } \\
\text { Round } 1722\end{array}$} & \multirow[t]{12}{*}{$1720-1820$} & 1.8 & 274 & & B1 \\
\hline & & 1.5 & 359 & & B1 \\
\hline & & 1.3 & 100 & & B1 \\
\hline & & CALM & & & B1 \\
\hline & & CALM & & & B1 \\
\hline & & 1.2 & 258 & & $\mathrm{~B} 1$ \\
\hline & & 1.3 & 193 & & $\mathrm{~B} 1$ \\
\hline & & 1.3 & 206 & & B1 \\
\hline & & 2.1 & 280 & & B1 \\
\hline & & 1.7 & 218 & & B1 \\
\hline & & 1.3 & 295 & & $\mathrm{~B} 1$ \\
\hline & & CALM & & & B1 \\
\hline
\end{tabular}

October 7, 1977

\begin{tabular}{|c|c|c|c|c|}
\hline \multirow{13}{*}{$\begin{array}{l}\text { Run } 4, \\
\quad \text { Round } 4 a, 1400\end{array}$} & \multirow[t]{13}{*}{$1401-1505$} & 4.1 & 308 & B1 \\
\hline & & 5.0 & 222 & B1 \\
\hline & & 5.5 & 216 & B1 \\
\hline & & 5.2 & 131 & B1 \\
\hline & & 4.4 & 137 & B1 \\
\hline & & 3.7 & 25 & B1 \\
\hline & & 2.7 & 140 & B2 \\
\hline & & 3.0 & 166 & B2 \\
\hline & & 2.8 & 331 & B2 \\
\hline & & 2.4 & 223 & B2 \\
\hline & & 2.8 & 38 & B2 \\
\hline & & 3.3 & 72 & B2 \\
\hline & & 2.1 & 51 & B2 \\
\hline
\end{tabular}


TABLE A.2.1. (Contd)

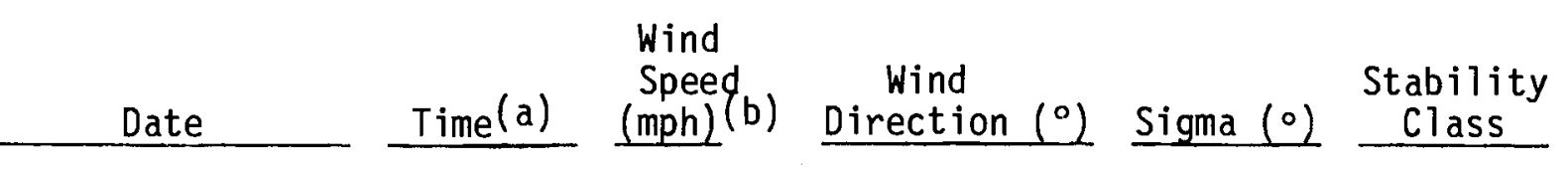

October 7, 1977

Round 4b, 1508

$$
1505-1600
$$

2.7

3.0

4.6

8.0

7.3

8.4

3.8

4.8

7.0

4.5

5.7

October 8,1977

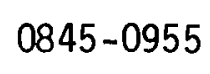

3.8

3.5

2.5

1.5

1.8

2.3

2.7

2.2

3.7

2.7

2.7

2.4

1.6

1.7
61

56

120

133

129

100

351

155

144

308

218

24

B2

B2

B2

B2

B1

B1

B1

B1

B1

B1

B1

$B 2$
$B 2$
$B 2$
$B 2$
$B 1$
$B 1$
$B 1$
$B 1$
$B 1$
$B 1$
$B 1$

$218-24$

1

- 8




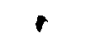




\section{PREPARATION OF SAMPLES FOR URANIUM ANALYSIS}

The samples from the wet fallout, probe wash and Lundgren impactor back-up filter required no further preparation before being submitted for analysis by UST. The other samples were divided so that portions could be reserved for other types of analyses.

The dry fallout material was dried in an oven and weighed. The paper towels used to clean the trays on 0ctober 6 were also dried and weighed, and small fractions of both towels and fallout were weighed before they were submitted to UST.

The deposited samples on the 8-in. $\times 10$-in. Whatman 41 filters from the total-particulate samplers and from the impactor back-up stages appeared uniform to the eye and to a beta radiation survey. The Whatman 41 filters were cut into sixteenths as shown in Figure B.1. (Two exceptions to this division will be discussed later.) Four of these sections were selected as samples from different quarters of the filter (see Figure B.1). These four selected pieces totaled one-fourth of the original sample and were further

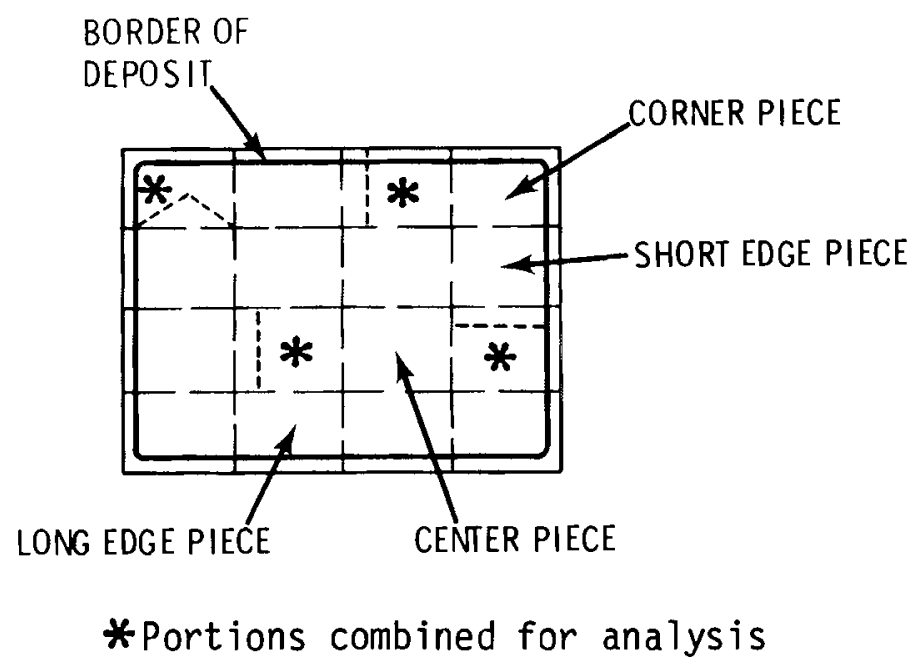

FIGURE B.1. Partitioning of 8-in. $\times 10$-in. Filter 
subdivided by removing one-fourth from each piece. A quarter from each selected one-fourth piece was submitted for analysis and the remaining parts reserved as spare samples; however, the spare samples were analyzed instead, ending in $3 / 16$ th of the original filter analyzed.

Two of the 8-in. $\times 10$-in. total-particulate samples were brushed and scraped to attempt to remove most of the radioactive material from the filter surface. This material was to be analyzed for uranium oxide forms by $X$-ray diffraction. However, since no significant amount of radioactive material was removed, the two filters were cut and prepared for analysis as described above.

The 12-in.-dia, perforated, high-volume impactor substrates were cut into quarters radially. Two quarters from opposite sides of the substrate were then cut in half, and half from each quarter was submitted to UST, as shown in Figure B.2.

The authors intended originally to analyze each entire 12-in. substrate and respective swabs together as one sample; however, sectioning the substrates required that the swabs (approximately 100) be divided or analyzed separately. However, the swabs could not be accurately divided into equal

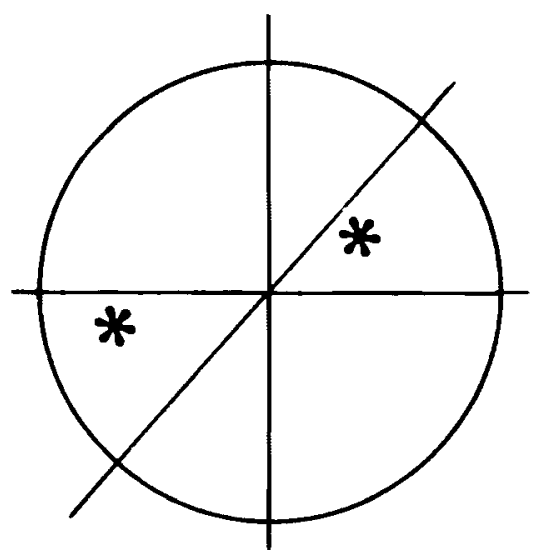

FIGURE B.2. Division of High-Volume Impactor 12-in. Substrates (the asterisk indicates portions sent to UST) 
parts because the authors felt the uranium content would not be uniformly distributed. Therefore, swabs from four impactors were submitted for analys is -- two each from the target area impactors and the upwind/downwind impactors. From the results, average ratio (swab/substrate) uranium contents were calculated for each stage. The swabs were later dropped from the data because their inclusion had an insignificant effect on the resulting size distributions.

The 4-in. dia. Whatman 41 filters from the Staplex samplers were quartered radially. The opposite quarters were submitted for analysis by UST, as shown in Figure B.3.

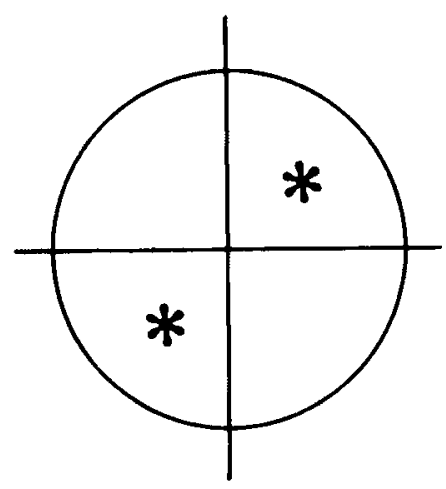

FIGURE B.3. Division of Staplex 4-in. Filter Samples (asterisk indicates portions submitted for analysis) 
APPENDIX B.2

\section{PREPARATION OF LUNDGREN IMPACTOR SUBSTRATES FOR ANALYSIS}

The drums around which the mylar substrates were fastened during operation of the Lundgren impactor had a circumference of $4.5 \mathrm{in}$. (excluding a substrate hold-down). The mylar substrate deposit area was 1.9-in. wide, making the total particulate deposit area $1.9 \times 4.5 \mathrm{in}$. As shown in Figure 18, time proceeds from right to left on the substrate. The substrates in Figure 18 show particularly high particle concentrations when the penetrator was fired and later during installation of new targets. (Only in Run 3 were there visibly distinct bands much later after the firing.)

Each substrate was cut into as many as 8 time increments. Generally, all the substrates from one impactor were cut into the same number of pieces. Ideally, the division into time increments should be identical for each substrate of an impactor; however, there was some variation because none of the visible bands (deposits) were cut and some of the bands ran together. The error, thus, introduced into the final concentration for each time interval calculation was small because the differences between the uranium content of the visible bands and of the other areas were large.

Figure 18 shows the segments into which the substrates from Run 3-L1 were cut. The impactors from Runs $1,2,3$, and 5 were operated during the test firing and during the normal routine of replacing the targets. The substrates from these runs were cut into 5 to 6 bands. The Lundgren impactors from Run 4 were operated for about one hour after the test firing when there was no activity in the target area except the shutting off of other samplers. The Lundgren substrates from Run 4 were cut into 8 bands each. The widths of all bands were recorded so that the measured uranium content could be related to an approximate time interval.

Each piece of substrate was placed in a labelled $35-\mathrm{mm}$ slide holder and backed with a larger piece of clean mylar. The slide frame mounts were used to enable the automatic and unattended changing of samples in the X-ray fluorometer. The samples were submitted to PNL's Chemical Methods and Kinetics Section for X-ray fluorescence analysis. 
APPENDIX B. 3

SAMPLE DATA REDUCTION FOR A LUNDGREN IMPACTOR, RUN 3-L1

TABLE B.3.1. Sample Data Reduction for a Lundgren Impactor, Run 3-L1

\begin{tabular}{|c|c|c|c|c|c|c|c|}
\hline \multirow[b]{2}{*}{ Substrate } & \multirow[b]{2}{*}{$\underline{\operatorname{Variable}(a)}$} & \multicolumn{5}{|c|}{ Segment Group (b) } & \multirow{2}{*}{$\begin{array}{c}\text { Total Mass Uranium } \\
. \mu g \\
\end{array}$} \\
\hline & & A & $\mathrm{B}$ & $\mathrm{C}$ and $\mathrm{D}$ & $E$ & $\bar{F}$ & \\
\hline S1 & $\begin{array}{l}W \\
T \\
F \\
X \\
g\end{array}$ & $\begin{array}{c}0.611 \\
7.8 \\
0.92 \\
484.0 \\
4000.0\end{array}$ & $\begin{array}{c}0.949 \\
12.0 \\
0.99 \\
3.09 \\
37.0\end{array}$ & $\begin{array}{c}0.907 \\
11.5 \\
0.99 \\
27.4 \\
310.0\end{array}$ & $\begin{array}{c}0.993 \\
12.6 \\
1.0 \\
9.41 \\
120.0\end{array}$ & $\begin{array}{c}1.068 \\
13.6 \\
1.0 \\
7.51 \\
99.0\end{array}$ & 4,600 \\
\hline \$2 & $\begin{array}{l}W \\
T \\
F \\
X \\
g\end{array}$ & $\begin{array}{c}0.219 \\
2.8 \\
0.42 \\
278.0 \\
1800.0\end{array}$ & $\begin{array}{c}1.346 \\
17.1 \\
1.0 \\
4.07 \\
68.0\end{array}$ & $\begin{array}{l}0.749 \\
9.5 \\
0.96 \\
4.87 \\
47.0\end{array}$ & $\begin{array}{c}1.104 \\
14.0 \\
1.0 \\
2.01 \\
27.0\end{array}$ & $\begin{array}{c}1.037 \\
13.2 \\
1.0 \\
4.89 \\
62.0\end{array}$ & 2,000 \\
\hline \$3 & $\begin{array}{l}W \\
T \\
F \\
X \\
g\end{array}$ & $\begin{array}{c}0.290 \\
3.7 \\
0.53 \\
159.0 \\
1100.0\end{array}$ & $\begin{array}{l}1.266 \\
16.1 \\
1.0 \\
0.618 \\
9.6\end{array}$ & $\begin{array}{l}0.718 \\
9.1 \\
0.95 \\
1.27 \\
12.0\end{array}$ & $\begin{array}{l}1.188 \\
15.1 \\
1.0 \\
0.345 \\
5.1\end{array}$ & $\begin{array}{c}1.066 \\
13.5 \\
1.0 \\
2.08 \\
27.0\end{array}$ & 1,200 \\
\hline S4 & $\begin{array}{l}W \\
T \\
F \\
X \\
g\end{array}$ & $\begin{array}{c}0.355 \\
4.5 \\
0.63 \\
207.0 \\
1400.0\end{array}$ & $\begin{array}{c}1.139 \\
14.5 \\
1.0 \\
2.16 \\
30.0\end{array}$ & $\begin{array}{l}0.780 \\
9.9 \\
0.97 \\
2.51 \\
25.0\end{array}$ & $\begin{array}{c}1.149 \\
14.6 \\
1.0 \\
3.25 \\
46.0\end{array}$ & $\begin{array}{c}1.079 \\
13.7 \\
1.0 \\
1.99 \\
26.0\end{array}$ & 1,500 \\
\hline $\begin{array}{l}\text { Subtotal M } \\
\% \text { of Total }\end{array}$ & $\mu g$ & $\begin{array}{r}8300.0 \\
90.2\end{array}$ & $\begin{array}{r}145.0 \\
1.6\end{array}$ & $\begin{array}{r}390.0 \\
4.2\end{array}$ & $\begin{array}{r}200.0 \\
2.2\end{array}$ & $\begin{array}{r}214.0 \\
2.3\end{array}$ & 9,200 \\
\hline \multicolumn{8}{|c|}{ Analysis of back-up filter $=1470 \mu \mathrm{g}$} \\
\hline \multicolumn{8}{|c|}{$\begin{array}{l}\text { Distributed Amount of } \\
\text { Back-up Filter Uranium, } \mu \mathrm{g} 1300.0\end{array}$} \\
\hline Total Mass & an ium & & 9600.0 & 170.0 & 450.0 & 230.0 & $250.0 \quad 10,700$ \\
\hline
\end{tabular}

(a) Where:

$W=$ Segment width, in.

$T=$ Time, $\min =0.0788^{\mathrm{W}}$

$F=$ Calibration factor

$X=$ Analysis, $\mu \mathrm{g} / \mathrm{cm}^{2}$

$\mu g=12.3 \frac{X W}{\bar{F}}$ micrograms

(b) The segment group was comprised of the four segments (one from each substrate) corresponding to a time interval denoted by a letter, e.g., "Segment Group F". See Figure 18 and page 31.

(c) The percentage of the total collected during each time increment was used to distribute the uranium on the back-up filter among the time increments. 


\section{APPENDIX B.4}

\section{PREPARATION OF SAMPLES FOR OXIDE ANALYSIS}

The analyses of target-area total-particulate and dry fallout samples were performed by the Metallurgy Research Section, PNL. The target-area total-particulate samples had already been cut as shown in Figure B.1. A single center piece of one sample from each run was submitted for analys is. The samples selected were:

$$
\begin{aligned}
& \text { Run } 1-T 2 \\
& \text { Run } 2-T 1 \\
& \text { Run } 3-T 2 \\
& \text { Run } 4-T 3 \\
& \text { Run } 5-T 2
\end{aligned}
$$

Small fractions of the dry fallout samples were also submitted for analysis.

The analysis of two sets of high-volume cascade impactor substrates were performed by the Analytical and Nuclear Research Section, PNL. Fractions of the four substrates and back-up filter were submitted from each of the impactors Run 3-I2 and Run 4-I2. These samples were already divided as shown in Figures B.1 and B.2. A short edge piece from each of the back-up filters was analyzed. One-eighth of the substrates from Run 3-I2 and one-sixteenth from Run 4-I2 were analyzed. Pieces of Whatman 41 media were submitted to both sections as blanks. 


\section{METHODS FOR OXIDE ANALYSIS}

The X-ray diffraction of the total-particulate and fallout samples was obtained by diffractometer tracing $2 \theta$ angles (angle between incident and diffracted beam) from $10^{\circ}$ to $70^{\circ}$ on a fraction of each sample. The crystalline phase was identified by comparing the intensity and the $2 \theta$ angles of the diffraction peaks with those of 24 uranium oxides listed in the American Society for Testing Materials Diffraction File. A semiquantitative estimate of the relative abundance of the uranium oxides present was determined by comparing the integrated diffraction intensities (peak areas) from the two phases. The uncertainty of this comparison is estimated at $15 \%$.

The size and morphology of the fallout particles and target-area total-particulate samples were examined using an SEM. The elemental composition of the particles was analyzed using an X-ray fluorescence microprobe. The microprobe could not analyze for the oxides, however.

The high-volume cascade impactor samples were analyzed using techniques similar to those described above: X-ray diffractometer, SEM and X-ray fluorescence microprobe. Uranium oxides were identified but not quantified. 


\section{SAMPLE PREPARATION FOR SOLUBILITY MEASUREMENTS}

The solubility of uranium-containing particles was investigated using simulated lung fluids. Samples of target-area total particulates and respirable particles from the target area and downwind were used for this measurement.

Fractions of the high-volume cascade impactor samples Run 3-I2, Run 4-I2 (target area), and Run 4-I3 (downwind) were prepared for solubility analysis. The particles smaller than 3.3-um AED were assumed to be respirable; therefore, one-eighth of substrates Numbers 3 and 4 and the back-up filter were analyzed. These samples were sectioned as shown in Figures B.1 and B.2. (A corner piece and a center piece of the 8- x 10-in. back-up filter contain approximately one-eighth of the deposited particulates.) The fractions were combined so that there was one composite sample for each impactor.

A center piece from each of the target-area total-particulate samples listed in Appendix B.4 was analyzed. Each piece contained approximately 8.2\% of the deposited particulates on the filter.

In total, three composite impactor samples and five total-particulate samples were submitted for analysis. Blanks of Whatman 41 media were also analyzed. 


\section{METHOD FOR SOLUBILITY ANALYSIS}

The solubilities of the materials collected were measured by immersing the samples in simulated lung fluid and extracting aliquots at pre-selected times. (PNL's Inhalation Technology and Toxicology Section performed the analysis.) The filter paper sections were immersed in bottles containing $55 \mathrm{ml}$ of fluid held at $37^{\circ} \mathrm{C}$, and gas $\left(5 \% \mathrm{CO}_{2}\right.$ in $\mathrm{O}_{2}$ to prevent a pH shift of the solution) was bubbled through the fluid until the free volume of the containers was swept free of air. The bottles were capped and placed in a shaker bath maintained at $37^{\circ} \mathrm{C}$ (body temperature). The initial pH of the fluid was 7.4. Three sets of duplicate samples were taken: one immediately after wetting, one after one week, and one after four weeks. Samples were extracted by injecting a volume of gas into the bottle and then removing an equivalent volume of solution containing a representative quantity of filter paper and solids. (Removing an equivalent quantity of all materials during each extraction means the solution remaining is always representative of the initial volume.) Each volume extracted (duplicate 1-ml aliquots) was forced through a membrane filter (0.1-um mean pore size), and the uranium content was measured by fluorometry (at UST, Richland Division). 


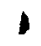


APPENDIX C

\section{SAMPLE SIZE DISTRIBUTION DATA REDUCTIONS}

TABLE C.1. High-Volume Cascade Impactor Example Size Distribution Run 1-I1

\begin{tabular}{|c|c|c|c|c|}
\hline Stage & $\begin{array}{c}\text { Aerodynamic } \\
\text { Cut Off Dia., } \mu \mathrm{m} \\
\end{array}$ & $\begin{array}{l}\text { Uranium on } \\
\text { Sample, } \mu \mathrm{g} \\
\end{array}$ & $\begin{array}{l}\% \text { per } \\
\text { Stage }\end{array}$ & $\begin{array}{c}\text { Cumulative } \\
\quad \%\end{array}$ \\
\hline Probe & & $3.85 \times 10^{4}$ & \multirow[b]{2}{*}{38.2} & \multirow[b]{2}{*}{100.1} \\
\hline 1 & 7.0 & $1.48 \times 10^{4}$ & & \\
\hline 2 & 3.3 & $1.11 \times 10^{4}$ & 8.0 & 61.8 \\
\hline 3 & 2.0 & $0.596 \times 10^{4}$ & 4.3 & 53.9 \\
\hline 4 & 1.1 & $0.281 \times 10^{4}$ & 2.0 & 49.6 \\
\hline \multirow[t]{2}{*}{ Filter } & & $6.64 \times 10^{4}$ & 47.6 & 47.6 \\
\hline & & $1.40 \times 10^{5}$ & & \\
\hline
\end{tabular}

TABLE C.2. Size Distribution Calculations for Lundgren Impactor Run 3-L1

\begin{tabular}{|c|c|c|c|c|c|c|c|}
\hline \multirow[b]{2}{*}{ Stage } & \multirow{2}{*}{$\begin{array}{l}\text { Equivalent } \\
\text { Cut Off } \\
\text { Diameter, } \mu \mathrm{m}\end{array}$} & \multicolumn{3}{|c|}{ Segment Group $A(a)$} & \multicolumn{3}{|c|}{ A11 Segment Groups $(b)$} \\
\hline & & Uranium, $\mu \mathrm{g}$ & $\%$ & Cumulative $\%$ & Uranium, $\mu \mathrm{g}$ & $\%$ & Cumulative $\%$ \\
\hline 1 & 9.4 & 4,000 & 41.7 & 100.1 & 4,600 & 43.0 & 100.0 \\
\hline 2 & 2.8 & 1,800 & 18.8 & 58.4 & 2,000 & 18.7 & 57.0 \\
\hline 3 & 0.9 & 1,100 & 11.5 & 39.6 & 1,200 & 11.2 & 38.3 \\
\hline 4 & 0.26 & 1,400 & 14.6 & 28.1 & 1,500 & 14.0 & 27.1 \\
\hline Back-up Filter & & 1,300 & 13.5 & 13.5 & 1,400 & 13.1 & 13.1 \\
\hline Total & & 9,600 & & & 10,700 & & \\
\hline
\end{tabular}

(a) See page $B 5$. These samples include material collected at the instant of the test firing.

(b) These samples include material collected during the entire operating time of the sampler. 


\section{APPENDIX D}

\section{AIRBORNE URANIUM CONCENTRATION IN TARGET AREA VERSUS TIME}

\section{TABLE D.1. Sample Calculations of Average Concentration per Time Interval}

\begin{tabular}{|c|c|c|c|c|c|c|c|c|}
\hline \multirow[b]{2}{*}{ Sampler } & \multirow{2}{*}{$\begin{array}{l}\text { Time After } \\
\text { Shot, min. }\end{array}$} & \multirow[b]{2}{*}{ Item } & \multicolumn{5}{|c|}{ Segment Group (a) } & \multirow[b]{2}{*}{$\mathrm{F}$} \\
\hline & & & A & $\bar{B}$ & $\bar{C}$ & $\bar{D}$ & $\vec{E}$ & \\
\hline \multirow[t]{4}{*}{ Run $4-L 1$} & 39 & Ave Time, min & 6.1 & 6.4 & 6.3 & 6.3 & 6.2 & 6.3 \\
\hline & & $\sum$ Time & 6.1 & 12.5 & 18.8 & 25.1 & 31.3 & 37.6 \\
\hline & & ug collected & $18,100.0$ & 208.0 & 136.0 & 74.0 & 51.0 & 61.0 \\
\hline & & $\mu g / m^{3}$ & $3.5 \times 10^{4}$ & $3.8 \times 10^{2}$ & $2.5 \times 10^{2}$ & $1.4 \times 10^{2}$ & $9.7 \times 10^{1}$ & $1.1 \times 10^{2}$ \\
\hline \multirow[t]{4}{*}{ Run 4-L2 } & 39 & Ave Time & 4.1 & 6.4 & 6.6 & 6.5 & 6.3 & 6.2 \\
\hline & & ¿ Time & 4.1 & 10.5 & 17.1 & 23.6 & 29.9 & 36.1 \\
\hline & & $\mu g$ & $2,780.0$ & 18.7 & 10.1 & 6.1 & 3.4 & 2.5 \\
\hline & & $\mu g / m^{3}$ & $8.0 \times 10^{3}$ & $3.4 \times 10^{1}$ & $1.8 \times 10^{1}$ & $1.1 \times 10^{1}$ & $6.4 \times 10^{0}$ & $4.7 \times 10^{0}$ \\
\hline
\end{tabular}

Concentration $\mu \mathrm{g} / \mathrm{m}^{3}=\mu \mathrm{g} \cdot \frac{\min }{3 \mathrm{ft}^{3}} \cdot \frac{1}{\mathrm{~T}, \mathrm{~min}} \cdot \frac{35.31 \mathrm{ft}^{3}}{\mathrm{~m}^{3}}$ where the samplerflow was $3 \mathrm{cfm}$

(a) Represents sample collected during time interval A, B, etc. See page B.5. 


\section{TABLE D.2. Average Concentration per Time Interval}

\begin{tabular}{|c|c|c|c|}
\hline Impactor & $\begin{array}{c}\text { Time Interval, } \\
\text { min } \\
\end{array}$ & $\begin{array}{c}\text { Interval } \\
\text { Midpoint, min }\end{array}$ & $\begin{array}{c}\text { Average Uranium } \\
\text { Concentration } \\
\mu \mathrm{g} / \mathrm{m}^{3}\end{array}$ \\
\hline Run $1-L 2(a)$ & $\begin{array}{l}0-5.8 \\
5.8-21.8 \\
21.8-37.8 \\
37.8-49.0\end{array}$ & $\begin{array}{r}2.9 \\
13.8 \\
29.8 \\
43.4\end{array}$ & $\begin{array}{r}28,000 \\
170 \\
29 \\
100\end{array}$ \\
\hline Run 2-L2 & $\begin{array}{l}0-4.1 \\
4.1-18.1\end{array}$ & $\begin{array}{r}2.1 \\
11.1\end{array}$ & $\begin{array}{r}18,000 \\
120\end{array}$ \\
\hline Run 3-L2 & $\begin{array}{l}0-5.4 \\
5.4-19.4 \\
19.4-33.4 \\
33.4-38.0\end{array}$ & $\begin{array}{r}2.7 \\
12.4 \\
26.4 \\
35.7\end{array}$ & $\begin{array}{r}18,000 \\
53 \\
34 \\
170\end{array}$ \\
\hline Run 4-L2 & $\begin{array}{l}0-4.1 \\
4.1-10.5 \\
10.5-17.1 \\
17.1-23.6 \\
23.6-29.9 \\
29.9-36.1\end{array}$ & $\begin{array}{r}2.1 \\
7.3 \\
13.8 \\
20.4 \\
26.8 \\
33.0\end{array}$ & $\begin{array}{r}8,000 \\
34 \\
18 \\
11 \\
6.4 \\
4.7\end{array}$ \\
\hline Run 5-L2 & $\begin{array}{l}0-4.3 \\
4.3-18.2 \\
18.2-32.8 \\
32.8-40.0\end{array}$ & $\begin{array}{r}2.2 \\
11.3 \\
25.5 \\
36.4\end{array}$ & $\begin{array}{r}18,000 \\
70 \\
45 \\
31\end{array}$ \\
\hline Run $1-L 1$ (b) & $\begin{array}{l}0-9.0 \\
9.0-13.6 \\
13.6-32.5 \\
32.5-49.0\end{array}$ & $\begin{array}{r}4.5 \\
11.3 \\
23.1 \\
40.8\end{array}$ & $\begin{array}{r}21,000 \\
1,800 \\
110 \\
170\end{array}$ \\
\hline Run 3-L1 & $\begin{array}{l}0-4.7 \\
4.7-19.7 \\
19.7-29.7\end{array}$ & $\begin{array}{r}2.4 \\
12.2 \\
24.7\end{array}$ & $\begin{array}{r}24,000 \\
130 \\
530\end{array}$ \\
\hline Run 4-L1 & $\begin{array}{l}0-6.1 \\
6.1-12.5 \\
12.5-18.8 \\
18.8-25.1 \\
25.1-31.3 \\
31.3-37.6\end{array}$ & $\begin{array}{r}3.1 \\
9.3 \\
15.7 \\
22.0 \\
28.2 \\
34.5\end{array}$ & $\begin{array}{r}35,000 \\
380 \\
250 \\
140 \\
97 \\
110\end{array}$ \\
\hline
\end{tabular}

\footnotetext{
(a) L2 - Sampler Behind Film Frame

(b) L1 - Target Accessway Sampler
} 
APPENDIX E

CONCENTRATION OF TOTAL EXPOSURE IN TARGET AREA

TABLE E.1. Calculation of Total Exposure in Target Area(a)

\begin{tabular}{|c|c|c|}
\hline Sampler & $\begin{array}{c}\text { Uranium Col lected, } \\
\mathrm{mg} \\
\end{array}$ & $\begin{array}{l}\text { Exposure } \\
\mathrm{mg} \mathrm{min} / \mathrm{m}^{3}\end{array}$ \\
\hline $\begin{array}{rr}\text { Run } 1 \text { - T1 } \\
\text { T2 } \\
\\
\text { T3 } \\
\text { T4 } \\
\\
\\
\text { T5 } \\
\text { T6 }\end{array}$ & $\begin{array}{l}252 \\
264 \\
164 \\
207 \\
218 \\
172 \\
\end{array}$ & $\begin{array}{l}178 \\
186 \\
116 \\
146 \\
154 \\
121\end{array}$ \\
\hline Total & $\overline{1277}$ & 150 \\
\hline $\begin{array}{rr}\text { Run } 2 \text { - T1 } \\
\text { T2 } \\
\text { T3 } \\
\text { T4 } \\
\text { T5 } \\
\text { T6 }\end{array}$ & $\begin{array}{c}305 \\
152 \\
172 \\
166 \\
79.1 \\
422 \\
\end{array}$ & $\begin{array}{l}215 \\
107 \\
121 \\
117 \\
55.9 \\
298\end{array}$ \\
\hline Total & $\overline{1296}$ & 153 \\
\hline $\begin{array}{r}\text { Run } 3-\text { T1 } \\
\text { T2 } \\
\text { T3 } \\
\text { T4 } \\
\text { T5 } \\
\text { T6 }\end{array}$ & $\begin{array}{l}492 \\
387 \\
280 \\
262 \\
238 \\
169 \\
\end{array}$ & $\begin{array}{l}347 \\
273 \\
198 \\
185 \\
168 \\
119\end{array}$ \\
\hline Total & $\overline{1828}$ & 215 \\
\hline $\begin{array}{rr}\text { Run } 4 \text { - T1 } \\
\text { T2 } \\
\text { T3 } \\
\text { T4 } \\
\text { T5 } \\
\text { T6 }\end{array}$ & $\begin{array}{l}316 \\
271 \\
483 \\
299 \\
283 \\
313\end{array}$ & $\begin{array}{l}223 \\
191 \\
341 \\
211 \\
200 \\
221\end{array}$ \\
\hline Total & $\overline{1965}$ & 231 \\
\hline $\begin{array}{r}\text { Run } 5 \text { - T1 } \\
\text { T2 } \\
\text { T3 } \\
\text { T4 } \\
\text { T5 } \\
\text { T6 }\end{array}$ & $\begin{array}{l}308 \\
329 \\
270 \\
178 \\
195 \\
194 \\
\end{array}$ & $\begin{array}{l}218 \\
232 \\
191 \\
126 \\
138 \\
137\end{array}$ \\
\hline Total & $\overline{1474}$ & 173 \\
\hline \multicolumn{3}{|c|}{$\begin{array}{l}\text { (a) Exposure }=\mathrm{mg} /(50 \mathrm{cfm} \times .02832) \\
\text { Total Exposure }=\text { Total } \mathrm{mg} /(300 \mathrm{cfm} \times \\
\text { where: cubic foot }=.02832 \mathrm{~m}^{3} \\
\text { See page } 44\end{array}$} \\
\hline
\end{tabular}

E. 1 



\section{DISTRIBUTION}

No. of

Copies

\section{OFFSITE}

A. A. Churm

DOE Chicago Patent Group

9800 South Cass Avenue

Argonne, IL 60439

Office of Secretary of Defense

(Health Affairs)

ATTN: LTC B. Chase

Pentagon, Room E171

Washington, DC 20301

Office of Secretary of Defense Office of Director of Defense

Research and Engineering

ATTN: $\mathrm{Mr}$. J. Persh

Washington, DC 20301

Office of Assistant Secretary

of Defense for Atomic Energy

ATTN: Cmdr. G. Cliff

Pentagon, Room 3E1069

Washington, DC 20301

Honorable Percy A. Pierre

Assistant Secretary of the Army

for Research, Development and

Acquis ition

Department of the Army

Washington, DC 20310

Office of the Undersecretary

of the Army

Deputy Undersecretary

(Operations Research)

ATTN: Mr. D. Hardison

Department of the Army

Washington, DC 20310
No. of

Copies

Undersecretary of Defense for Research and Engineering

Deputy Undersecretary (Tactical Warfare Programs)

Department of Defense

Washington, DC 20310

Undersecretary of Defense for Research and Engineering

Deputy Undersecretary

(Tactical Warfare Programs)

ATTN: Mr. C. McKinley

Department of Defense

Washington, DC 20310

Undersecretary of Defense for

Research and Engineering

Deputy Undersecretary

(Tactical Warfare Programs)

ATTN: Mr. R. Moore

Department of Defense

Washington, DC 20310

Undersecretary of Defense for Research and Engineering

Deputy Undersecretary (Research and Advanced Technology)

ATTN: Dr. Ruth Dav is

Department of Defense

Washington, DC 20310

Office of the Deputy

Undersecretary of Defense,

Research and Engineering

ATTN: Mr. R. Thorkildsen

Pentagon

Washington, DC 20301

Headquarters

Department of the Army

ATTN: DASG-TSP-E, COL Wangemann

Washington, DC 20310 
No. of Copies

Commander

U.S. Army Comb ined Arms Combat

Development Activity

ATTN: APCA-BC

Fort Leavenworth, KS 66027

Commander

U.S. Army Environmental Hygiene Agency

ATTN: HSE-0, COL J. Thiessen

Aberdeen Proving Ground, MD 21005

20 Commander

U.S. Army Armament Research and Development Command

ATTN: DRDAR-SCM-P, Dr. E. Bloore

Dover, NJ 07801

Director

U.S. Army Human Engineering Laboratory

ATTN: DRXHE-HE, Mr. Erickson

Aberdeen Proving Ground, MD 21005

Headquarters

Department of the Army

ATTN: DACS-DMT

Washington, DC 20310

Headquarters

Department of the Army

ATTN: DAMA-ARX-A, Dr. M. Lasser

Washington, DC 20310

Headquarters

Department of the Army

ATTN: DAMA-CSS, Dr. J. Bryant

Washington, DC 20310

Headquarters

Department of the Army

ATTN: DAMA-CSM, LTC German

Washington, DC 20310
No. of

Copies

Headquarters

Department of the Ariny

ATTN: DAMA-CSM-CA, Mr. Lippi

Washington, DC 20310

Headquarters

Department of the Army

ATTN: DAMA-WSW, LTC Hinson

Washington, DC 20310

Headquarters

Department of the Army

ATTN: DAMA-WSZ-A

Washington, DC 20310

Project Manager

XM1 Tank System

ATTN: DRCPM-GCM BG Babers

Warren, MI 48092

Project Manager

XM1 Tank System

ATTN: DRCPM-GCM-SI, Mr. D. Bartle

Warren, MI 48090

Project Manager

Tank Main Armament System

ATTN: DRCPM-TMA-120mm,

COL Appling

Dover, NJ 07801

Project Manager

Tank Main Armament System

ATTN: DRCPM-TMA, MAJ Michlik

Dover, NJ 07801

Project Manager

Division Air Defense Gun

ATTN: DRCPM-ADG

Dover, NJ 07801

Project Manager

Production Base Modernization and Exp

ATTN: DRCPM-PBM, Mr. C. Kolis Dover, NJ 07801 
No. of

Copies

Project Manager

M60 Tank

Michigan Army Missile Plant

ATTN: DRCPM-M60

Warren, MI 48090

Commander

U.S. Army Logistics Center

ATTN: ATCL-M, Mr. Thompson

Fort Lee, VA 23801

Commander

U.S. Army Missile Munitions

ATTN: ATSK-CD

Redstone Arsenal, AL 35809

Commander

U.S. Army Logistics Evaluation Agency

ATTN: DALO-LEI, Mr. Frye

New Cumber land Army Depot

New Cumberland, PA 17070

Commander

U.S. Army Materiel Development and Readiness Command

ATTN: DRCDR-DW, COL Collins

5001 Eisenhower Avenue

Alexandria, VA 22333

Commander

U.S. Army Materiel Development and Readiness Command

ATTN: DRCQA, Mr. R. Fahy

5001 Eisenhower Avenue

Alexandria, VA 22333

Commander

U.S. Army Materiel Development and Readiness Command

ATTN: DRCDMD, LTG R. J. Baer

5001 Eisenhower Avenue

ALexandria, VA 22333
No. of

Copies

Commander

U.S. Army Materiel Development and Readiness Command

ATTN: DRCBSI, MG I. Hunt 5001 Eisenhower Avenue

Alexandria, VA 22333

Commander

U.S. Army Materiel Development and Readiness Command

ATTN: DRCDMA-ST

5001 Eisenhower Avenue

Alexandria, VA 22333

Commander

U.S. Army Materiel Development and Readiness Command

ATTN: DRCSMA-ST, COL Vincent

5001 Eisenhower Avenue

Alexandria, VA 22333

Commander

U.S. Army Materiel Development and Readiness Command

ATTN: DRCSG, COL R. Cutting

5001 Eisenhower Avenue

Alexandria, VA 22333

Commander

U.S. Army Materiel Development and Readiness Command

ATTN: DRCPA-E, Mr. Pace

5001 Eisenhower Avenue

Alexandria, VA 22333

Commander

U.S. Army Materiel Development and Readiness Command

ATTN: DRCSF-P, Mr. Taras

5001 Eisenhower Avenue

Alexandria, VA 22333

Director

DARCOM Field Safety Activity

ATTN: DRXOS-ES, Mr. E. Olsen

Charlestown, IN 47111 
No. of

Copies

Director

U.S. Army Materials and Mechanics Research Center

ATTN: DRXMR-X, Dr. E. Wright

Watertown, MA 02172

Director

U.S. Army Materials and Mechanics Research Center

ATTN: DRXMR-AR, Mr. S. Levin

Watertown, MA 02172

Director

U.S. Army Materiels Systems

Analys is Agency

ATTN: DRXSY

Aberdeen Proving Ground, MD 21005

Director

U.S. Army Materiels Systems Analys is Agency

ATTN: DRXSY-GA, Mr. W. Brooks

Aberdeen Proving Ground, MD 21005

Director

U.S. Army Materiels Systems Analysis Agency

ATTN: DRXSY-GA, Mr. J. McCarthy

Aberdeen Proving Ground, MD 21005

Director

U.S. Army Materiels Systems Analys is Agency

ATTN: DRXSY-GA, Mr. R. Smith

Aberdeen Proving Ground, MD 21005

Commander

U.S. Army Armament Materiel Readiness Cmd

ATTN: DRSAR-MAD-C, Mr. P. Shaw

Dover, NJ 07801

Commander

U.S. Army Armament Materiel

Readiness Cmd

ATTN: DRSAR-ASR, LTC Counihan

Rock Is land, IL 61201
No. of

Copies

\section{Commander}

U.S. Army Armament Research and Development Cmd

ATTN: DRDAR-CG, MG A. Light Dover, NJ 07801

Commander

U.S. Army Armament Research and Development Cmd

ATTN: DRDAR-TD, Dr. R. Weigle Dover, NJ 07801

Commander

U.S. Army Armament Research and Development Cmd

ATTN: DRDAR-SC, Dr. D. Gyorog Dover, NJ 07801

\section{Commander}

U.S. Army Armament Research and Development Cmd

ATTN: DRDAR-LC, Dr. J. Frasier Dover, NJ 07801

Commander

U.S. Army Armament Research and Development Cmd

ATTN: DRDAR-LC, Dr. J. Frasier Dover, NJ 07801

Commander

U.S. Army Armament Research and Development Cmd

ATTN: DRDAR-SCM, J. Corrie Dover, NJ 07801

\section{Commander}

U.S. Army Armament Research and Development Cmd

ATTN: DRDAR-LCU-D-T, Mr. Davitt Dover, NJ 07801 
No. of

Copies

Commander

U.S. Army Armament Research \& Development Cmd

ATTN: DRDAR-SF, Mr. Elliott

Dover, NJ 07801

Commander

U.S. Army Armament Research \& Development Cmd

ATTN: DRDAR-BLT, Mr. R. Vitali

Aberdeen Proving Ground, MD 21005

Commander

U.S. Army Armament Research and Development Cmd

ATTN: DRDAR-BLT, Dr. W. Gillich

Aberdeen Proving Ground, MD 21005

Commander

U.S. Army Armament Research and Development $\mathrm{Cmd}$

ATTN: DRDAR-BLV, Mr. E. Wilsey

Aberdeen Proving Ground, MD 21005

Commander

U.S. Army Armament Research and Development Cmd

ATTN: DRDAR-BLP, Mr. R. Comer

Aberdeen Proving Ground, MD 21005

Cormander

U.S. Army Armament Research and Development Cmd

ATTN: DRDAR-AD-SA, Mr. Mark land

Aberdeen Proving Ground, MD 21005

Commander

U.S. Army Armament Research and Development Cmd

ATTN: DRDAR-LCB, Mr. P. Rummel Watervliet, NY 12189

Director

U.S. Army Ammunition Center

ATTN: SARAC-D, Mr. K. Croscost

Savanna, IL 61074
No. of

Copies

Commander

U.S. Army Armament Materiel

Readiness Cmd

ATTN: DRSAR-CG

Rock Is land, IL 61201

Commander

U.S. Army Armament Materiel Readiness Cmd

ATTN: DRSAR-LEA, Mr. E. Beckman

Rock Is land, IL 61201

Commander

U.S. Army Armor Center and School

ATTN: MG T. V. Lynch

Fort Knox, KY 40121

Commander

U.S. Army Armor Center and School

ATTN: Mr. M. Falkovitch

Fort Knox, KY 40121

Commander

U.S. Army Missile Command

ATTN: DRCPM-LCE, Mr. Crosswhite

Redstone Arsenal, AL 35809

Commander

U.S. Army Mobility Equipment

Research and Development Cmd

ATTN: DRSME-RZT,

Tech Doc Ctr B/315

Fort Belvoir, VA 22060

Commander

U.S. Army Research Office

ATTN: Dr. G. Mayer

P. 0. Box 12211

Research Triangle Park, NC 27709

Commander

U.S. Army Research Office

ATTN: Dr. E. Saibel

P. 0. Box 12211

Research Triangle Park, NC 27709 
No. of

Copies

Commander

U.S. Army Tank Automotive

Research and Development Cmd

ATTN: DRDTA-RWL

Warren, MI 48090

Commander

U.S. Army Tank Automotive

Research and Development Cmd

ATTN: DRDTA-RKA, Mr. V. Pagano

Warren, MI 48090

Commander

U.S. Army Test \& Evaluation Cmd

ATTN: DRSTE

Aberdeen Proving Ground, MD 21005

Commander

U.S. Army Test \& Evaluation Cmd

ATTN: DRSTE-AR, Mr. Brown

Aberdeen Proving Ground, MD 21005

Commander

U.S. Army Test \& Evaluation Cmd

ATTN: DRSTE-CE

Aberdeen Proving Ground, MD 21005

Commander

U.S. Army Test \& Evaluation Cmd

ATTN: DRSTE-PP-E

Aberdeen Proving Ground, MD 21005

Commander

U.S. Army Test and Evaluation Cmd

ATTN: DRSTE-ST, Mr. J. Starkey

Aberdeen Proving Ground, MD 21005

Commander

U.S. Army Training and

Doctrine Cmd

Fort Monroe, Hampton, VA 23651
No. of

Copies

Director

U.S. Army TRADOC Systems

Analys is Act

ATTN: ATAA-SA

White Sands Missile Range, NM 88002

Commander

U.S. Army Foreign Science \& Technology Center

ATTN: DRXST-CB, J. Bollendorf

Building 220

7 th Street, NE

Charlottesville, VA 22901

Commander

Naval Facilities Engineering Cmd

Code 04N2, Mr. G. Hendrix

200 Stovall Street

Alexandria, VA 22333

Commander

U.S. Naval Ordinance Systems Cmd ATTN: ORD-9132

Washington, DC 20360

Sup er intendent

U.S. Naval Postgraduate School

ATTN: Dir. of Lib.

Monterey, CA 93940

Commander

Naval Sea Systems Cmd

ATTN: PMS-404-31,

Mr. E. Ger lach

Washington, DC 20362

Commander

U.S. Naval Surface Weapons Center

ATTN: Code WR-32,

Dr. S. Fishman

White Oak, MD 20910 
Commander

U.S. Naval Surface Weapons Center

ATTN: Code DG-52, W. Wishard

White 0ak, MD 20910

Commander

U.S. Marine Corps Liaison Office

Aberdeen Proving Ground, MD 21005

Commander

U.S. Air Force Headquarters

ATTN: SG-PA, LTC J. Bayer

Washington, DC 20314

$\mathrm{HQ}, \mathrm{CMS} / \mathrm{EE}$

ATTN: TSGT Cirilo

Nell is AF Base, NV 89191

$H Q, A D T C / S C V$

ATTN: MAJ R. Conrad

Eglin AFB, FL 32542

HQ ADTC/DLV

ATTN: Dr. J. Cornette

Englin AFB, FL 32542

Commander

U.S. Air Force Tactical Air Cmd

ATTN: SG-PA, LTC J. Couglin

Langley AFB, VA 23665

National Lead Company of Ohio

ATTN: Mr. L. Levy

Box 39158

Cincinnati, OH 45239

Rockwe 11 International

Rocky Flats Plant

ATTN: Dr. M. Werkema

B Idg. 123, P. 0. Box 464

Golden, CO 80401
The Analytic Sciences

Corporation

ATTN: Dr. S. Bucci

6 Jacob Way

Reading, MA 01867

Union Carbide Corporation

Nuclear Division

ATTN: Mr. M. Sanders

P. 0. Box $Y$

Oak Ridge, TN 37830

Nuclear Regulatory Commission

Division of Fuel Cycle and Material Safety

ATTN: Mr. E. Wright

Washington, DC 20555

University of California

Los Alamos Scient ific Laboratory

ATTN: Dr. D. Sandstrom, CMB-6

Los Alamos, NM 87544

Air Force Materiel Laboratory

ATTN: LTM S. Inouye

Wright-Patterson AFB, OH 45433

Air Force Materiel Laboratory

ATTN: YXD, CPT D. Schuur

Wright-Patterson AFB, OH 45433

HQ, ADTC

ATTN: CEED0/CC Detachment 1

Tyndall AFB, FL 32403

USA Ordnance Center and School

Aberdeen Proving Ground, MD 21005

Headquarters

Department of the Army

ATTN: DAMO-RQD, LTC Idey

Washington, DC 20310 
No. of

Copies

Headquarters

Department of the Army

ATTN: DAM0-TRS, LTC Lyon

Washington, DC 20310

Headquarters

Department of the Army

ATTN: DAM0-TRI, MAJ Steedy

Washington, DC 20310

Headquarters

Department of the Army

ATTN: DAIG-SD, Mr. J. Coak ley

Washington, DC 20310

Headquarters

Department of the Army

ATTN: DALO-TSP, LTC Deakey

Washington, DC 20310

Headquarters

Department of the Army

ATTN: DALO-SMS, Ms. T. Ueckert

Washington, DC 20310

Headquarters

Department of the Army

ATTN: DASC-DPA, LTC Rogers

Washington, DC 20310

Headquarters

Department of the Army

ATTN: DAEN-ZCE, COL Herndon

Washington, DC 20310

Headquarters

Department of the Army

ATTN: SARDA, COL Drudvig

Washington, DC 20310

Headquarters

Department of the Army

ATTN: SAIL-SN, Mr. Hildebrand

Washington, DC 20310
No. of

Copies

Headquarters

Department of the Army

ATTN: SAGC, Mr. Henke

Washington, DC 20310

Commander

U.S. Army Materiel Development \& Readiness Command

ATTN: DRCSG-R, LTC Bell

5001 Eisenhower Avenue

Alexandria, VA 22333

3 Commander

U.S. Army Armament Materie 1 Readiness Cmd

ATTN: ERSAR-SS, Mr. B. Morris

Rock Island, IL 61201

Commander

U.S. Army Training and Doctrine Cmd

ATTN: ATEM-SE, Mr. Dery

Fort Monroe, VA 23651

Commander

U.S. Army Training and Doctrine Cmd

ATTN: ATTR-HR-S, Mr. Teichmann

Fort Monroe, VA 23651

Commander

U.S. Army Center and School

ATTN: ATZK-CG-AM-L, LTC Robinson

Fort Knox, KY 40121

27 DOE Technical Information Center

\section{ONSITE}

DOE Richland Operations Office

H. E. Ransom 
No. of

Copies

29 Pacific Northwest Laboratory

W. T. Bartlett

C. E. Elderkin

R. L. Gilchrist (3)

J. A. Gl issmeyer (3)

R. K. Hadlock

M. A. Halvorsen

H. Larson

G. B. Long (2)

J. Mishima (2)

0 . R. Moss

P. W. Nickola

G. B. Parker

L. C. Schwendiman

J. M. Selby

C. Unruh

R. K. Woodruff

Technical Information (5)

Publishing Coordination (2) 


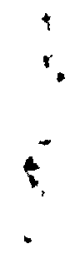

